\title{
Die Gattungen und Arten der Larriden Autorum.
}

\author{
Von
}

\section{Franz Friedrich Kohl}

in Wien.

(Mit Tafel VIII und IX.)

(Vorgelegt in der Versammlung am 2. Juli 1884.)

I.

Vorliegende Arbeit behandelt alle jene Hymenopterengattungen, welche von den Autoren jemals zu den Larriden (Leach) gerechnet worden sind, dazu noch die Gattungen Trypoxylon und Nitela, welche sich bisher im Systeme noch keine natürliche Stelle zu erringen vermochten; sie stehen, wie sich nachweisen lässt, in sehr enger Verwandtschaft zu den Larridengattungen Pison und Sylaon.

Aus Gründen, die in der Einleitung vorgebracht werden, wurde die Familienbezeichnung Larridae aufgehoben. Von jeder Gattung, einschliesslich der exotischen, habe ich eine Beschreibung entworfen, gleichfalls von den paläarktischen (manchmal nur europäischen) Arten. Jede Beschreibung enthält auch Angaben über Lebensweise und geographische Verbreitung, sowie die Synonymie. Zur Erleichterung der Bestimmung soll eine analytische Tabelle der Gattungen, und im Anschlusse an jede Gattungsbeschreibung eine Tabelle zur Bestimmung der Arten dienen. Mein Wunsch, auch die exotischen Arten zu behandeln, scheiterte bei der Unmöglichkeit, die Typen zur Einsicht zu erhalten, an dem Wuste der zahlreichen unzulänglichen, sehr häufig nicht einmal zur sicheren Erkennung der Gattung ausreichenden Beschreibungen, und ich musste mich begnügen, auf die Artbeschreibungen ein blosses Verzeichniss der sämmtlichen bisher beschriebenen Arten einer Gattung folgen zu lassen. Auch glaubte ich den Hymenopterologen damit einen Dienst zu leisten, jene Beschreibungen, welche eine Gattung oder eine Art am unzweideutigsten erkennen lassen, in der Synonymenliste mit durchschossenen Lettern zu kennzeichnen. Was die Nomenclatur betrifft, so hielt ich die Ansicht fest, dass man, um nicht durch unfruchtbare Prioritätsdeuteleien Wirrwarr hervorzurufen, nur hinreichend verbürgte, das ist solche Namen verwenden soll, die durch ausreichende Beschreibungen geschützt sind. In Fällen, wo die Identität durch Typen festgestellt werden konnte, wurden Namen für prioritätsberechtigt angesehen. 
Die benützte Literatur erhielt ich durch die liebenswürdige Vermittlung bekannter Fachgenossen (Prof. Dr. Fr. Brauer, Prof. Dr. Dalla-Torre, Emil Frey-Gessner in Genf, P. Dir. V. Gredler, Prof. Dr. K. Heller in Innsbruck, Dr. L. v. Heyden in Frankfurt, Dr. Kriechbaumer, Assist. Al. Mocsáry in Budapest, Custos A. Rogenhofer in Wien, Hr. de Saussure in Genf) und umfasst 156 Arbeiten, eine Zahl, die Anspruch auf Vollständigkeit macht. Das untersuchte Materiale befindet sich theils in den Sammlungen der Museen von Berlin (Tachysph. fluctuatus Gerst.), Bern, Budapest, Genf, Innsbruck, Wien und Zürich, theils im Privatbesitze bekannter Entomologen: v. Aichinger (†), L. Fairmaire, Frey-Gessner, C. Jullian in Marseille, J. Lichtenstein, Schmiedeknecht in Kahla, H. Tournier in Genf (Peney). Bei der Untersuchung kamen zwei Lupen in Verwendung: eine Cylinderlupe mit 12 facher (L. a) und eine zusammengesetzte Lupe mit 45 facher (L. b) Vergrösserung.

Die Arten, von denen mir die Typen zu Gesicht gekommen sind, wurden an passender Stelle mit (!) gekennzeichnet. Es sind dies Typen von Aichinger, Chevrier (durch Tournier), Dahlbom (durch Heyden), Destefani (durch Tournier), Gerstäcker, Mocsáry und Saussure.

Die Typen der in dieser Arbeit beschriebenen Arten befinden sich zum grössten Theile in den Sammlungen des k. k. zoologischen Hofcabinetes in Wien.

Allen Herren, welche mich in dieser Arbeit irgendwie unterstützten, sei hiemit der beste Dank ausgedrückt, vor allen den Herren: Prof. Dr. Fr. Brauer in Wien, Emil Frey-Gessner in Genf, Dr. Luc. v. Heyden in Frankfurt, Dr. Kriechbaumer in München, Al. Mocsáry in Budapest, Al. Rogenhofer in Wien, Regierungsrath Dr. Steindachner in Wien, Henri de Saussure in Genf und Henri Tournier in Peney.

Die Larriden werden in der Systematik als eine Familie oder Unterfamilie der Grabwespen (Fossoria) angeführt. Leach stellte diese Familie im Jahre 1817 auf; nach ihm wurde sie von verschiedenen Autoren im Ganzen nicht weniger als zwanzigmal beschrieben. ${ }^{1}$ ) Alle diese Beschreibungen zu erörtern würde zu weit führen, doch sei erwähnt, dass die Familie in den allerwenigsten Fällen übereinstimmend aus den nämlichen Gattungen zusammengestellt wurde. Eine Erklärung für die verschiedene Auffassung der Larriden liegt darin, dass die Autoren in Ermangelung durchgreifender und wirklicher Familienmerkmale gezwungen waren, die Familie auf das Zusammentreffen mehrerer Merkmale, auf die Combination von Charakteren zu gründen. Solche Merkmale sind: 1. der Ausschnitt in der unteren Aussenkante der Oberkiefer,

1) Samouelle (1819), Newmann (1835), Blanchard (1840), Westwood (1840), Le Peletier (1845), Dahlbom (1835, 1845), Eversmann (1849), Wesmaël (1851), Schenck (1857), S mith (1858), Tas chenbérg $(1857,1866,1870)$, Thomson $(1871,1874)$, Radoszkowsky (1877), Saunders (1880), Patton (1881), Provancher (1883). 
2. die einspornigen Mittelschienen, 3. die Convergenz der Netzaugen gegen den Scheitel hin, 4. die Form der hinteren Nebenaugen, 5. das Vorhandensein einer "Anhangszelle" in den Vorderflügeln.

Prüft man diese Merkmale auf den Werth, so kommt man zur Ueberzeugung, dass sie sich, wenn sie auch zum Theile einer ganzen Reihe von Gattungen zukommen, dennoch nicht zur Begründung einer Familie eignen, sondern höchstens in die Gattungsbeschreibungen hineinpassen.

Wollte man das unter 1. angeführte Merkmal der Oberkiefer, da es einer grossen Anzahl von Gattungen (Morphota, Larraxena, Larra, Notogonia, Piagetia, Tachysphex, Tachytes, Prosopigastra, Gastrosericus, Dinetus, Palarus, Tachyrhostus, Miscophus, Solierella) zukommt, zur Abgrenzung einer Familie verwenden, so müssten Liris und Paraliris, dann Sylaon und Nitela von dieser ausgeschlossen bleiben, da bei ihnen der Oberkieferausschnitt fehlt.

Diese Lostrennung von Liris und Paraliris wäre eine ganz unnatürliche und gewaltsame, da sie gerade von jenen Gattungen entfernt würden, die man als die typischen anerkennt, nämlich von Larra Fabr. und Notogonia Costa. Mit diesen wurde Liris (vielleicht auch Paraliris?) von Smith und anderen Autoren wegen der nahen Verwandtschaft bis in die jüngste Zeit in der Sammelgattung "Larrada" Smith vereinigt. Andere, dem Typus Larra ferner stehende Genera, wie Tachyrhostus, Solierella, Miscophus Jur. etc. hingegen müssten dann bei der Zusammenstellung der Larriden Aufnahme finden.

Bei Solierella Spin. kommt ein Oberkieferausschnitt vor, bei Sylaon Picc. und Nitela Latr. aber, die doch, wie weiter unten bei der Behandlung dieser Gattungen nachgewiesen werden wird, aufs Engste mit jener verwandt sind, ist keiner bemerkbar. Es wäre nun gewiss unzulässig, Solierella den Larriden einzuverleiben, dagegen ihre allernächsten Verwandten auszuscheiden.

In den erwähnten Fällen wiederholt sich ein Merkmal bei entfernteren Verwandten, welches viel näheren fehlt; hiemit verliert es selbstverständlich die Bedeutung eines Familiencharakters.

Noch werthloser ist das Merkmal der einspornigen Mittelschienen; ${ }^{1}$ ) dass seine Bedeutung von dem Zusammentreffen mit gewissen anderen Merkmalen abhängig gemacht wurde, muss sofort schon Zweifel an seinem natürlichen Werth erregen. Nur ein einziger Mittelschienensporn ist übrigens bei der Mehrzahl der Grabwespen entwickelt, seien es nun Gattungen mit oder ohne Oberkieferausschnitt, mit convergenten oder divergenten Netzaugen, mit oder ohne Anhangszelle an der Radialzelle der Vorderflügel. Die $\sigma$ bei Dinetus, einer Form, welche man aus dem Familienverbande der typischen Larridengattungen nicht ausscheiden könnte, haben merkwürdiger Weise gar keinen Mittelschienensporn.

Ferner wurde bei der Feststellung der Larriden von einigen Autoren die Erscheinung beachtet, dass die Augen gegen den Scheitel hin convergiren. Man

1) Wes ma ël bringt dieses Merkmal bei der Zusammenfassung seiner Larriden (p. 167 S. Rev. crit. 1851), hat aber dann Unrecht, wenn ex die Gattung Astatus mit zwei Mittelschienenspornen auch dazurechnet. 
kann bei den Fossorien Formen beobachten, bei denen die Augen gegen den Scheitel hin stark divergiren, solche, bei denen sie bis zur vollkommenen Berührung convergiren, und dazwischen Formen, welche alle Abstufungen in dem Grade der Augenannäherung repräsentiren; daher ist man nicht im Stande, in dieser Hinsicht eine Grenze zu ziehen.

Es lässt sich wohl nicht läugnen, dass die als Larriden bezeichneten Gattungen - besonders gilt dies von den genuinen Gattungen: Larra, Notogonia, Tachytes, Tachysphex etc. - vorwiegend convergente Augen haben; bedenkt man jedoch, dass die Augenconvergenz 1. bei den Geschlechtern, 2. bei den Arten einer und derselben Gattung, wo sie ganz gute Dienste zur Artbestimmung leistet, 3 . bei den verschiedenen Gattungen wechselt, so muss sie als Familiencharakter ganz werthlos erscheinen. Es wäre auch unrichtig, zu glauben, Gattungen mit grösserer Augenannäherung müssten auch nothwendig in näherer Verwandtschaft zu einander stehen. Wollte man beispielsweise zu den Larriden nur Genera mit convergenten Augen stellen, so würde Lyroda Say (= Morphota Smith), eine den genuinen Larriden (Tachysphex, Tachytes, Larra, Notogonia, Liris) nachweisbar sehr nahe verwandte Gattung, gewaltsam ausgeschlossen, da bei ihren Arten die Innenränder der Augen fast parallel verlaufen; dagegen müssten ferner stehende Gattungen mit convergenten Augen, z. B. Palarus oder Astatus, herangezogen werden.

Bei Larridengattungen, bei denen die Scheitelbreite in Folge der starken Annäherung der Augen stark reducirt ist, sind die Nebenaugen unregelmässig länglich und flach, und es scheint, als ob diese aussergewöhnliche Form der Nebenaugen in Beziehungen zu der Convergenz der Netzaugen stünde. Dies dünkt mich auch um so wahrscheinlicher, als ich bei Palarus-Arten mit geringerer Augenannäherung die hinteren Ocellen in der Form schon der normalen runden und gewölbten nahestehend ( $P$. latifrons Kohl) oder vollkommen normal ( $P$. orientalis Kohl) gefunden habe, während bei Arten mit grosser Annäherung (P. flavipes Fabr.) langgestreckte und flache Ocellen, wie bei Tachytes, Larra etc. vorkommen.

Nur durch diese Annahme kann man sich auch erklären, dass bei Lyroda und Dinetus, Gattungen mit ganz unbedeutender Augenconvergenz oder fast parallelen Innenrändern der Augen, von denen erstere doch die ausgesprochenste Verwandtschaft zu Larra und Tachytes, letztere zu Gastrosericus Spin. hat, die hinteren Nebenaugen eine normale Gestalt haben, während sie bei den Verwandten flach und gestreckt sind.

Eine Ausnahme von den erwähnten Beziebungen macht nur Astatus; dass sie bei dieser Gattung nicht herrschen, ist für mich nur ein neuer Beweis für meine Anschauung, dass Astatus dem Complexe der eigentlichen Larridengattungen nicht sehr nahe, vielleicht ferner steht als manche andere Grabwespengattung, die man noch nie versucht hat, zu den Larriden zu zählen, jedenfalls aber ferner als irgend eiue andere von den in dieser Arbeit behandelten Gattungen. Zu dieser Ansicht bringen mich auch andere Eigenthümlichkeiten von 
Astatus, als: die zweispornigen Mittelschienen, der Bau des Hinterleibes u. s. w. Thomson gründete für Astatus sogar eine eigene Familie.

In Folge der Bedeutungslosigkeit des Augenabstandes für die Abgrenzung einer Familie verliert auch die Form der hinteren Nebenaugen jeden Werth als Familiencriterium.

Auch das Vorhandensein einer Anhangszelle in den Vorderflügeln kann nicht als Merkmal zur Festhaltung einer Larridenfamilie dienen; denn es kommen Anhangszellen bei verschiedenen unter sich nicht besonders eng verwandten Gattungsgruppen, z. B. bei Crabro (s. 1.) und Oxybelus vor.

Sämmtliche Merkmale, welche den Autoren zur Abgrenzung der Larriden gedient hatten, haben sich als hinfällig erwiesen; auch wollte es mir trotz der sorgfältigsten Untersuchungen .an einem überaus reichen Materiale einheimischer und exotischer Grabwespen nicht gelingen, Merkmale zu einer schärferen Charakterisirung aufzufinden, und so kam ich zu dem Resultate: 1. dass sich in der Systematik eine natürliche Larridenfamilie nicht abgrenzen lässt und die von den Autoren zu den Larriden gerechneten Gattungen nur als eine Gruppirung von mehr weniger nahe verwandten Grabwespengattungen aufzufassen sind, diezu Gattungen anderer Grabwespen-Subfamilien zum Theile nicht weniger verwandt sind als unter sich, 2. dass auch die anderen Sphegidenfamilien (Unterfamilien), als: die Nyssoniden, Pemphredoniden, Bembeciden etc. keinen Anspruch auf Natürlichkeit machen können, wie etwa die Pompiliden, Scoliiden, Mutilliden, Formiciden u. s. w. Ich betrachte die Sphegidenals eine an Gattungen reiche Hymenopterenfamilie, in welcher neben nachweisbar sich enger aneinanderschliessenden Gattungen (Gattungscomplexe) isolirte stehen. Solche Gattungscomplexe bilden beispielsweise die Untergattungen von Crabro, die der Gattung Pisonentstammenden Genusformen: Parapison, Aulacophilus und Trypoxylon, ferner die Gattungen Nitela, Sylaon und Solierella, die Gattungen Larra, Notogonia, Liris, Paraliris und Larraxena und die diesen wieder sehr nahestehenden Gattungen Piagetia, Tachytes, Tachysphex, Prosopigastra, die Gruppe der Gattungen Ammophila (s. 1.), Pelopoeus, Trigonopsis, Podium und Sphex. Von dem letzterwähnten Complexe sind Ammophila und Sphex (s. l.) im Begriffe, sich selbst wieder in Gattungen aufzulösen. Als Beispiele isolirter Gattungen können gelten: $O x y$ belus, Miscophus, Tachyrhostus, Astatus, Philanthus, Bothynostethus.

Die Gattungen, welche zur Besprechung gelangen, sind in natürlicher Anordnung folgende: Pison, Subg. Parapison, Aulacophilus, Trypoxylon, Solierella, Sylaon, Nitela, Miscophus, Larra, Notogonia, Liris, Paraliris, Larraxena, Dalara, Piagetia, Lyroda, Tachytes, Prosopigastra, Tachysphex, Gastrosericus, Dinetus, Palarus, Tachyrhostus, Bothynostethus. 
Pison, Aulacophitus und Trypoxylon bilden, wie oben bemerkt, einen Complex aufs Engste aneinanderschliessender Gattungen (Gattungscomplex von Pison), welchem sich ein anderer, aus den Gattungen Solierella, Sylaon, Nitela gebildeter (Gattungscomplex von Solierella) anreiht. Grösser als der verwandtschaftliche Abstand zwischen diesen beiden Gattungsgruppen ist der Abstand des Gattungscomplexes von Solierella von den genuinen Larridengattungen. Miscophus steht ziemlich isolirt zwischen beiden, scheint sich aber mehr zur Gattungsgruppe Solierella hinzuneigen. Als die genuinen Larridengattungen können gelten Larra, Notogonia, Liris, Paralivis, Larraxena, Dalara, Piagetia, Lyroda, Tachytes, Prosopigastra, Tachysphex, Gastrosericus und Dinetus.

Die darauffolgenden Gattungen Palarus, Tachyrhostus, besonders aber Astatus und Bothynostethus stehen mehr isolirt.

Was den Werth der genannten Gattungen betrifft, so muss bemerkt werden, dass er durchaus kein gleicher ist. So liessen sich die Gattungen Notogonia, Liris, Paraliris, obschon ihre Unterschiede, so viel ich an einem grossen Materiale durch Untersuchung erfahren habe, recht beständig sind, am Ende auch als Untergattungen von Larra auffassen; dasselbe gilt von Pison, Parapison, Aulacophitus und Trypoxylon. Viel grösser ist der Werth von den Gattungen, deren nächste Verwandte entweder noch nicht aufgefunden worden sind oder nicht mehr existiren, so dass ihre Stellung eine isolirte ist.

Palarus aus der Nähe der genuinen Larriden zu bringen, wie Gerstäcker bei der Besprechung der systematischen Stellung von Oxybelus in seiner vorzüglichen Arbeit über Oxybelus will, ist durchaus unstatthaft, da die Eigenthümlichkeiten, wodurch sich Palarus auszeichnet, nicht den Werth besitzen, den ihnen Gerstäcker beilegt; dies lehrt die Untersuchung einer grösseren Arten- und Individuenzahl. Auch scheint es mir unstatthaft, nach einer Summe nummerirter Verschiedenheiten oder Aehnlichkeiten über den Grad der Verwandtschaft zu entscheiden, so lange man nicht diese Merkmale auch auf ihre Wichtigkeit geprüft hat. Ein Dutzend solcher Merkmale wiegen zusammen oft nicht so viel als irgend ein anderes, scheinbar unbedeutendes. Das Nähere über die Stellung von Palarus bei der Besprechung dieser Gattung.

\section{Bestimmungstabelle der Gattungen.}

1 Innenseite der Augen ohne Ausrandung (Augen nicht nierenförmig). Die Häkchen des Retinaculums bilden eine zusammenhängende Reihe. Radialzelle der Vorderflügel mit oder ohne Anhangszelle

- Innenseite der Augen ausgerandet (Augen nierenförmig). Die Häkchen des Retinaculums bilden zwei Gruppen. Radialzelle gestreckt, ohne Anhangszelle. [Gattungsgruppe von Pison.]

2 Vorderflügel mit einer oder zwei Cubitalzellen, je nachdem die zweite entschieden ausgeprägt oder nur mehr durch die Reste des untergegangenen Geäders angedeutet, manchmal kaum sichtbar ist. [Hieher gehören Gattungen, welche durch das Verschwinden der mittleren drei- 
eckigen Cubitalzelle aus der folgenden Gattung hervorgegangen und deren Cubitalzellen durch eine aus der Vereinigung der ehemaligen beiden mittleren Cubitalqueradern entstandene Querader getrennt sind.]

- Vorderflügel mit drei Cubitalzellen, die mittlere dreieckig und gestielt. Einmündung der Discoidalqueradern sehr veränderlich. [Stammgattung der drei folgenden Genera.].

Gen. Pison Spin.

3 Zweiter Hinterleibsring von normaler Länge

Gen. Pison (Subg. Parapison Smith)

- Zweiter Hinterleibsring stielförmig gestreckt

4 Venenrohre der zweiten (respective dritten des Pison-Flügels) Cubitalquerader, zweiten Discoidalquerader und des zwischen der zweiten Cubitalund zweiten Discoidalzelle gelegenen Theiles der Cubitalader vollkommen

Gen. Aulacophilus Smith

- Venenrohre der zweiten Cubitalquerader, zweiten Discoidalquerader und des zwischen der zweiten Cubital- und der zweiten Discoidalzelle gelegenen Theiles der Cubitalader mehr weniger, oft bis zur Unkenntlichkeit aufgelöst .

. Gen. Trypoxylon Latr.

5 Vorderflügel mit einer Cubitalzelle. [Oberkiefer ohne Ausschnitt im Unterrande.]

Gen. Nitela Latr.

- Vorderflügel mit zwei Cubitalzellen, Beine bedornt, manchmal nur in schwachem Grade; Oberkiefer nahe der Mitte ihrer Unterkante mit einem Ausschnitte .

- Vorderflügel mit drei Cubitalzellen

6 Radialzelle der Vorderflügel ohne Anhangszelle; zweite Cubitalzelle gestielt. Endsegment ohne Pygidialfeld, kegelförmig. [Augen in geringem Masse gegen den Scheitel convergent; hintere Nebenaugen von normaler Bildung, rund und gewölbt. Gestalt klein.] . . . Gen. Miscophus Jur.

- Radialzelle der Vorderflügel mit einer Anhangszelle. - Radialader in ihrer Fortsetzung über die Radialzelle hinaus manchmal undeutlich, erlośchen.

- Zweite Cubitalzelle sitzend. Endsegment mit einem Pygidialfelde .

7 Die zweite Cubitalzelle nimmt beide rücklaufende Adern auf; die Basalader trifft in ziemlicher Entfernung hinter der durch die Schulterquerader abgeschlossenen inneren mittleren Schulterzelle auf die Medialader. In den Hinterflügeln endigt die mittlere Schulterzelle vor dem Ursprunge der Cubitalader. Hintere Nebenaugen länglich verflacht, nach hinten einander sehr genähert. Fühler der $\sigma^{\top}$ normal. Mittelschienen der $\sigma^{\top}$ einspornig .

Gen. Gastrosericus Spin.

- Die erste Cubitalzelle nimmt noch die erste, die zweite Cubitalzelle die zweite rücklaufende Ader auf. Die Basalader trifft mit der Schulterquerader zusammen. In den Hinterflügeln entspringt die Cubitalader an der mittleren Schulterzelle, und zwar in einiger Entfernung vor ihrem Abschlusse. Hintere Nebenaugen regelmässig rund, gewölbt, von einander merklich entfernt. Fühler des $\sigma$ spiralig gedreht. Mittelschienen der $\sigma^{\prime}$ ungespornt

Gen. Dinetus Jur. 
8 Radialzelle ohne Anhangszelle; Augen gegen den Scheitel zu divergent. Zweite Cubitalzelle gestielt; sie nimmt beide Discoidalqueradern auf. Beine schwach bedornt, mit einem einzigen Mittelschienensporn. Aftersegment mit einem grossen, flachen, behaarten Pygidialfelde. Oberkiefer ohne Ausschnitt in ihrer Unterkante . . . Gen. Bothynostethus Kohl

- Radialzelle mit einer Anhangszelle. Innere Augenränder parallel oder gegen den Scheitel hin convergent

9 Beine, abgesehen von den Schienenspornen, unbewehrt, höchstens mit Spuren von Dörnchen. Obere Afterklappe (ㅇ) kegelförmig, ohne Pygidialfeld. [Hintere Nebenaugen rund und gewölbt. Zweite Cubitalzelle gestielt. Anhangszelle schmal.]

- Beine deutlich bewehrt. Obere Afterklappe mit einem Pygidialfelde

10 Die erste Cubitalzelle nimmt die erste, die zweite Cubitalzelle die zweite Discoidalquerader auf. Oberkiefer ohne Ausschnitt in ihrem Unterrande

Gen. Sylaon Picc.

- Die zweite Cubitalzelle nimmt beide Discoidalqueradern auf. Oberkiefer mit einem Ausschnitte in ihrem Unterrande

Gen. Solierella Spin. (= Nitelopsis Saund.)

11 Hintere Nebenaugen rund gewölbt und deutlich . . . . . . . . 12

- Hintere Nebenaugen länglich, flach und meistens undeutlich . . . . 14

12 Oberkiefer ohne Ausschnitt in ihrem Unterrande. Augen beim $\sigma^{7}$ auf dem Scheitel zusammenstossend. Die Schulterbeulen reichen bis zu den Flügelschuppen hinauf. Schienen der Mittelbeine mit zwei Spornen

Gen. Astatus Latr.

- Oberkiefer mit einem deutlichen Ausschnitte in ihrem Unterrande. Augen beim $\sigma^{\nearrow}$ nicht zusammenstossend. Die Schulterbeulen reichen nicht bis zu den Flügelschuppen hinauf. Schienen der Mittelbeine mit einem einzigen Sporne

13 Radialzelle schmal abgestutzt, Anhangszelle klein. Mittelsegment viel kürzer als das Dorsulum. Cubitalader 1 verläuft an der ersten, 2 an der zweiten Cubitalzelle. Fühler kurz, gegen die Spitze verdickt, mehr weniger keulenförmig Gen. Tachyrhostus Sauss.

- Radialzelle breit abgestutzt, Anhangszelle gross. Mittelsegment von der Länge des Dorsulum. Cubitalzelle 2 nimmt beide rücklaufende Adern auf. Fühler fadenförmig, verhältnissmässig lang

Gen. Lyroda Say (= Morphota Smith)

14 Dritte Cubitalzelle an der Radialader breiter als an der Cubitalader. [Zweite Cubitalzelle dreieckig oder kurz gestielt; Oberkiefer mit einem tiefen Ausschnitte. Mittelsegment viel kürzer als das Dorsulum. Hinterleibsringe fast wie bei Cerceris eingeschnürt.] . Gen. Palarus Latr.

- Dritte Cubitalzelle an der Radialader schmäler als an der Cubitalader 15

15 Zweites Hinterleibssegment fast stielförmig gestreckt. Pronotum auffallend verengt ........... Gen. Piagetia Ritsema 
- Zweites Hinterleibssegment normal, nicht stielförmig gestreckt. Pronotum nicht auffallend verengt

16 Gesicht mit leistenartigen Auftreibungen an den inneren Augenrändern. Mittelsegment verhältnissmässig lang, manchmal länger als das Dorsulum

- Gesicht ohne kantige Erhebungen längs der inneren Augenränder. [Mittelsegment meist sichtlich kürzer als das Dorsulum.] . . . . . . 20

17 Oberkiefer mit einem Ausschnitte in ihrem Unterrande . . . . . 18

- Oberkiefer ohne Ausschnitt im Unterrande. [Pronotumwulst unter das Niveau des Dorsulum herabgedrückt.] . . . . . . . . . . . 19

18 Pronotumwulst nicht oder nur unbedeutend unter das Niveau des Dorsulum herabgedrückt. Oberkiefer an ihrem Innenrande unbezahnt. Ventralplatte des dritten Hinterleibsringes regelmässig. Pygidialfeld ( + ) unbehaart, am Ende ohne stiftenartige Börstchen. Aussenseite der Vorderschienen bedornt. Klauen nicht auffallend lang . . . Gen. Larra Fabr.

- Pronotumwulst schmal, unter das Niveau des Dorsulum herabgedrückt, besonders an seinen Seiten. Oberkiefer an ihrem Innenrande mit einem Zahne bewehrt. Ventralplatte des dritten Hinterleibsringes meistens mit einer Erhabenheit in der Mitte und seitlich daran mit je einem flachen, ovalen, matten Eindrucke. Pygidialfeld (q) bei frischen Stücken mit einem reifartigen Tomente belegt und nahe dem Ende mit kurzen, nach hinten gerichteten, stiftenartigen Börstehen. Aussenseite der Vorderschienen unbedornt. Klauen langgestreckt

Gen. Notogonia Costa

19 Pygidialfeld ( $($ ) mit kurzen Haaren bekleidet und am Ende mit stiftenartigen Börstchen. Dorsalringe dicht befilzt oder wenigstens fein bereift. Mittelsegment hinten abgestutzt, steil abfallend. Aussenseite der Vorderschienen bedornt . . . . . . . . . . Gen. Liris Fabr.

- Pygidialfeld (q) und die Dorsalringe, welche mit zerstreuten, sehr deutlichen (L. a) Punkten behaftet sind, abgesehen von vereinzelten, längeren Haaren, nackt und glänzend. Mittelsegment hinten abgerundet, nicht steil abfallend. Aussenseite der Vorderschienen unbedornt

Gen. Paraliris Kohl

20 Wimpernkamm der Vordertarsen ( $q$ ) aus starren, ziemlich kurzen Dornen gebildet. Pygidialfeld $\left(\sigma^{\top}\right.$,, ) mit einem kurzen Haarfilz bedeckt. Tracht bienenartig. [Vorderschenkelbasis der of nahezu ausnahmslos ohne Ausrandung.]

Gen. Tachytes $\mathrm{Pz}$.

- Wimpernkamm der Vordertarsen aus sehr langen, biegsamen Borsten gebildet. Pygidialfeld $\left(\sigma^{\top}\right.$,,$)$ nackt. Tracht nicht bienenartig . . .

21 Stirne mit einem kräftigen, glänzend glatten, rundlichen Wulste in gleichem Abstande von dem vorderen Nebenauge und der Fühlerbasis. Vorderschenkel bei den ơ ohne Ausrandung. Beine schwächlich, Hinterleib auffallend grob punktirt

Gen. Prosopigastra Costa. 
- Stirne ohne centralen Wulst, höchstens mit zwei kleinen Höckerchen hart ober der Füblerbasis. Schenkelbasis der Vorderbeine bei den $\sigma^{\nearrow}$ deutlich ausgerandet. Beine verhältnissmässig ziemlich kräftig. Hinterleib nicht grob punktirt . . . . . . Gen. Tachysphex Kohl. ${ }^{1}$ )

\section{Gen. Pison Spin. (Taf. VIII, Fig. 1-3.)}

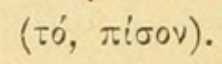

Alyson Spin., Ins. Lig. spec. nov., t. II, Fse. IV, p. 253 . . . . . . . . . . . . . 1808

Pison Spin. (et Jurine in lit.), Ins. Lig. spec. nov., t. II, Fsc. IV, p. 255 . . . . . . . 1808

Tachybulus Latr., Gen. Crust. et Ins., t. IV, p. 75, CDXCVI . . . . . . . . . . . . 1809

Nephridia Brullé, Ann. soc. ent. France, t. II, p. 408 . . . . . . . . . . . . . 1833

Pisonitus Shuck., Trans. Ent. Soc. Lond., vol. II, p. 79 . . . . . . . . . . . . . . 1837

Pison Shack., Trans. Ent. Soc. Lond., vol. II, p. 73 . . . . . . . . . . . . . . . 1837

Pison Blanchard, Hist. nat. d. Ins., t. III, p. 360 . . . . . . . . . . . . . . . . 1840

Pison Lep., Hist. nat. Ins. Hym., t. III, p. 229, 2. Genre . . . . . . . . . . . . . 1845

Pison Spin., Hist. fis. y pol. Chile, Gay. Zool., t. VI, p. 325 . . . . . . . . . . . . 1851

Pisonoides Smith, Journ. Proc. Linn. Soc., vol. II, p. 104 (unbeschrieb. Subg. = Parapison Sm.) 1857

Parapison Smith, Trans. Ent. Soc. Lond., p. 298, pl. VI, fig. 6 (Subg.) . . . . . . . . 1869

Pisonitus Smith, Trans. Ent. Soc. Lond., p. 298, pl. VI, fig. 7 . . . . . . . . . . . 1869

Pison Costa, Ann. Mus. zool. Univ. Napoli (Ann. VI), p. 81 . . . . . . . . . . . . 1871

Pison et Pisonitus Smith, Trans. Zool. Soc. Lond., t. VII, p. 187-188 . . . . . . . 1872

Pison Sidn. Sm. Saunders, Trans. Ent. Soe. Lond., pl. III, p. 411 . . . . . . . . . . 1873

Pisonitus Sidn. Sm. Saunders, Trans. Ent. Soc. Lond, pl. III, p. 412 . . . . . . . . 1873

Pison Patton, List North. Am. Larr. (Proc. Bost. Soc. Nat. Hist., vol. XX, p. 385) . . . . 1880

Taranga Kirby, Trans. Ent. Soc. Lond., pl. II, p. 201 (Subg. = Parapison) . . . . . . 1883

Kopf so breit oder breiter als das Bruststück. Oberkiefer von geringer Grösse, unter das Kopfschild hereingerückt, ohne Ausschnitt im Unterrande. Die Augen reichen bis zur Oberkieferbasis und stehen bei den mir bekannten Arten am Kopfschilde weiter von einander ab als auf dem Scheitel und erscheinen in Folge eines Ausschnittes in ihrem Innenrande nierenförmig. Nebenaugen regelmässig rund und gewölbt; sie stehen in einem gleichschenkeligen Dreiecke, die beiden hinteren einander näher als eines der hinteren dem vorderen, auch liegen sie vor der Linie, die man sich an den Hinterrändern der Netzaugen quer über den Scheitel gezogen denkt. Fühler mittelmässig lang, hart am oberen Kopfschildrande eingefügt, ibre Insertionsstellen von einander meistens so weit entfernt als eine Insertionsstelle vom benachbarten Auge. Geissel faden-, seltener keulenförmig; vom zweiten Gliede an, welches regelmässig das längste ist, werden die Glieder zusehends kürzer. Endglied stumpf kegelförmig.

Hinterwulst des Pronotums so ziemlich im gleichen Niveau mit dem Dorsulum oder unter dieses ein wenig herabgedrückt. Die Schulterbeulen reichen nicht bis zur Flügelbasis zurück. Mittelsegment kürzer als das Mesonotum,

1) Die Gattungen Larraxena Smith und Dalara Rits. wurden in obiger Tabelle nicht aufgenommen, da sie mir nur aus den Beschreibungen und nicht durch Autopsie bekannt sind. 
nicht in Felder getheilt; hinten ist es an den Seiten abgerundet und fällt steil, aber nicht senkrecht ab. Radialzelle der Vorderflügel lang, lanzettlich, zugespitzt, ohne Anhangszelle. Cubitalzellen sind nur zwei oder drei vorhanden; bei drei Cubitalzellen ist die mittlere dreieckig und langgestielt. Was den Verlauf des Geäders überhaupt, insbesondere den der Discoidalqueradern betrifit, so herrscht bei dieser Gattung nicht jene Beständigkeit, wie man sie von anderen Gattungen, z. B. Tachysphex, Tachytes u. s. w., wo sie sogar Anhaltspunkte zur Artunterscheidung liefert, gewohnt ist, sondern eine bei Grabwespengattungen seltene Veränderlichkeit. Mir sind in Hinsicht des Discoidalqueraderverlaufes bei Pison folgende Fälle zu Gesichte gekommen:

1. Die erste Discoidalquerader trifft vor dem Ende der ersten Cubitalzelle auf die Cubitalader; die zweite Discoidalquerader mündet hinter der Mitte der zweiten Cubitalzelle.

2. Die erste Discoidalquerader trifft vor dem Ende der ersten Cubitalzelle auf die Cubitalader, während die zweite am Ende der zweiten Cubitalzelle mündet und mit der zweiten Cubitalquerader zusammenstösst.

3. Die erste Discoidalquerader verläuft wie im ersten und zweiten Falle; die zweite Discoidalquerader mündet deutlich hinter der zweiten Cubitalquerader in die dritte Cubitalzelle.

4. Die erste Discoidalquerader trifft genau auf das Ende der ersten Cubitalzelle und mit der ersten Cubitalquerader zusammen, während die zweite noch vor dem Ende der zweiten Cubitalzelle verläuft.

5. Die erste Discoidalquerader verläuft wie im vierten Falle, die zweite genau im Ende der zweiten Cubitalzelle.

6. Die erste Discoidalquerader verläuft wie im vierten Falle, die zweite hinter der zweiten Cubitalquerader an der dritten Cubitalzelle.

7. Die erste Discoidalquerader trifft hinter der ersten Cubitalquerader, die zweite vor der zweiten Cubitalquerader auf die zweite Cubitalzelle. ${ }^{1}$ )

1) Shn ckard errichtet in seinem Aufsatze „Deser. of new exot. Acul. Hym." (Trans. Ent. Soc. Lond., vol. II, 1837, p. 79) unter dem Namen Pisonitus für den ersten der sieben oben verzeichneten Fälle eine eigene "Division“, welche Smith im Jahre 1869 (Trans. Ent. Soc. Lond.) zur selbstständigen Gattung erhebt. Smith hat mit der Erhebung von Pisonitus zur Gattung, deren Werth für die Systematik er durch andere, entscheidendere Merkmale nicht zu begründen vermochte, keinen glücklichen Griff gethan; denn wollte man dem Beispiele von Smith folgen, müssten auch die übrigen sechs Fälle in gleicher Berechtigung mit Gattungsnamen bedacht werden; die Folge davon wäre aber, dass beim Bestimmen das eine Exemplar einer Art zu dieser, das andere derselben Art zu jener der anfgestellten Gattungen gerathen würde. Bedenkt man noch, dass sehr oft sogar die Flügel eines und desselben Individuums ungleich geädert sind, so erscheint die Nothwendigkeit geboten, Pisonitus als Gattung und als „Division“ aus der Systematik zu entfernen.

Die Gıösse der zweiten Cubitalzelle ist ebeufalls verschieden und um so geringer, als sich der Stiel - in der Art und Weise, wie Dr. A dolph („Ueber abnorme Zellbildung einiger Hymenopterenflügel“, Nov. Act. Deutsch. Akad. Naturforsch., Bd. XLI, P. II, Nr. 4, p. 318) den Vorgang bei Bildung der Zellenstiele schildert - anf Kosten der Seitenschenkel der Areieckigen Zelle in der Richtung gegen die Cubitalader verlängert. Zu dem, was $\Lambda$ dolph ūber die Bildung gestielter Zellen sagt, muss hinzngefügt werden, dass in dem Masse, als sich der Stiel verlängert und die Zelle verkürzt, auch die beiden Schenkel schiefer gegen die Cubitalader einfallen und mit dieser 
Bei den Arten mit zwei Cubitalzellen (Parapison Smith) mündet die erste Discoidalquerader in die erste, die zweite in die zweite Cubitalzelle. Die Basalader trifft meist genau im Abschlusse, selten vor oder hinter dem Abschlusse der inneren mittleren Schulterzelle auf die Medialader. Die Zahl der Frenalhäkchen, welche zwei Gruppen bilden, ist nach der Grösse der Arten sehr schwankend. Die Cubitalader der Hinterflügel entspringt hinter dem Abschlusse der inneren mittleren Schulterzelle, also näher dem Flügelrande, an der Medialader. Bewehrung der Beine sehr dürftig, Mittelschienen mit einem einzigen Sporne. Aussenseite der Vorderschienen mit winzigen Dörnchen oder ganz und gar unbedornt. Mittelhüften von einander ein wenig abstehend.

Der zweite Hinterleibsring hat ober seiner Basishälfte eine linienartige Vertiefung, welche meistens inmitten eines ausgedehnten, flachen Eindruckes liegt, und ist an den Seiten an der Stelle, wo die Dorsalplatte auf den Bauchring übergreift, gekantet. Der Endrand der Dorsalringe zeigt mitunter eine kräftige Depression und besonders der zweite Ring eine entschiedene Neigung zur Verlängerung und Abschnürung. Endring beim 9 kegelförmig, ohne Pygidialfeld, beim $\sigma^{\nearrow}$ kürzer, bogenförmig oder gerade abgestutzt.

Die meisten Pison-Arten sind ganz schwarz, nur einige an den Beinen oder auch am Körper andersfärbig. Der Körperfilz ist weiss, auch messing - oder goldgelb glänzend, und tritt mitunter reichlich, auf dem Hinterleibe sehr oft in Form von Filzbinden auf.

in der nämlichen Weise verschmelzen. Mit der Verkủrzung der zweiten Cubitalzelle ist somit auch stets deren Verschmälerung im Gefolge und mit der Versehmälerung eine Aenderung im Verlaufe der Discoidalqueradern. Bei Pison liegt die Ursache des so sehr wechselnden Verlaufes der Discoidalquerader wohl nur in der Veränderlichkeit der zweiten Cubitalzelle.

Bei einem mir zu Gebote stehenden Stücke einer Pison-Art hat sich auf dem rechten Flügel (Taf. VIII, Fig. 2) der Zellstiel in abnormaler Weise bis zur unteren concaven Cubitallinie, welche ihm im weiteren Vorrücken wie eine Barrière hinderlich gewesen ist, verlängert, und von den ursprünglichen Venenrohren der ersten und zweiten Cubitalquerader sind, da die untere concave Cabitallinie sehr knapp an der Cubitalader hinstreicht, als Sparen nur zwei winziger Stümpfehen übrig geblieben; bei weiterem Fortschreiten solcher Verhältnisse müssten diese durch den resorbirenden Einfluss der concaven Cubitallinie von der Cubitalader weggefegt werden und so endlich spurlos verschwinden. Der Flügel würde dann in Hinsicht auf die Cubitalzellenzahl vollkommen zweizellig erscheinen. Im vorliegenden Falle erscheint also der rechte Flügel bei einer echten Pison-Art bis auf unbedentende Venenrudimente aussergewöhnlicher Weise zweizellig, während im linken Flügel die zweite Cubitalzelle zwar noch vorhanden, aber auf ein Minimum reducirt ist. Untersucht man die von Smith aufgestellte Gattung Parapison (Trans. Ent. Soc. Lond. 1869), so hat man bei deren Arten nichts Anderes vor sich als Pison-Arten mit Flügeln, welche in erwähnter Weise die zweite Cabitalzelle vollständig eingebüsst haben. Während sich aus dem Pison-Flügel die Flügel von Parapison ohne grosse Schwierigkeiten entwickeln konnten, hat die Umgestaltung der plastischen Merkmale in Folge deren thatsächlichen Beständigkeit bei Pison keinen Schritt gemacht, was zur Charakterisirung einer Gattung veranlassen kōnnte. Darum zögere ich nicht, auch Parapison (als Untergattung) zu Pison zu ziehen, umsomehr, als die Parapison-Arten in den nãmlichen Regionen wie die Pison-Arten vorkommen und mit ihnen die Lebonsweise gemein haben.

Die Gattung Taranga Kirby (Trans. Ent. Soc. Lond., pl. II, p. 201, 1883) ist, wie man aus der Beschreibung des Autors nicht schwer entnehmen kaun, synonym mit Parapison. 
Die Artunterschiede liegen bei Pison 1. in der Gesichtsbildung, die zum Theile von dem Verhältnisse der Augenannäherung beim Kopfschilde zu der auf dem Scheitel bedingt wird, 2. in der Fühlergeisselbildung und dem Längenverhältnisse der Fühlerglieder, 3. in der Art der Punktirung oder Runzelung des Gesichtes, Thorax, Mittelsegmentes und Abdomens, 4. in der Bildung des Kopfschildes, des Collare. Auch die Färbung, die Dicke der Beine und die Flügel bieten manchmal Anhaltspunkte bei der Bestimmung.

Lebensweise. Ueber das europäische $P$. atrum Spin. berichtet Sidney Smith Saunders (Trans. Ent. Soc. P. III, 1873, p. 413), dass er dessen Puppengehäuse bei Prevesa in Albanien in Brombeerstengeln getroffen habe. Der Zweig, welcher sie barg, war bis in eine Tiefe von 9-10 Zoll hohl; eine Puppe lag am Grunde, einen Zoll weit davon berührten sich zwei, dann wieder zwei von diesen weniger als einen Zoll weit entfernt; die sechste lag einen halben Zoll höher. Die Zellen wurden durch dünne Querscheidewände aus Lehm getrennt. Die Gehäuse der Puppen waren grau, runzelig, ziemlich gebrechlich und durch ein zartes Gewebe an den Wandungen des Ganges befestigt; sie enthielten blassstrohge-lbe Pseudopuppen mit stark eingeschnürten Segmenten und gegen die Körpermitte hin gekrümmtem Kopfe. Länge der Puppe $8 \mathrm{~mm}$. bei $3 \mathrm{~mm}$. Dicke. Das fertige Insect erscheint Ende Juni und im Juli.

Lichtenstein berichtet ebenfalls, das $P$. atrum aus Brombeerstengeln erzogen zu haben (Ann. Ent. France, 5. sér., t. IX, p. 43, 1879) und bestätigt insoweit die Angaben Saunders.

Aehnlich wie bei $P$. atrum ist die Lebensweise von $P$. rugosum Smith. Nach Horne (Trans. Zool. Soc. Lond., t. VIII, 1872) nistet es in den Löchern von altem Holz, z. B. in Schraubenlöchern von Thürpfosten, und füttert seine Larven mit Spinnen.

Andere exotische Arten, wie P. erythropus Kohl (= Parapison rufipes Smith) aus Indien und $P$. nitidum Smith (Journ. Proc. Linn. Soc. zool. III, 1859, p. 160 , Tab. V, fig. 10 et 11, Q - non P. nitidum Smith, Trans. Ent. Soc. Lond., 1869, p. 299, Nr. 2, Q !) bauen Gehäuse aus Lehm, ähnlich wie die OdynerusArten. Vom ersteren erzählt Horne (I. c.), dass es im September und October, nie weit vom Wasser entfernt, eine Menge Zellen an die Spitze eines hängenden Gegenstandes, z. B. an die Ranken von Schlinggewächsen, an hängendes Stroh oder vertrocknete aufgerollte Blätter heftet (Taf. IX, Fig. 9 und 10). Das Innere der Zellen wird durch eine ursprünglich klebrige, seidenartige Substanz ausgekleidet, die den Zweck hat, das Gehäuse zu festigen und es vor Zerstörung durch Nässe zu schützen. Die kugelförmigen Zellen sind im Vergleich zum Körper des Insectes sehr gross, locker aneinandergefügt, jedoch innerlich mit einander in Verbindung, und werden mit einer beträchtlichen Anzahl (in zwei Zellen zählte Horne achtzehn) ganz kleiner, graugrüner Spinnen versorgt.

Auch erwähnt Horne, dass ein kleines, Pemphredon-artiges Insect mit sehr ähnlicher Puppe von der Zelle des Pison Besitz ergreife. Die ErscheinungsZ. B. Ges, B. XXXIV. Abh. 
periode des entwickelten Thieres ist der März und der April, fällt also mit dem Wiedereintreten der Wärme zusammen.

Das Pison nitidum Sm., ebenfalls aus der orientalischen Region, gibt seinen Zellen, die es aus schwarzer Lehmerde verfertigt, eine unregelmässig abgerundete Form und gleichen denen von Zethus Romandinus Sauss. Innen sind sie geglättet und werden mit kleinen, Jagdspinnen ähnlichen Arachniden (oft über zwanzig an der Zahl) gefüllt.

Alle übrigen über die Lebensweise von Pison-Arten gemachten Angaben, wie die Brullé's (über $P$. xanthopus), Blanchard's, sind unbegründete Vermuthungen.

Nach Obigem gibt es also Rison-Arten, welche nach Art der Trypoxylonen 1. entweder in hohlen Zweigen oder Bohrlöchern nisten, oder 2. Nester aus Lehm bauen. Es wäre nun interessant zu wissen, ob sie sich die Höhlungen in den Zweigen selbst anfertigen, oder bereits vorhandene benützen, oder bei ein und derselben Species beides der Fall sein kann, und ob die näpfchenbauenden Pison-Arten nicht auch in Löchern nisten und ihre Bauthätigkeit nur auf das Verdeckeln der Zellen beschränken. Bei der Pison so nahestehenden Gattung Trypoxylon gibt es Arten (z. B. Tr. figulus L.), welche je nach Bedürfniss selbst Zweige und altes Holz aushöhlen, oder verlassene Bohrlöcher anderer Insecten zur Anlegung der Zellen verwenden, deswegen scheint es nicht unwahrscheinlich, dass ein ähnliches Verhältniss auch bei Pison-Arten vorkommt.

Geographische Verbreitung. Von den 54 bekannt gewordenen Arten kommen 2 auf die paläarktische Region (1 auf Europa), 4 auf die äthiopische, 7 auf die orientalische, 30 auf die australische, 19 auf die neotropische und 1 auf die nearktische.

\section{Pison atrum Spin.}

Alyson ater Spin., Ins. Lig. spec. nov. ant. rar., t. II, Fasc. IV, p. 253, t. III, fig. 12, $q$. 1808 Pison Jurini Spin., Ins. Lig. spec. nov. aut. rar., t. II, Fasc. 1V, p. 256, ठ . . . . 1808 Tachybulus niger Latr., Gen. Crust. et Ins., t. IV, p. 75, Q . . . . . . . . . . . . 1809 Pison Jurinii Lep. et Serv., Encycl. Méth., t. X, p. 143, Nr. 1 . . . . . . . . . . . 1825 Pison ater Shuck., Trans. Ent. Soc., t. II, p. 75, Nr. 1 . . . . . . . . . . . . . . 1837 Pison niger Blanchard, Hist. nat. des Ins., t. III, p. 360 . . . . . . . . . . . . . 1840 Pison Jurinei Lep., Hist. nat. Ins. Hym., t. III, p. 230, Nr. 1, §7, † . . . . . . . . 1845 Pison ater Costa, Ann. Mus. zool. Univ. Napoli (Annuar. VI), p. 81 . . . . . . . . . 1871

Long. 7-10 mm. $0^{7}$. Nigrum; palpi testacei; alae affumato-hyalinae; tarsi apicem versus paulum rufescentes. Calcaria nigro-fusca. Facies infra argenteo-tomentosa. Corpus compactile. Clypeus in medio dentis instar productus. Oculi in vertice antennarum quam flagelli articuli secundi longitudine inter se duplo plus distant; articulus secundus primo sesqui longior. Frons convexiuscula dense et grosse punctata. Dorsulum et mesopleurae nitida et subdense punctata (L. a). Femora punctulata praesertim antica (L. b). Segmentum medianum breviusculum, punctatum in medio areae dorsalis impressione 
lata, transverse striata, longitudinali instructa. Segmenta abdominis sequentia evidenter punctata, in margine postico argenteo-tomentosa.

ㅇ mihi ignota.

Gallia, Helvetia, Italia, Albania.

Schwarz. Taster lehmgelb. Tarsen gegen das Ende zu ein wenig röthlich. Schienensporne schwarz oder schwarzbraun. Flügel fast gleichmässig angedunkelt.

Kopfschild und der darangrenzende Theil des Gesichtes mit weissem Filze besetzt.

Körper von gedrungenem Bau. Kopfschild ( $\left.\sigma^{\top}\right)$ in der Mitte in eine zahnartige Spitze vorgezogen. Die Stirne ist deutlich gewölbt, sehr gedrängt und grob, fast runzelig gegittert punktirt; auch der Scheitel und die kräftigen Wangen sind punktirt, aber weniger dicht. Die Nebenaugen liegen nicht in Vertiefungen; der Abstand eines Nebenauges von dem benachbarten Facettauge beträgt die Länge des eigenen Durchmessers, sein Abstand von der Linie, die man sich am Hinterrande der Facettaugen quer über den Scheitel gezogen denkt, etwas mehr. Die geringste Entfernung der Facettaugen am Scheitel entspricht etwa der doppelten Länge des zweiten Fühlergeisselgliedes, welches selbst $1.5 \mathrm{mal}$ so lang als das erste ist. Hinterwulst des Pronotum an den Seitenecken abgerundet. Der Mesothorax glänzt einigermassen, da seine Punktirung viel weniger dicht als die auf der Stirne ist; zwischen den Punkten kann man deutlich kleine, glatte Zwischenflächen wahrnehmen. An den Vorderflügeln wird die erste Discoidalquerader von der zweiten Cubitalzelle allermeist hinter deren Anfang, die zweite Discoidalquerader in deren Ende aufgenommen, obwohl in Betreff dessen auch Unregelmässigkeiten vorkommen. Die Beine sind im Einklang mit dem derben Körperbau dieser Wespen kräftig, ihre Schenkel punktirt, was bei genauerer Besichtigung an den von Haarfilz entblössten, abgeflogenen Stücken auch schon die Lupe $a$ erkennen lässt.

Das Mittelsegment ist kurz, hinten abgerundet, allenthalben deutlich und ziemlich dicht punktirt (L. a), Punktirung an den Seiten und auf der abstürzenden Fläche gedrängter. Die Horizontalfläche besitzt in der Mitte eine breite, flache Längsvertiefung, welche quergestrichelt, an den Seiten von glänzenden Leisten eingerahmt und in ihrer Mitte meist selbst wieder von einer erhabenen Längslinie durchzogen wird.

Die übrigen Hinterleibsringe besitzen an den Hinterrändern wie die meisten Pison-Arten sehr schwache Einschnürungen und sind in mässiger Dichte punktirt; ihre Punkte sind rein gestochen (L. a) und nehmen nach dem Aftersegmente hin mehr und mehr an Dichte und Feinheit zu. Das Endsegment ist breit abgestutzt.

Das $Q$ ist mir unbekannt, dürfte aber anderen Pison-Arten analog kaum nennenswerthe Unterschiede in der Sculptur aufweisen, etwa die Kopfschildbildung ausgenommen.

Geographische Verbreitung: Genua (Spin.), Frankreich (Lichtenstein), Albanien (Saunders), Syra (Erber), Schweiz (bei Nyon, Chevrier). 


\section{Verzeichniss der bisher beschriebenen Pison-Arten:}

P. (Parapison) agile Smith. Q. Reg. III, Subreg. 2. Ceylon.

Parapison agilis Smith: Trans. Ent. Soc. Lond. 1869, 300, Nr. 4, Q.

P. areolatum Spin. Reg. V, Subreg. 1. Chile.

Pison aureolatum Spin.: Hist. fis. y pol. de Chile. Zool. VI, 1851, 327, Nr. 2.

P. (Pisonitus) argentatum Shuck. ㅇ Reg. II, Subreg. 4. Mauritius.

Pison argentatus Shuck.: Trans. Ent. Soc. Lond. II, 1837, 79, Nr. 9, $q$.

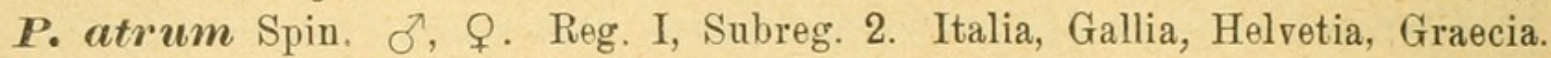

Pison atrum Spin.: Ins. Ligur. II, 1808, 253.

P. auratum Shuck. Q. Reg. II, Subreg. 3. Cap.

Pison auratus Shuck.: Trans. Ent. Soc. Lond. II, 1837, 78, Nr. 7, Q.

P. aurifex Smith. $Q$, $\sigma$. Reg. VI, Subreg. 2. Australia.

Pison aurifex Smith: Trans. Ent. Soc. Lond. 1869, 293, Nr. 26, 우 $\sigma^{\nearrow}$.

P. basale Smith. $q$. Reg. VI, Subreg. 2. Australia.

Pison basale Smith: Trans. Ent. Soc. Lond. 1869, 292, Nr. 24, $q$.

P. chilense Spin. Reg. V, Subreg. 1. Chile.

Pison chilensis Spin.: Hist. fis. y pol. Chile. Zool. VI, 1851, 326, Nr. 1, Taf. I, Fig. 6.

P. collare Kohl. + . Reg. VI, Subreg. 2. Australia.

Pison collare Kohl: Verhandl. d. k. k. zool.-bot. Gesellsch. Wien, XXXIII $1883,336, \mathrm{Nr} .2$, Q.

P. conforme Smith. $\sigma^{7}$. Reg. V, Subreg. 3. Mexico.

Pison conformis Smith: Trans. Ent. Soc. Lond. 1869, 297, Nr. 35, $q$.

P. convexifrons Taschenb. Q. Reg. V, Subreg. 2. Nova Friburg, Rio Janeiro.

Pison convexifrons Taschenb. : Zeitschr. f. d. ges. Naturwissensch. XXXVI, $1870,18$.

P. decipiens Smith. б’. Reg. VI, Subreg. 2. Champion-Bay.

Pison decipiens Smith: Trans. Ent. Soc. Lond. 1869, 295, Nr. 29, б’.

P. dimidiatum Smith. $\sigma^{7}$. Reg. VI, Subreg. 2. Champion-Bay.

Pison dimidiatus Smith: Trans. Ent. Soc. Lond. 1869, 295, Nr. 30, o’.

P. (Parapison) erythrocerus Kohl. ‥ Reg. VI, Subreg. 2. Australia.

Parapison ruficornis Smith: Trans. Ent. Soc. Lond. 1869, 300, Nr. 3, + .

P. (Parapison) erythropus Kohl. ․ Reg. III, Subreg. 1. India.

Parapison rufipes Smith: Trans. Ent. Soc. Lond. 1869, 299, Nr. 2, ㅇ․

Parapison rufipes Smith: Trans. Zool. Soc. Lond. VII, 1872, 188, Taf. XXI, Fig. $1 a$. ㅇ․

P. fabricator Smith. ․ Reg. III, Subreg. 3. Hong Kong.

Pison fabricator Smith: Trans. Ent. Soc. Lond. 1869, 297, Nr. 34.

P. fasciatum Kohl. Q. Reg. V, Subreg. 3.(?) Mexico.

Pison fasciatum Kohl: Verhandl. d. k. k. zool.-bot. Gesellsch. Wien, XXXIII, 1883, 339, Nr. 3, ㅇ. 
P. fenestratum Smith. ‥ Reg. VI, Subreg. 2. Australia.

Pison nitidus Smith: Trans. Ent. Soc. Lond. 1868, 248, 오 (non 1859).

Pison fenestratus Smith: Ibid. 1869, 290.

P. festivum Smith. Q. Reg. VI, Subreg. 2. Champion-Bay.

Pison festivus Smith: Trans. Ent. Soc. Lond. 1869, 295, Nr. 31, $\subsetneq$.

P. favopictum Smith. Reg. V, Subreg. 2. Ega, Brasilien.

Pison flavopictus Smith: Journ. Entom. I, 1861, 80.

P. fuscipenne Smith. . . Reg. VI, Subreg. 2. Champion-Bay.

Pison fuscipennis Smith: Trans. Ent. Soc. Lond. 1869, 294, Nr. 28, ㅇ.

P. hospes Smith. $\$$, $ठ$. Reg. VI, Subreg. 3. Sandwich-Inseln.

Pison hospes Smith: Journ. of Proc. Linn. Soc. Zool. XIV, 1879, 676, ‥

Pison hospes Smith: Descr. n. sp. Hym. 1879, 139.

P. insulare Smith. $q$. Reg. VI, Subreg. 3. New-Hebrides.

Pison insularis Smith: Trans. Ent. Soc. Lond. 1869, 297, Nr. 33, $\subsetneq$.

P. iridipenne Smith. $\sigma^{7}$. Reg. VI, Subreg. 3. Honolulu.

Pison iridipennis Smith: Journ. of Proc. Linn. Soc. Zool. XXIV, 1879, 676.

Pison iridipennis Smith: Descr. n. sp. Hym. 1879, 139, ठ7.

P. laeve Smith. Q. Reg. IV, Subreg. 3, Georgia.

Pison laevis Smith: Catal. Hym. Brit. Mus. IV, 1856, 317, Nr. 21, .

P. laetum Smith. Reg. V, Subreg. 2. Brasilia, Ega.

Pison laetum Smith: Journ. of Entom. I, 1861, 80.

P. maculipenne Smith. ㅇ. Reg. V, Subreg. 2. Brasilia, Ega.

Pison maculipennis Smith: Journ. of Entom. I, 1861, 80, ‥

Pison maculipennis Smith: Aun. et Mag. of N. H. (4) XII, 1873, 295, $q$.

P. marginatum Smith. . . Reg. VI, Subreg. 2. Australia.

Pison marginatus Smith: Catal. Hym. Brit. Mus. IV, 1856, 314, Nr. 8, ㅇ.

P. morosum Smith. . . Reg. VI, Subreg. 1 et 4 . Nova Seeland et Nova Guinea.

Pison morosus Smith: Catal. Hym. Brit. Mus. IV, 1856, 317, Nr. 17, ․․

Pison morosus Smith: Journ. of Proc. Linn. Soc. Zool. VIII, 1864, 85, $q$.

P. nitidum Smith. Q. Reg. VI, Subreg. 1. Aru, Key, Mysol, Ternate.

Pison nitidus Smith: Journ. of Proc. Linn. Soc. Zool. III, 1859, 160,

Taf. V, Fig. 10 et 12 , $q$.

Pison nitidus Maindr.: Ann. Soc. Ent. Fr. (5), IX, 1879, 181, ㅇ․

P. obliquum Smith. ․ Reg. VI, Subreg. 2. Van Diemensland.

Pison obliquus Smith: Catal. Hym. Brit. Mus. IV, 1856, 316, Nr. 15, $q$.

P. (Parapison) obliteratum Smith. \&. Reg. III, Subreg. 4. Borneo.

Pisonoides obliteratus Smith: Journ. of Proc. Linn. Soc. Zool. II, 1857, 104 , 오.

P. obscurum Shuck. ㅇ, $\sigma^{\top}$. Reg. II, Subreg. 3. Cap.

Pison obscurus Shuck.: Trans. Ent. Soc. Lond. II, 1837, 75, Nr. 3, \&, ơ.

(Nach Smith [Trans. Ent. Soc. Lond. 1869, 290] synonym mit P. xanthopus Brullé.)

P. pallidipalpe Smith. ㅇ. Reg. VI, Subreg. 1. Ceram.

Pison pallidipalpis Smith: Journ. of Proc. Linn. Soc. Zool. VII, 1863, 35, 오. 
P. Paraense Spin. ․ Reg. V, Subreg. 2. Para, Brasilia.

Pison Paraensis Spin.: Mem. Accad. sc. Torino (2) XIII, 1853, 58, Nr. 40.

P. Peletieri Gouill. ‥ Reg. VI, Subreg. 2. Austral. bor.

Pison Peletieri Gouill.: Revue zool. IV, 1841, 322, note.

Pison Peletieri Gouill.: Ann. Soc. Ent. Fr. X, 1841, 311.

P. perplexum Smith. 万. Reg. VI, Subreg. 2. Australia.

Pison perplexus Smith: Catal. Hym. Brit. Nius. IV, 1856, 314, Nr. 9, ठ’.

P. pilosum Smith. O. Reg. V, Subreg. 2. Brasilia, Ega.

Pison pilosus Smith: Ann. et Mag. of N. H. (4) XII, 1873, 295, ․․

P. punctifrons Shuck. Q. Reg. III, Subreg. 1 et 2. India oder St. Helena.

Pison punctifrons Shuck.: Trans. Ent. Soc. Lond. II, 1837, 77, Nr. 5, Q.

P. punctulatum Kohl. Reg. VI, Subreg. 2. Pek. Downs.

Pison punctulatum Kohl: Verhandl. d. k. k. zool.-bot. Gesellsch. XXXIII, $1883,336, \sigma^{\top}$, 오.

P. regale Smith. . . Reg. I, Subreg. 4. China bor., Ning-pa-fo.

Pison regalis Smith: Trans. Ent. Soc. Lond. 1852, 34, Taf. VIII, Fig. 9, ㅇ․

P. (Pisonitus) ruficorne Smith (non Parapison ruficorne Smith, vide P. erythrocerus Kohl). O. Reg. VI, Subreg. 2. Australia, Mac Inthyre River.

Pison ruficornis Smith: Catal. Hym. Brit. Mus. IV, 1856, 315, Nr. 12.

P. (Pisonitus) rufipes Shuck. (non Smith! vide erythropus Kohl). ‥ Reg. VI,

Subreg. 2. Van Diemens Island.

Pison rufipes Shuck.: Trans. Ent. Soc. Lond. II, 1837, 79, Nr. 8, ㅇ.

P. (Pisonitus) rugosum Smith. $q$. Reg. III, Subreg. 1. India, Maipuri.

Pison rugosus Smith: Catal. Hym. Brit. Mus. IV, 1856, 313, Nr. 3, ㅇ.

Pisonites rugosus Smith: Trans. Zool. Soc. Lond. VII, 1872, 188, Taf. XXI,

Fig. $5 a$, ‥

P. separatum Smith. ठ․ Reg. VI, Subreg. 2. Champion-Bay.

Pison separatus Smith: Trans. Ent. Soc. Lond. 1869, 294, Nr. 27, o’?

P. simillimum Smith. $\precsim$. Reg. VI, Subreg. 2. Australia.

Pison simillimum Smith: Trans. Ent. Soc. Lond., 1869, 292, Nr. 25, б.

P. Spinolae Shuck. $9, \sigma$. Reg. VI, Subreg. 2. Sidney, Van Diemensland.

Pison Spinolae Shuck.: Trans, Ent. Soc. Lond. II, 1837, 76, Nr. 4, ㅇ.

Pison australis Sauss.: Mém. Soc. Phys. Genève XIV, 1854, 11, Tab. I, Fig. 2, 우 !

Pison Tasmanicus Smith: Catal. Hym. Brit. Mus. IV, 1856, 316, Nr. 14, б’

Pison Spinolae Sauss.: Reise d. „Novara“, Zool. II, 1867, 66, Nr. 2, ㅇ !

P. suspiciosum Smith. ․ Reg. III, Subreg. 4. Singapore.

Pison suspiciosus Smith: Journ. of Proc. Linn. Soc. II, 1857, 104, ㅇ.

P. tahitense Sauss. $q$, $\sigma$. Reg. VI, Subreg. 3. Otahiti.

Pison tahitense Sauss.: Reise d. „Novara“, Zool. II, 1867, 65, Nr. 1, 오, $\sigma^{\top}$ !

P. tibiale Smith. $\sigma^{7}$. Reg. VI, Subreg, 2. Austral. occid.

Pison tibialis Smith: Trans. Ent. Soc. Lond., 1869, 292, Nr. 23, ð’.

P. tuberculatum Smith. $\sigma^{\nearrow}$. Reg. VI, Subreg. 4. Nova Seelandia.

Pison tuberculatus Smith: Trans. Ent. Soc. Lond 1869, 296, Nr. 32, ð. 
P. vestitum Smith. ․ Reg. VI, Subreg. 4. Australia.

Pison vestitus Smith: Catal. Hym. Brit. Mus. IV, 1856, 315, Nr. 10, ․

P. Westwoodii Shuck. Q. Reg. VI, Subreg. 2. Van Diemensland.

Pison Westwoodii Shuck.: Trans. Ent. Soc. Lond. II, 1837, 77, Nr. 6, Q.

P. xanthopus Brullé. \&. Reg. II, Subreg. 2. Guinea.

Nephrodia xanthopus Brullé: Ann. Soc. Ent. Fr. II, 1833, 409, ․

Pison xanthopus Shuck.: Trans. Ent. Soc. Lond. II, 1837, 75, Nr. 2, Q.

Pison obscurus Shuck.: Trans. Ent. Soc. Lond. II, 1837, 75, Nr. 3, ○’, Q (sec Smith).

\section{Gen. Aulacophilus Smith}

$$
(\alpha \tilde{\nu} \lambda \alpha \xi-\delta-\varphi i \lambda \circ \varsigma-) \text {. }
$$

Aulacophilus Smith, Deser. of new Gen. and Exot. Hym. (Trans. Ent. Soc. Lond., p. 305,

pl. VI, Fig. $4,4 a, 4 b)$.

Diese Gattung kenne ich zwar nicht aus eigener Anschauung, aber die gute Smith'sche Beschreibung und die Abbildungen, die zu dieser gehören, lassen keinen Zweifel darüber aufkommen, dass Aulacophilus eine Parapison-Art mit stielförmig verlängertem zweiten Hinterleibsring, also die Uebergangsgattung von Pison zu Trypoxylon ist.

Ich lasse hier die Beschreibung Smith's in deutscher Uebersetzung folgen:

„Kopf so breit als das Bruststück, Augen breit, ihr Innenrand tief ausgeschnitten; die Nebenaugen in einem gleichseitigen Dreiecke auf dem Scheitel; Fühler an der Basis des Kopfschildes eingefügt und von einander ebensoweit wie vom Innenrande der Augen entfernt. Vorderrand des Kopfschildes abgerundet; Oberkiefer zahnlos, am Ende spitzig. Fühler gegen ihr Ende hin verdickt, Schaft verkehrt kegelförmig, zweites Glied (erstes Geisselglied) fast kugelförmig. Bruststück länglich eiförmig, Hinterwulst des Pronotum („collare“) quer, mit bogenförmigem Hinterrande; Mittelsegment („metathorax ${ }^{4}$ ) länglich, hinten abgerundet. Beine einfach, Vorder- und Mittelschienen mit einem einzigen Enddorne. Vorderflügel mit einer verlängerten Radialzelle („c. marginal ${ }^{4}$ ) und zwei Cubitalzellen („c. submarg. “), die erste doppelt so lang als die zweite; die erste Cubitalquerader („recurr. nervure ${ }^{4}$ ) vereinigt sich mit der ersten Discoidalquerader („transv. med. nerv.“), die zweite wird in einiger Entfernung davon von der zweiten Cnbitalzelle aufgenommen. Hinterleib herzförmig gestaltet; zweiter (Segm. med. eingerechnet!) Hinterleibsring ("the first segm.") zu einem länglichen Stiele umgeformt, welcher sich am Ende keulenartig verdickt."

Bis jetzt ist eine einzige Art bekannt geworden:

Aul. vespoides Smith. ‥ Reg. V, Subreg. 2. Brasilia.

Aulacophilus vespoides Smith: Trans. Ent. Soc. Lond. 1869, 305, 오, Taf. IV,

Fig. $4 a, 4 b$.

\section{Gen. Trypoxylon Latr.}


Sphex Villers, C. L. Faun. Suec. descript. auct., p. 221 . . . . . . . . . . . . 1789

Sphex Fabr., Ent. Syst., t. II, p. 198. . . . . . . . . . . . . . . . 1793

Trypoxylon Latr., Préc. Car. gén. Ins. . . . . . . . . . . . . . . . . . . 1796

Trypoxylon Fabr, Syst. Piez., p. 180, Nr. 29 . . . . . . . . . . . . . . . . 1804

Trypoxylon Latr., Hist. Nat. gén. part. Crust. Ins, t. XIII, p. 310 . . . . . . . . . . . 1805

Trypoxylon Panz., Krit. Revis. Insectenk. Dentschl., Bdch. II, p. 106 . . . . . . . . . . . 1806

Apius Jur., Nouv. méth. de class. Hym, t. I, Hym. p. 140 . . . . . . . . . . . . . . 1807

Trypoxylon Latr, Gen. Crust. et Ins., t. IV, p. 75 . . . . . . . . . . . . . . 1809

Trypoxylon Lep. et Serv., Encycl. Méth., t. X, p. 749 . . . . . . . . . . . . . . . . 1825

Trypoxylon Shuck., Ess. indig. foss. Hym. Lond., p. 114, Nr. 1 . . . . . . . . . . 1837

Trypoxylon Blarch., Hist. nat. Ins., t. III, p. $360 \ldots . . . . . . . . . . . . . .1840$

Trypoxylon Herr. Schäff., Nomencl. entom. Ins., 2, Heft, p. 53 . . . . . . . . . . . 1840

Trypoxylon Westwood, Intr. mod. Classif. Ins. Syn. Gen. Brit. Ins., p. 79 . . . . . . . . 1840

Trypoxylon Labram et Imhoff., Ins. d. Schweiz, III. Bdch. . . . . . . . . . . . . . . . . . 1842

Trypoxylon Dhlb., Disp. meth. spec. Scand., P. I, 5. Fam., 27. Gen. . . . . . . . . . 1842

Trypoxylon Dhlb., Hym. eur., t. I, p. 508, 59. Gen. u. Tab. exam. syn. gen. 59. Gen. . . 1845

Trypoxylon Lep., Hist. nat. Ins. Hym., t. III, p. 224, 1. Gen. . . . . . . . . . . . . 1845

Trypoxylon Eversm., Faun. Hym. Volg. Ural (Bull. Mose. IV, p. 414, Gen. 37) . . . . . . 1849

Trypoxylon Wesm., Rev. crit. Hym. fouiss. Belg. (Bull. Acad. r. Belg., t. XVII, Nr. 10, p. 106) 1852

Trypoxylon Schenck, Nass. Grabwesp. (Jahrb. Ver. Naturk. Herz. Nassau, 12. Heft, p. 20 u. 38,

1. Gen., Fig. VII, VIII) . . . . . . . . . . . . . . . . 1857

Trypoxylon Taschenb., Schlüssel z. Bestimm. (Zeitschr. f. d. ges. Naturw. X.) . . . . . 1857

Trypoxylon Smith, Cat. Brit. Acul. Hym., p. 116, Gen. 1, Tab. VI, Fig. 6. . . . . . . 1858

Trypoxylon Taschenb., Hym. Deutschl., p. 155, Gen. 7, et p. 184, Gen. 7 . . . . . . . 1866

Trypoxylon Packard, Revis. Foss. Hym. North Amer. (Proc. Ent. Soc. Phil., vol. VI, p. 412) 1867

Trypoxylon Thoms., 0pusc. Ent. Fasc. II, p. 250 . . . . . . . . . . . . . . 1870

Trypoxylon Costa, Prosp. sist. Imen. ital. (Ann. VI), p. 46 . . . . . . . . . . 1871

Trypoxylon Thoms., Hym. Scand., t. III, p. $251 \ldots . . . . . . . . . . . . .1874$

Trypoxylon Taschenb., Nyss, und Crabr. d. zool. Mus. Univ. Halle (Zeitschr. f. d. ges. Naturw.,

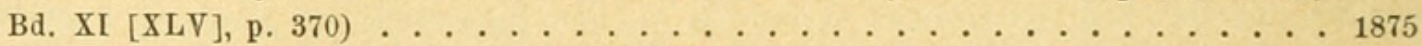

Trypoxylon Radoszk., Fedsch. Reise, Turkest. Zool. Th. Spheg. p. 67 (in russischer Sprache!) 1877

Trypoxylon Edw. Saunders, Syn. Brit. Heterog. Foss. Hym. (Trans. Ent. Soc. Lond., P. IV,

p. 277, pl. VIII, fig. 44) . . . . . . . . . . . . . . . 1880

Trypoxylon Provancher, Faun. Ent. Canada, Hym. p. 669, Nr. 14. . . . . . . 1883

Der Kopf ist so breit oder ein wenig breiter als der Thorax, ähnlich wie bei Pison gebildet. Oberkiefer obne Ausschnitt am unteren Aussenrande. Die Augen berühren die Oberkieferbasis und stehen am Kopfschilde weniger oder ebensoweit auseinander als auf dem Scheitel; diesbezüglich herrscht grosse Abwechslung bei den Arten. Innenrand der Augen wie bei Pison ausgerandet, die Ausrandung verschieden tief und weit. Nebenaugen regelmässig rund und gewölbt, die beiden hinteren einander meistens mehr genähert als eines der hinteren dem vorderen. Fühler mässig lang, im Tode schwach gebogen, manchmal, und zwar bei den Männchen in stärkerem Grade als bei den Weibchen, keulenförmig. Das Endglied fast immer verlängert, beim q wenig, beim $\sigma^{\top}$ in der Regel stark, und übertrifft an Länge in sehr vielen Fällen das zweite Geisselglied, welches sonst als das längste Glied der Geissel gelten kann. Kopfschild sehr verschieden gestaltet. Hinterwulst des Pronotum von verschiedener Mächtigkeit, entweder in gleichem Niveau mit dem Dorsulum oder ein wenig unter dieses herabgedrückt. Die Schulterbeulen reichen nicht an die Flügelschuppen heran. 
In den Hinterflügeln entspricht die Cubitalader hinter dem Abschlusse der inneren mittleren Schulterzelle an der Medialader. Das Retinaculum beginntan der Stelle, wo die Radialader die Randader trifft; sein $\theta$ Häkchen werden wie bei Pison durch eine Lücke in zwei Gruppen gesondert, ein Merkmal, welches für eine nahe Verwandtschaft zu dieser Gattung spricht, da es meines Wissens bei anderen Grabwespen-Gattungen nicht zu finden ist.

Die Bewehrung der Beine ist sehr dürftig; an den Mittel- und Hinterschienen bemerkt man aussen meistens Dörnchen, welche öfters bis zur Undeutlichkeit klein und unter einer kurzen Pubescenz versteckt und nicht auffällig sind. Mittelschienen einspornig. Den Vordertarsen fehlt ein Wimpernkamm. Klauen ungezähnt, ihre Ballen von ziemlicher Entwicklung. Die Mittelhüften stehen ein wenig von einander ab.

Die Radialzelle der Vorderflügel ist lang, lanzettlich, am Ende zugespitzt, eine Anhangszelle somit nicht entwickelt. Abgesehen von den basalen Flügelzellen und der äusseren mittleren Schulterzellezeigt sichnureine einzige Cubital- und eine einzige Discoidal$\left.z e l l e^{1}\right)$ nebst den Spuren einer erloschenen Cubitalquerader, Discoidalquerader

1) Bei der Beschreibung der Gattung Pison (p. 181) wurde erōrtert, auf welche Weise deren Flügelgeäder die mittlere, gestielte Cubitalzelle verlieren kann, eine Umgestaltung, die zur Untergattung Parapison Smith geführt hat. Durch die Neigung des zweiten Hinterleibsringes, sich zu verlängern, wie sie bei vielen Pison- und Parapison-Arten zu beobachten ist, wird auch der Weg zu einer Pison-ähnlichen Form mit gestieltem Hinterleibe vorgezeichnet; eine solche kommt in der Natur thatsächlich vor und ist von Smith (Deser. of new Gen. and Spec. of Exot. Hym., Trans. Ent. Soc. Lond. p. 305, 1869) als Aulacophilus beschrieben worden. Dächte man sich, dass bei der Gattung Aulacophilus durch weiter fortgeschrittene Vereinfachung des Geädernetzes folgende drei Stūcke verschwänden: a) die Cubitalquerader, durch welche ihre zweite Cubitalzelle gegen die Flügelspitze hin abgeschlossen wird, b) die zweite Discoidalquerader, c) der zwischen der zweiten Cubital- und zweiten Discoidalzelle gelegene Theil der Cubitalader, so hätte man einen Flügel mit einer einzigen Cubital- und einer einzigen Discoidalzelle vor sich. Einen solchen Flügel findet man in der Natur wirklich vor, nämlich bei der Gattung Trypoxylon. Man sieht auch, und besonders bei grösseren Formen mit dunklen Flügeln, recht deutlich die Reste der untergegangenen Venenrohre. Trypoxylon ist durch Abzweigung unmittelbar aus Aulacophilus oder Parapison und mittelbar aus Pison hervorgegangen. Wenn diese Behauptung richtig sein soll, so muss die nntergegangene Cubitalquerader (zweite Cubitalquerader im Trypoxylon-Flügel) der dritten Cubitalquerader des Pison-Flügels entsprechen, während die recente erste Cubitalquerader in der bei der Besprechung von Pison (p. 181) erklärten Weise, daher auch ohne Hinterlassung von Spuren einer zweiten Cubitalquerader, aus der Vereinigung der ersten und zweiten Cubitalquerader des Pison-Flügels entstanden ist. Dass die untergegangene Cubitalquerader wirklich der dritten bei Pison entspricht, geht sowohl aus ihrer grossen Entfernung vom „kritischen Punkte“ hervor, welcher sich nach Erfahrung immer in der nächsten Nähe der zweiten Cubitalquerader befindet, als auch aus ihrer grossen Entfernung von der Einmündungsstelle der erloschenen Discoidalquerader. Diese mündet nämlich, wie die vielen Grabwespenflügel zur Genüge zeigen, immer in beträchtlicher Entfernung von der dritten Cubitalquerader. Der stielförmigen, gestreckten Gestalt des zweiten und auch dritten Hinterleibsringes kann übrigens für sich allein kein besonderer Werth zuerkannt werden, nicht der eines Gattungsmerkmales; das lehrt uns die stielförmige Gestalt des zweiten Hinterleibsringes bei den Untergattungen von Crabro, vorzüglich aber der Umstand, dass der Grad dieser Verlängerung und Verdünnung bei den Arten einer und derselben Gattung, z. B. gerade bei Trypoxylon selbst, sehr schwankt. Beachtet man überdies die zwischen Pison und Trypoxylon 
und des bei der Bildung einer ehemaligen zweiten Cubital- und zweiten Discoidalzelle betheiligten, nunmehr erloschenen Cubitaladerstückes.

Mittelsegment hinten abgerundet, mitunter durch Runzeln in undeutliche Felder getheilt. Der übrige Hinterleib ist langgestreckt, keulenförmig, der zweite, oft auch der dritte Ring stielförmig gestreckt. Der zweite Ring hat oben oft eine Längsfurche, unten bei einigen Arten im männlichen Geschlechte einen derben, nach hinten gebogenen Haken. Endsegment ohne Pygidialfeld, beim 오 kegelförmigzugespitzt, beim $\sigma^{\nearrow}$ abgestutzt.

Die Trypoxylon-Arten sind meistens schwarz, seltener zum Theile roth oder gelb; die Tarsen der Hinterbeine sind bei mehreren Arten weisslich. Körperfilz weisslich, braun, aber auch silber-, messing- und goldglänzend.

Bei der Unterscheidung der Arten hat man die Bildung des Kopfschildes, die Entfernung der Fühler unter sich und vom Augenrande, das Verhältniss des Augenabstandes am Scheitel zu dem am Kopfschilde, den Grad der Stirnwölbung, die Form des Augenausschnittes, die Sculptur der Stirne, des Mesothorax und Mittelsegmentes, das Längenverhältniss des zweiten und dritten Hinterleibsringes, die Form der Hinterschenkel und erst in letzter Reihe die Färbung der Pubescenz des Körpers und der Beine zu berücksichtigen.

Die Lebensweise der Trypoxylon-Arten ist so ziemlich die nämliche wie die der Pison-Arten, wodurch auch die nahe Verwandtschaft dieser Gattung verbürgt erscheint. Die Trypoxylonen nisten, so viel bekannt geworden ist, wie die Formen von Pison entweder im Innern von Zweigen verschiedener Gewächse, oder in verlassenen Bohrlöchern alten Holzes - in diesem Falle werden die Zellen mit Lehm abgeschlossen - oder sie erbauen förmliche Lehmnester, welche an beliebige Gegenstände festgeheftet werden; auch die Sitte, die Larven mit Spinnen zu versorgen, hat Trypoxylon mit Pison gemein. Unsere einheimischen Arten: Tr. figulus L., attenuatum Sm. und clavicerum Lep. nisten in verlassenen Bohrlöchern oder in selbstausgehöhlten Gängen im Marke verschiedener Sträucher. Zu den näpfchenbauenden Arten gehört das exotische (Indien) Tr. rejector Sm. Horne, dem wir auch die Kenntniss über die Lebensweise zweier exotischer Pison verdanken, sagt von ihm, dass es sich im September

herrschende Aehnlichkeit in der Bildung des Kopfes, des Mittel- und Endsegmentes, die Augenausrandung, welche sonst noch ausser Aulacophilus und dem mir unbekannten Pseudo-Nysson keiner Sphegidengattung zukommt, die Beschaffenheit der Beine, besonders aber die oben angeführte Eigenthümlichkeit des Retinaculums, so muss all dies von meiner Ansicht über die $\mathbf{A b}$ stammung der Gattung Trypoxylon überzeugen. Selbst die Lebensweise von Pison-Arten, nämlich deren Vorliebe, Lehmnester zu errichten oder wenigstens die Zellen mit Lehmmassen zu schliessen und die Larven mit Spinnen zu versorgen, ist auf Trypoxylon übergegangen.

Selbstverständlich kann kein Zweifel mehr darüber herrschen, zu welcher Gesellschaft vou Gattungen Trypoxylon gehört. Pison, Parapison, Aulacophilus und Trypoxylon bilden einen Complex enge verwandter Gattungen. Dieser Complex reiht sich durch natürliche Verwandtschaft und manche Analogien einem anderen an, welcher den Uebergang zu den genuinen „Larridengattungen“ vermittelt und von den Gattungen Solierella Spin. (= Nitelopsis Saund.), Sylaon Picc. und Nitela Latr. gebildet wird. 
und October Zellen aus Lehm und Sand errichte und diese an geschützten Stellen an Halmen von Gräsern befestige.

Geographische Verbreitung. Trypoxylon-Arten kommen in allen Regionen vor. Bis jetzt sind 74 beschrieben worden; 7 bewohnen die paläarktische Region, 5 die afrikanische, 8 die orientalische, 7 die australische, 12 die nearktische und 36 die neotropische. Eine Art findet man in der paläarktischen und äthiopischen Region zugleich.

\section{Bestimmungstabelle der europäischen Trypoxylon-Arten.}

1 Mittel- und Hintertarsen schwarz .

- Mittel- und Hintertarsen weiss oder lehmgelb, oder in Folge dichter Pubescenz silberweiss

2 Stirne mit einem prägnanten, wappenschildförmigen Eindrucke. Kopfschildrand von erheblicher Breite und gleichmässig. Dorsulum glänzend, deutlich und sparsam punktirt. Mittelsegment oben und hinten grobrunzelig. [Hinterleib schlank. Länge $7-12 \mathrm{~mm}$.]

Tr. scutatum Chevr. (4)

- Stirne ohne wappenschildförmigen Eindruck. Kopfschildrand unscheinbar, nur in der Mitte mehr vorgezogen. Dorsulum mikroskopisch feinrunzelig und ziemlich dicht punktirt, fast matt. Mittelsegment oben und hinten mit Runzelstreifen versehen, jedoch nicht grobrunzelig

3 Vorderbeine schwarz. Der Abstand der Augen ist am Scheitel so gross als am Kopfschilde oder wenigstens deutlich kleiner als doppelt so gross. Endglied der Fühler beim $\sigma^{\top}$ sehr bestimmt gekrümmt .

- Vorderschienen an ihrer Vorderseite und Vordertarsen lehmfarben. Der Abstand der Augen ist auf dem Scheitel doppelt so gross als am Kopfschilde. Endglied der Fühler beim $\sigma^{\top}$ sehr schwach gekrümmt. [Mittelpartie des Kopfschildrandes ausgerandet. Fühler kurz und stark keulenförmig verdickt. Der zweite Hinterleibsring kürzer als der dritte und vierte zusammengenommen. Länge $5-10 \mathrm{~mm}$.]

Tr. clavicerum Lep. et Serv.

4 Mittelpartie des Kopfschildrandes gerade abgestutzt. Der Abstand der Augen ist am Scheitel und am Kopfschilde ungefähr gleich gross. Endglied der Fühler beim $o^{\gamma}$ so lang als die drei vorhergehenden Glieder zusammen. Zweiter Hinterleibsring kürzer als die beiden folgenden Ringe zusammengenommen. [Länge $6-12 \mathrm{~mm}$.] . . . Tr. figulus Linn.

- Mittelpartie des Kopfschildrandes ausgerandet. Der Abstand der Augen ist auf dem Scheitel sichtlich grösser als am Kopfschilde, jedoch nicht doppelt so gross. Endglied der Fühler beim $\sigma^{x}$ so lang als die vier vorhergehenden Glieder zusammen. Zweiter Hinterleibsring so lang als 
die beiden folgenden Ringe zusammengenommen und sehr verdünnt. [Länge $6-10 \mathrm{~mm}$.]

Tr. attenuatum Smith (2)

5 Hinterleib schwarz. [Länge $8 \mathrm{~mm}$.] . Tr. albipes Smith (6)

- Hinterleib zum Theile lehmgelb. [Länge $5 \mathrm{~mm}$.]

Tr. ammophiloides Costa (5)

\section{Trypoxylon figulus Linn.}

Sphex figulus Linn., Syst. Nat., t. I, Ed. X, Holm. p. 570, Nr. $9 \ldots \ldots \ldots \ldots \ldots$. . 1758

Sphex figulus Linn., Faun. Suec., p. 411, 1650 . . . . . . . . . . . . 1761

Sphex figulus Linn., Syst. Nat., t. I, p. 942, Nr. $11 \ldots \ldots \ldots \ldots \ldots \ldots$

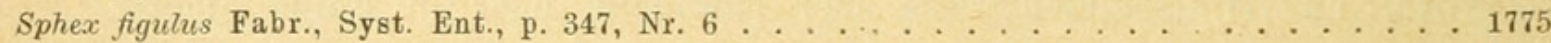

Sphex fuliginosa Scop., Ent. Carn., Nr. $711 \ldots \ldots \ldots \ldots \ldots \ldots \ldots \ldots \ldots$

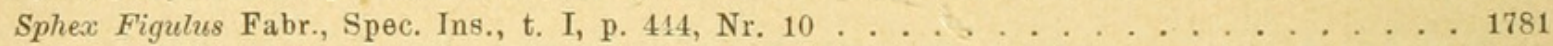

Sphex leucostoma Schrank, Enum. Ins. Austr., p. 381, Nr. $771 \ldots \ldots \ldots \ldots \ldots \ldots$

Sphex figulus Fabr., Mant. Ins., t. I, p. 274, Nr. $15 \ldots \ldots \ldots \ldots \ldots \ldots$. . . . . . . . . . . . . .

Sphex fuliginosa Rossi, Faun. Etrusc., t. II, p. 63, Nr. $817 \ldots \ldots \ldots \ldots \ldots$. . . . . 1790

Sphex figulus Christ., Naturg., Classif. u. Nomencl. d. Ins., p. 291 . . . . . . . . . . 1791

Sphex figulus Fabr., Ent. Syst., t. II, p. 203, Nr. 19 . . . . . . . . . . . 1793

Trypoxylon figulus Fabr., Syst. Piez, p. 181, Nr. 2 . . . . . . . . . . 1804

Trypoxylon figulus Latr., Hist. Nat. gen. part. Crust. Ins,, t. XIII, p. $310 \ldots \ldots$. . . 1805

Apius figulus Jur., Nouv. méth. de class. Hym., t. I, Hym., tab. IX, g. 8 . . . . . . 1807

Sphex leucostoma Illig., Faun. Etrusc. it. ed., vol. II., p. 63, Nr. $817 \ldots \ldots \ldots \ldots \ldots$. . 1807

Trypoxylon figulus Shuck., Ess. on the indig. foss. Hym. Lond., p. 114, Nr. 1 . . . . 1837

Trypoxylon figulus Blanch., Hist. nat. des Ins., t. III, p. 360 . . . . . . . . . . 1840

Trypoxylon figulus Zetterst., Ins. Lapp., p. 445, Nr. 1 . . . . . . . . . . . . 1840

Trypoxylon figulus Labr, et Imhoff, Ins, d. Schweiz, III. Bdch. . . . . . . . . . . . . 1842

Trypoxylon figulus Dhlb., Disp. meth. spec. Scand., P. I . . . . . . . . . . . 1842

Trypoxylon figulus Guér., Icon. régn. anim. Ins., pl. LXXI, fig. $3 \ldots \ldots \ldots \ldots \ldots$

Trypoxylon figulus Dhlb., Hym. Eur, t. I, p. 280, Tab. exam. syn. spec. Crabr., p. 509, Nr. 21845

Trypoxylon figulus Lep., Hist. nat. Ins. Hym., t. III, p. 228, Nr. 2, $\sigma^{\nearrow}$, ㅇ… . . . 1845

Trypoxylon figulus Eversm., Faun. Hym. Volgo-Ural. (Bull. Mosc., p. 414, Nr. 1) . . . . . 1849

Trypoxylon Figulus Schenck, Jahrb. d. Ver. f. Naturk. Herz. Nassau, 12. Heft, p. 132,

Nr. $1, \sigma^{\top}$, o . . . . . . . . . . . . . . . . . . 1857

Trypoxylon figulus Taschenb., Schlüss. z. Bestimm. (Zeitschr. f. d. ges. Naturwiss. X) . . . 1857

Trypoxylon figulus Smith, Cat. Brit. Acul. Hym., p. 117, Nr. 1, $\sigma^{\top}$, 오 . . . . . . . 1858

Trypoxylon figulus Taschenb., Hym. Deutschl., p. 184, Nr. 2 . . . . . . . . 1866

Trypoxylon Figulus Thoms., Opusc. Ent., Fasc. II, p. $250, \sigma^{\top}$, 오 . . . . . . 1870

Trypoxylon figulus Costa, Ann. Mus. zool. Univ. Napoli (Ann. VI), p. 184 . . . . . . 1871

Trypoxylon Figulus Thoms., Hym. Scand., t. III, p. 251, o', ㅇ․ . . . . . . . 1874

Trypoxylon figulus Radoszk., Fedtsch. Reise n. Turkest., p. 68 , Nr. 1 . . . . . 1877

Trypoxylon figulus Edw. Saund., Trans. Ent. Soc. Lond., P. IV, p. 278, Nr. 1, ठ, 우 . . 1880

Long. 6-12 mm. $0^{7}$, ㅇ. . Nigrum, pedes concolores, calcaria testacea. Alae leviter fumatae. Clypeus arcuate truncatus in medio apice muticus. Frons convexiuscula, subtilissime coriaceo-rugulosa dense punctulata (L. b.); pari modo dorsulum. Segmentum medianum in area dorsali sulco vago instructum, oblique striatum; latera fere aciculate striolata. Segmentum secundum petioliforme longitudine segmenti tertii et quarti brevius. 
o'. Long. 6-11 mm. Flagelli articulus apicalis subuncinatus, articulis antecedentibus tribus unitis longitudine aequalis. Segmentum anale recte truncatum. ․ Long.
sima instructa.

Kopfschild vorne unvollkommen bogenförmig, mit einer äusserst schmalen Randleiste, die nur in der Mitte und daselbst in geringer Breitenausdehnung vorgezogen und gerade abgestutzt erscheint; beiderseits von dem abgestutzten Mittelrande bemerkt man eine sehr seichte Bucht. Die geringste Entfernung der Augen am Scheitel entspricht ungefähr jener unterhalb der Fühlerbasis. Stirne lederartig, mikroskopisch feinrunzelig, dicht punktirt (L. b), matt, mit feiner $\mathrm{Pu}$ bescenz bedeckt, ganz schwach gewölbt. Fühler schwarz, schwach gekrümmt, ihr Schaft kürzer als das zweite Geisselglied, Endglied kegelförmig, beim 오으 der Länge des zweiten, beim $\sigma^{\nearrow}$ aber von der Länge der drei vorhergehenden Glieder, viel spitzer als beim 우 und sichtlich gekrümmt. Die Stirne drängt eine mit einer kurzen Längskante, die erhabene Fortsetzung der deutlichen, vertieften Stirnlinie, versehene Erhebung zwischen die Basis der Fühler herein. Die Fühler sind am Grunde in sichtlicher Entfernung von einander eingefügt. Hinterwulst des Pronotum verhältnissmässig stark, mit einem deutlichen, linienartigen Quereindrucke und stumpfen Schulterecken. Mesonotum und Mesopleuren mikroskopisch feinrunzelig und unter der Lupe $b$ dicht und deutlich sichtbar punktirt; unter der Lupe $a$ erscheinen diese Theile mattglänzend und die Pünktchen nur schwer bemerkbar. Spuren des untergegangenen Geäders kräftig. Die Zahl der in zwei Gruppen getheilten Flügelhäkchen beträgt dreizehn. Horizontalpartie des Mittelsegmentes mit einem sehr flachen, querrunzeligen Eindrucke, im Uebrigen mit schräg nach hinten aussen verlaufenden Längsstreifchen. Mittelsegmentseiten schief von unten nach oben gestrichelt; diese Strichelung ist von nadelrissigem Aussehen und sehr fein (L. a). Der übrige Hinterleib ist gestreckt, keulenförmig, das zweite Segment, wenn die Ringe regelrecht eingezogen sind, höchstens so lang als das dritte und die Hälfte des vierten zusammengenommen, hat oben eine Längsfurche, die in ihrer Länge wechselt, was auch von folgender Art gilt. Auf dem Endsegmente des $q$ sieht man oben der ganzen Länge nach sich eine sehr feine Linie hinziehen; am Ende wird sie zu einem feinen Kielchen. Beim $\sigma^{\nearrow}$ ist das Endsegment gerade abgestutzt, an grossen Exemplaren scheint es fast ein wenig ausgerandet.

Die Lebensweise von $T r$. figulus ist zum Theile schon früh bekannt geworden. Linné citirt (l. c.) darüber die Beobachtungen Bergmann's; diese wurden besonders durch Dufour (Ann. soc. ent. France IX, p. 31, 1840) und Giraud ergänzt. $T r$. figulus hält sich an Orten auf, wo sich ihm gute Gelegenheit bietet, zu nisten; so auf Schilf, Hollunder, Berberitzen, Johannisbeerund Brombeersträuchern, an Eichen, durchlöcherten Balken u. s. w. In der 
Wahl seiner Brutstätten ist es eben nicht wählerisch; in den wärmeren Monaten des Jahres (Mai bis September) höhlt es sich im Marke der genannten Pflanzenarten Gänge aus, die ihm zur Anlage von Kammern dienen; häufig bedient es sich auch der von anderen Insecten verlassenen Bohrgänge in altem Holze. Prof. Dr. G. Mayr und Custos Rogenhofer erzogen es aus Eichengallen (Taf. IX, Fig. 4) der Cynips Kollari, wo es den verlassenen Gang dieser Gallwespe benützt hatte. Einmal sah ich diese Art an Fichtenbalken unter einem zirpenden Geräusch bohren. Die Weite der Gänge beträgt ungefähr $2.5 \mathrm{~mm}$. und entspricht der Grösse und dem Entwicklungsbedürfnisse des Thieres; ihre Wandungen bestehen selbstverständlich nur dann aus dem Mark eines bewohnten Zweiges, wenn jenes nicht ganz entfernt werden musste, um die nöthige Weite der Zellen zu erzielen.

Im Grunde des Ganges wird ein längliches Ei abgesetzt, dazu das Larvenfutter gelegt, welches aus mehreren kleinen und verschiedenartigen Spinnen besteht. $18-25 \mathrm{~mm}$. weit davon wird der Gang durch eine $1-2 \mathrm{~mm}$. dicke Querscheidewand aus Lehm abgeschlossen, und so die erste Zelle abgeschlossen. An dieser Querscheidewand wird ein zweites Ei abgesetzt, in der nämlichen Weise wie früher mit Spinnen versorgt und der Gang neuerdings durch eine Lehmwand abgeschlossen, die von der ersteren ebenfalls $18-25 \mathrm{~mm}$. weit entfernt ist und den Raum der zweiten Zelle abschliesst. Auf die zweite Zelle folgt meistens eine dritte, vierte, fünfte u. s. w. Die grösste Zahl der bisher in einem und demselben Markgange beobachteten Zellen ist acht.

Die Larven sind fusslos, blassgelb und etwa einen Monat nach dem Ausschlüpfen 6-7 mm. lang und 1.5 mm. dick. Am kleinen Kopfe sitzen die undeutlichen Fresswerkzeuge: eine schuppenförmige Oberlippe, die paarigen, hornartigen, dunklen Oberkiefer und darunter in Form von drei Wärzchen die Maxillen und die Unterlippe; kleine Fortsätze an diesen mögen zum Tasten dienen. Die Körpersegmente (ohne Kopf dreizehn) treten in Folge tiefer Einschnürungen deutlich hervor. Die Verpuppung geht im August und September vor sich; in diesem Zustande überwintert auch das Insect. Die Puppenhülle ist 9-12 mm. lang, 2-2.5 mm. dick, fein seidenartig, schmutzigweiss und durch feine Seidenfädchen an die Wandungen des Ganges geheftelt, vor dem Ende etwas verengt, welches der gegen den Grund des Bohrganges gerichteten Querscheidewand anliegt und selbstverständlich flach abgestutzt erscheint. Der Puppentheil zwischen der Einschnürung und dem abgestutzten Ende ist angedunkelt, oft mit schwärzlichen Längsstreifchen geziert. Das andere Ende ist convex und steht in einigem Abstande von der anderen Zellenquerwand. Im Zellraume kann man ausser der Puppe noch Reste von Spinnen, die Excremente der Larve und kleine Markstückchen wahrnehmen.

Die Puppe selbst ist weisslich und tritt im März oder im April in ähnlicher Weise wie bei anderen Aculeaten und den Ichneumoniden aus dem Stadium der Pseudo-Nymphe (Siebold) in das der Nymphe.!) Das vollendete Insect

1) Dufour beschreibt in dem oben citirten Werke eingehend den Uebergang in das eigentliche Nymphenstadium bei Tryp. fig. 
erscheint bei uns nicht selten schon Mitte April und ist bis October eine der häufigsten Hymenopteren.

Interessant ist von diesem Trypoxylon auch die grosse Aehnlichkeit der Lebensweise mit jener von Diphlebus Westw. (Cemonus-Arten), besonders der des D. unicolor. Die überraschende Aehnlichkeit der Bedürfnisse führt diese beiden Grabwespen überall zusammen, was viele Autoren zur Ansicht verleitet hat, dass Diphlebus parasitisch bei Trypoxylon wohne. Auch Dufour hatte diese Ansicht; Gir a u d widerlegte sie (Ann. soc. ent. France, 4. sér., t. VI, p. 474, 1866). Als sichere Parasiten der Töpferwespe können gelten: Chrysis cyanea L., Chr. obtusidens Duf. (Ann. soc. ent. France 1840, p. 37), Foenus affectator Auct., Cryptus gyrator, Cr. odiferator Nees, Ephialtes divinator Rossi, Eph. mediator Grav. und Eurytoma rubicola.

Geographische Verbreitung. Trypoxylon figulus ist in Europa mit Ausnahme des äussersten Nordens fast überall beobachtet worden. In den Alpen trifft man es auch über die subalpine Region bis zu 2000 Meter s. m. verbreitet.

\section{Trypoxylon attenuatum Smith.}

Trypoxylon attenuatum Smith, List of the specim. of Brit. Anim. in the coll. of the Brit.

Mus., P. IV, Hym. acul. Append., p. 120, $\sigma^{\nearrow}, \uparrow \ldots . . . . . . . . . .1851$

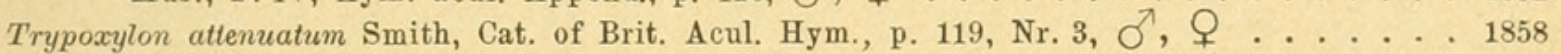

Trypoxylon attenuatum Schenck, Zus. u. Berichtig. Nass. Grabwesp. (Jahrb. d. Ver. f. Naturk.

Herz. Nassau, 16. Heft), p. 151, Nr. 2, $\delta^{\top}, Q^{2} \ldots . . . . . . . . .1861$

Trypoxylon attenuatum Thoms., Opusc. Entom. Ofv. Sver. Rofst., p. 250, Nr. 2 . . . . . 1870

Trypoxylon attenuatum Thoms., Hym. Scand., t. III, p. 253, Nr. 2 . . . . . . . . . 1874 Trypoxylon attenuatum Edw. Saunders, Syn. of Brit. Foss. Hym. (Trans. Ent. Soc. Lond.,

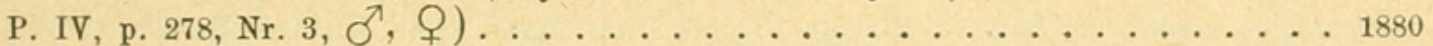

Long. 6-10 mm. o', ‥ Nigrum, pedibus concoloribus, calcaribus testaceis. Alae leviter fumatae. Clypeus subarcuate truncatus in apice medio subbidentatus. Frons, thorax et segmentum medianum pari modo ut in specie praecedente sunt sculpturata. Segmentum abdominis subcompressi secundum petioliforme tenue, valde elongatum, longitudine segmenti tertii et quarti.

o. Long. 6-8 mm. Flagelli articulus subuncinatus longitudine articulis quatuor antecedentibus unitis aequalis. Segmentum anale recte truncatum. instructa.

․ Long. 7-10 mm. Segmentum anale linea longitudinali tenuissima

Anglia, Scandinavia, Germania, Alpes Tirolis et Helvetiae, Sicilia.

Ist der vorigen Art sehr ähnlich und trotzdem leicht davon zu trennen. Seine Gestalt ist in allen Theilen (Beine, Fühler) gestreckter und zierlicher; die unbedeutend vorgestreckte Mittelpartie des Kopfschildrandes ausgerandet, daher fast zweizähnig. Die Fühler

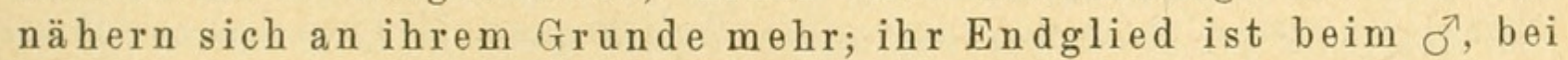
dem es leicht die Länge der vier vorhergehenden Glieder zusammengenommen einnimmt, länger, übrigens ebenfalls gekrümmt. Stirne gewölbter. Augenabstand auf dem Scheitel deutlich grösser als in 
der Kopfschildgegend. Der zweite Hinterleibsring ist entschieden dünner und länger, was zugleich mit dem Umstande, dass der Hinterleib in stärkerem Grade seitlich zusammengedrückt aussieht, diesen auch viel schlanker erscheinen lässt. Der zweite Hinterleibsring erreicht nämlich, vorausgesetzt, es seien die Segmente im Tode normal eingezogen, reichlich die Länge derbeiden darauffolgenden Glieder zusammengenommen.

Geographische Verbreitung. Tr. attenuatum, von dem Smith angibt, dass es im Marke von Rosenstöcken und ähnlichen Gewächsen (Rubus Saund.) nistet, ist durchaus nicht häufig, wenn es gleich verbreitet zu sein scheint. Wahrscheinlich ist es vou manchen Autoren nicht erkannt und mit Tr. figulus zusammengeworfen worden, darum in den Verzeichnissen fast nirgends zu finden. In England soll es nach Saunders nicht selten vorkommen (Bristol, Reigate, Common [Smith]; Cobham [Saunders]), in Scandinavien ziemlich selten (Thomson). Aus Deutschland wurde es durch Kirschbaum bekannt (Weisel beim Rhein). Frey, Gessner und Tournier sammelten es in der Schweiz, ersterer bei Sierre $(10 / 7)$, Mornex $(2 / 7)$ und Genthod $(17 / 5)$, letzterer bei Peney. Klobenstein, 1200 Meter s. m., und St. Justina $(28 / 6)$ bei Bozen in Tirol. Sicilien (Frey-Gessner).

\section{Trypoxylon clavicemum Lep. et Serv.}

Trypoxylon clavicerum Lep. et Serv., Encycl. Méth., t. X, p. 750, Nr. 1 . . . . . . . 1825 Trypoxylon clavicerum Shuck., Ess. on the ind. foss. Hym. Lond., p. 118, Nr. 3 . . . . . 1837 Trypoxylon tibiale Zetterst., Ins. Lapp., p. 466 . . . . . . . . . . . . . . . . . . 1840 Trypoxylon clavicerum Dhlb., Hym. Eur., t. I, p. 279. Tab. exam. syn. spec. Crabr., p. 509,

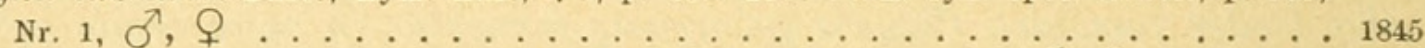

Trypoxylon clavicerum Lep., Hist. Nat. Ins. Hym., t. II, p. 229, Nr. 3, $\sigma^{\nearrow}, 9$. . . . 1845 Trypoxylon clavicerum Schenck, Grabwesp. Herz. Nassau (Jahrb. d. Ver. f. Naturk. Herz. Nassau,

12. Heft, p. 133, Nr. 2, $\left.\delta^{\top}, \uparrow\right] \ldots \ldots \ldots \ldots . \ldots \ldots 57$

Trypoxylon clavicerum Taschenb., Schlüss. z. Bestimm. (Zeitschr. f, d. ges. Naturwiss. X) . . . 1857 Trypoxylon clavicerum Smith, Cat. of. Brit. Acul. Hym., p. 118, Nr. 2, ठ, $\uparrow . . . .1858$ Trypoxylon clavicerum Taschenb., Hym. Deutschl., p. 184, Nr. 1 . . . . . . . . . 1866 Trypoxylon clavicerum Thoms., Opusc. Entom., Fasc. II, p. 250, Nr. 3 . . . . . . . 1870 Trypoxylon clavicerum Costa, Ann. Mus. zool. Univ. Napoli (Ann. VI), p. 46 . . . . . . 1871 Trypoxylon clavicerum Thoms., Hym. Scand., t. III, p. 253, Nr. 3 . . . . . . . . . . 1874 Trypoxylon clavicerum Edw. Saunders, Syn. Brit. Heterog. Foss. Hym. (Trans. Ent. Soc. Lond., P. IV, p. $\left.278, \mathrm{Nr} .2, \sigma^{\prime}, q^{\prime}\right) \ldots \ldots \ldots \ldots \ldots \ldots \ldots$

Long. 5-10 mm. $\sigma^{7}, \mathrm{Q}$. Nigrum, tibiae anteriores in parte antico, tarsi anteriores et genua omnia testacea; calcaria pallida aut fusca. Antennae breves, clavatae, in $\sigma^{\top}$ multo crassiores quam in $\$$. Clypeus in apice medio bidentatae. Oculi in vertice duplo plus distant quam infra antennas. Venae spuriae alarum anteriorum minus clarae. Frons, thorax et segmentum medianum simili modo ut in speciebus praecedentibus sculpturata. Abdominis segmentum secundum petioliforme latius. 
6. Long. 5-7 mm. Flagelli articulus apicalis crassus, paulum curvatus, longitudine articulis antecedentibus tribus aequalis. Segmentum anale fere recte truncatum.

\section{Q. Long. 6-10 $\mathrm{mm}$. Segmentum anale linea mediana distincta. Europa.}

Ist durchschnittlich kleiner als $T r$. attenuatum Smith und in vieler Beziehung, z. B. dem kräftigeren Bau, der Gestalt des zweiten Hinterleibssegmentes, dem $T r$. figulus L. näher verwandt als jenem. Von $T r$. figulus unterscheidet es sich 1. durch die weit geringere Grösse, 2. die durch eine Ausrandung in der Mittelpartie des Kopfschildes gebildeten stumpfen Zähnchen, 3. durch die grössere Divergenz der Augen (während der geringste Abstand der Augen auf dem Scheitel bei Tr. figulus dem geringsten Abstande der Augen unten am Kopfschilde gleichkommt, ist er bei clavicerum am Scheitel doppelt so gross), 4. durch die kurzen, keulenförmigen, beim $\sigma^{\top}$ ganz besonders verdickten Fühler (ihr Endglied ist beim $\sigma^{\gamma}$ sehr dick und nur ganz wenig gekrümmt), 5. die schwächeren Spuren des untergegangenen Flügelgeäders, 6. den verhältnissmässig breiteren zweiten Hinterleibsring, 7. die Färbung der Beine. Die Vorderseite der Vorderschienen, die Vordertarsen und sämmtliche Kniee sind lehmfarben.

Das Längenverhältniss des zweiten Hinterleibsringes ist ungefähr das nämliche wie bei figulus. Während bei figulus sich die Gesichtsfläche ziemlich gleichmässig dehnt, erscheint die Stirnpartie des Gesichtes bei clavicerum mehr aufgequollen, und oberhalb der Fühlerbasis erstreckt sich zu beiden Seiten eine deutliche Impression in schiefer Richtung bis über die Augenausrandung hinauf, ein Merkmal, in welchem sich clavicerum mehr attenuatum nähert.

Von $T r$. attenuatum weicht clavicerum besonders durch die durchschnittlich geringere Grösse, die grössere Augendivergenz, die viel kürzeren und dickeren Fühler $\left(\sigma^{\nearrow}\right.$,, ), die geringere Länge und die unbedeutende Krümmung des Endgliedes der Fühler beim $\sigma^{\nearrow}$, den viel derberen und kürzeren zweiten Hinterleibsring und endlich in der Färbung der Beine ab.

\section{Trypoxylon scutatum Chevr.}

! Trypoxylon scutatus Chevrier, Hymen. nouv. ou rar. du Bassin du Léman (Mitth. d. schweiz. ent. Gesellsch., Bd. II, Nr. 6, p. 231, Q) . . . . . . . . . . . 1867 Trypoxylon scutigerum Taschenb., Hymen. Ergänz. z. früh. Arb. (Zeitschr. f. d. ges. Naturw., Bd. V [LIH], p. 780 , Nr. $\left.14, \delta^{\top}\right) \ldots \ldots \ldots \ldots . \ldots \ldots 18 \ldots \ldots$

Long. 7-12 mm. $\sigma^{7}$, ㅇ. Nigrum, pedes concolores, calcaria pallida. Alae subhyalinae. Clypei margo arcuatus. Oculi in vertice sesqui plus quam infra antennas inter se distant. Frons impressione scutiforme distinctissime marginata instructa. Dorsulum nitidum sparse punctatum (L. a). Area dorsalis et postica segmenti mediani rude rugosa in medio longitudinaliter impressa; latera transverse striata. Segmenta abdominis reliqua elongata, praecipue 
segm. secundum tertium etiamque quartum; segm. secundum tenue tertio paulo longius.

07. Long. 7-9 mm. Flagelli articulus apicalis longitudine articulis antecedentibus tribus aequalis, quam flagelli articulo secundo multo longior, paulum curvatus. Segmentum anale recte truncatus.

\section{․ Long. 9-12 mm. Segmentum anale linea mediana distincta.}

Tr. scutatum Chevr. ist eine schlanke schwarze Art, fast so gross wie Tr. figulus, vor allen europäischen Arten durch einen tiefen, schildförmigen Eindruck an der Stirne auffallend gekennzeichnet. Dieser Eindruck wird von vier Kanten umschlossen; die beiden unteren Kanten stossen unter einem Winkel zusammen und setzen sich in einen Kiel fort, der sich zwischen die Basis der sehr nahe aneinander eingefügten Fühler hereindrängt; jede der beiden anderen Kanten läuft dem Innenrande des naheliegenden Auges parallel, und zwar in einer Entfernung von ihm, welche der Entfernung der beiden hinteren Nebenaugen untereinander nahezu gleichkommt. Weiter oben an der Stirne verlassen sie die eingeschlagene Richtung, neigen sich in einem Bogen gegeneinander bis zu ihrer Vereinigung hinter dem vorderen Nebenauge, so dass dieses in die obere Partie des Schildes hineinfällt. Die Schildfläche selbst ist punktirt und von den Seiten gegen die Mitte hin vertieft.

Von den Punkten, wo diese beiden letzterwähnten Kanten mit den früher erwähnten in einem scharfgezeichneten, ein wenig mehr als $90^{\circ}$ betragenden Winkel sich treffen, gehen auch Kanten gegen die Augenausrandungen ab, verlieren sich aber, noch ehe sie in diese hineindringen.

Eine Verwechslung mit $T r$. figulus $\mathrm{L}$. ist auch wegen anderer Unterschiede nicht leicht möglich. So unterscheidet sie sich von dieser 1 . durch den viel breiteren, entschieden abgesetzten und gleichmässig verlaufenden Kopfschildrand, 2. die grössere Annäherung der Augen unterhalb der Fühler, 3. das weniger gekrümmte Fühlerendglied beim $\sigma^{7}$, 4. die Sculptur des Kopfes, Dorsulums und der Mesopleuren (diese Theile sind bei scutatus glänzend, mit stärkeren und nur dünn gesäeten Punkten besetzt), 5. durch die grobe, stellenweise zerknittert runzelige Sculptur der oberen und hinteren Mittelsegmentfläche, 6. dieviel gröbere Streifung der Mittelsegmentseiten, 7. den schlanken, seitlich mehrzusammengedrückten Hinterleib, dessen zweiter, dritter, wohl auch vierter Ring mehr verdünnt und gestreckt erscheinen, 8. die dünnen Beine. Der Hinterwulst des Pronotums wird wie bei $T r$. figulus oben von einer Querrinne durchzogen, doch greift seine Vorderkante nicht wie bei diesem in der Mitte spitz nach hinten.

Von Tr. attenuatum weicht scutatum ebenfalls durch die Stirnbildung, die Gestalt des Kopfschildes, das kürzere Fühlerendglied beim $\sigma^{7}$, die Sculptur des Kopfes, Thorax und Mittelsegmentes ab. Tr. clavicerum endlich ist etwas kleiner, hat eine verschiedene Färbung der Beine, viel dickere Fühler, eine andere Gesichtsbildung und Sculptur, einen dickeren Hinterleib u. s. w. 
Geographische Verbreitang. Tr. scutatum ist eine seltene Art und wurde von dem verstorbenen Schweizer Entomologen Friedr. Chevrier bei Genf entdeckt; Gessner fand sie ebenfalls in der Nähe von Genf bei Genthod, Tournier bei Peney $(9 / 7)$. Taschenberg beschrieb sie (1881) nach einem in der Sammlung des Universitäts-Museums zu Halle befindlichen, aus Nord-Afrika (Abyssinien) stammenden Stücke unter dem Namen Tr. scutigerum.

\section{Trypoxylon ammophiloides Costa.}

Trypoxylon ammophiloides Costa, Ann. Mus. zool. Univ. Napoli (Ann. VI), p. 47, Nr. 3 . . 1871

„Gracile, nigrum, abdominis segmentis primis tribus et quarti basi, palpis pedibusque totis fulvo-testaceis; antennis clavatis ; metanoto subtilissime striolato; al. antic. cellulae cubitalis angulo externo recto $\sigma^{\top}$. - Long. corp. mill. 5; exp. al. mill. $7 \cdot 12 . "$

Eine durch die Färbung des Hinterleibes und der Beine, sowie durch die viel feinere Strichelung des Mittelsegmentes von der vorigen verschiedene Art. Sardinia.

Trypoxylon ammophiloides ist mir aus eigener Anschauung nicht bekannt, scheint aber nach den Costa'schen Angaben eine gute, wahrscheinlich seltene mediterrane Art zu sein.

\section{Trypoxylon albipes Smith.}

"ㅇ․ Länge $8 \mathrm{~mm}$. $\left(4^{1} / 2^{\prime \prime \prime}\right)$. Schwarz; Gesicht mit einer hell silberglänzenden Pubescenz bedeckt; Mandibeln und Taster blass lehmfarben; Beine fein silberweiss behaart. Bruststück mit einer spärlichen, feinen Pubescenz bedeckt, welche am Ende des Metathorax (Mittelsegmentes) auf der Brustseite und an den Hüften am dichtesten und glänzendsten erscheint; der Mesothorax und das Schildchen ist glatt und glänzend; an der Basis des Metathorax ist ein derb netzrunzeliger und mit einer tiefen, mittleren Längsrinne versehener herzförmiger Raum abgegrenzt; zu beiden Seiten des eingeschlossenen Raumes ist der Metathorax quergefurcht; Flügel glashell mit irisirendem Glanze, Flügelschuppen lehmgelb. Basis und äusserste Spitze der Schienen blass röthlichgelb. Tarsen weiss, ihre Endglieder schwach rostfarben. Hinterleib langgestreckt; die beiden ersten Ringe (respective Segment zwei und drei) von der Länge des Thorax; Basalsegment dünn. Der Hinterleib ist vollständig mit einer feinen, silberweissen Pubescenz bedeckt, welche in gewissem Lichte besonders an den Seiten deutlich hervortritt.“

Albanien.

Diese Smith'sche Art, in deren Beschreibung ebenso wie bei der vorigen Art feinere kritische Angaben fehlen, scheint doch eine selbstständige Form zu sein; mir ist sie unbekannt. 


\section{Verzeichniss der bisher beschriebenen Arten von Trypoxylon.}

T. accumulator Smith. \&. Reg. III, Subreg. 1. India.

Trypoxylon accumulator Smith: Trans. Ent. Soc. Lond. 1875, p. 38, ․․

T. albipes Smith. ㅇ. Reg. I, Subreg. 2. Albania.

Trypoxylon albipes Smith: Catal. Hym. Brit. Mus. IV, 1856, p. 377, Nr. 4, ․

T. albitas'se Fabr. + , $\sigma^{7}$. Reg. IV, Subreg. 2 u. 3. California, U.-Stat., Mexico (Sauss.), Brasilia? (Smith).

Trypoxylon albitarse Fabr.: Syst. Piez. 1804, p. 180, Nr. 1.

Trypoxylon albitarse Dahlb.: Hym. Eur. T. 1845, p. 286 u. 509, Nr. 6, ठ7. ? Trypoxylon albitarse Pel.: Hist. nat. Ins. Hym. III, 1845, p. 228, Nr. 1, Taf. XXVII, Fig. 3, 9 , $\sigma^{\nearrow}$.

Trypoxylon albitarse Taschenb.: Zeitschr. f. d. ges. Naturw. XLV, 1875, p. $371, \mathrm{Nr} .1$, $7, \sigma^{7}$.

Trypoxylon albitarse Sauss.: Reise d. „Novara“, Zool. II, Zool., 1867, p. 76, $\mathrm{Nr} .1$, , $c^{\lambda}$ (var. mexicana Sauss.).

T. ammophiloides Costa. $0^{7}$. Reg. I, Subreg. 2. Sardinia.

Trypoxylon ammophitoides Costa: Ann. Mus. Zool. Napoli 1871, p. 47, Nr. 3, 0 .

T. annulare Dahlb. Reg. V, Subreg. 2. Brasilia.

Trypoxylon annulare Dhlb.: Hym. Eur. I, 1845, p. 282 u. 509, Nr. 3.

Trypoxylon annulare Taschenb. : Zeitschr. f. d. ges. Naturwissensch. XLV, 1875 , p. 373 , Nr. 5, ㅇ.

T. annulipes Taschenb. $\sigma^{\nearrow}$. Reg. V, Subreg. 2. Venezuela.

Trypoxylon annulipes Taschenb.: Zeitschr. f. d. ges. Naturwissensch. XLV, 1875, p. $377, \sigma^{\top}$.

T. armatum Taschenb. $\sigma^{\nearrow}$. Reg. V, Subreg. 2. Venezuela.

Trypoxylon armatum Taschenb. : Zeitschr. f. d. ges. Naturwissensch. XLV, 1875, p. $377, \sigma^{7}$.

T. aureovestitum Taschenb. $\sigma^{\pi}$. Reg. V, Subreg. 1, Mendoza.

Trypoxylon aureovestitum Taschenb.: Zeitschr. f. d. ges. Naturwissensch.

XLV, 1875 , p. $376, \mathrm{Nr} .10$, $\sigma^{\nearrow}$.

T. aurifrons Shuck. Reg. V, Subreg. 2. Brasilia, Santarem.

Trypoxylon aurifrons Shuck.: Ess. ind. foss. Hym. 1837, p. 112, Nr. 2.

Trypoxylon aurifrons Dahlb.: Hym. Eur. I, 1845, p. 285.

T. attenurtum Smith. + , $\sigma^{7}$. Reg. I, Subreg. 1. Eur. bor. et centr.

Trypoxylon attenuatum Smith: Catal. Brit. Hym. Mus. 1851, p. 120, , ఠ’

T. aztecum Sauss. †, ठ․ Reg. V, Subreg. 3. Mexico, Pueblo viejo, Tampico.

Trypoxylon aztecum Sauss.: Reise d. „Novara“, Zool. II, 1867, p. 80, Nr. 11, , ơ (excl. var. ơ).

T. Bahiae Sauss. ․ Reg. V, Subreg. 2. Bahia.

Trypoxylon Bahiae Sauss.: Reise d. „Novara“, Zool. II, 1867, p. 80, Nr. 10, 오. 
T. bicolor Smith. ९. Reg. III, Subreg. 4. Singapore, Java.

Trypoxylon bicolor Smith: Catal. Hym. Brit. Mus. IV, 1856, p. 377, Nr. 6, q.

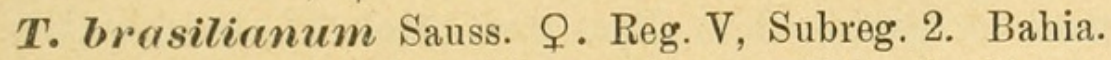

Trypoxylon Brasitianum Sauss.: Reise d. „Novara“, Zool. II, 1867, p. 84, Nr. 19, ㅇ.

T. brevipenne Sauss. $q$. Reg. II, Subreg. 2. Guinea.

Trypoxylon brevipenne Sauss.: Reise d. „Novara“, Zool. II, 1867, p. 85, Nr. 20, Taf. IV, Fig. 50, ‥

T. californicum Sauss. + . Reg. IV, Subreg. 2. California.

Trypoxylon californicum Sauss.: Reise d. „Novara“, Zool. II, 1867, p. 78, Nr. 6, ㅇ․

T. carinatum Say. $\sigma^{\nearrow}$. Reg. IV, Subreg. 3. Indiana.

Trypoxylon carinatus Say: Boston Journ. I, 1837, p. 374, Nr. 3, ठ

Trypoxylon carinatus Lec. : Say, Compl. Writ. II, 1859, p. 757, Nr. 3, ð.

T. chichimecum Sauss. \&. Reg. V, Subreg. 3. Mexico.

Trypoxylon chichimecum Sauss. : Reise d. „Novara“, Zool. II, 1867, p. 83, Nr. 16, Taf. IV, Fig. 48, ․

T. clavatum Say. $\uparrow$. Reg. IV, Subreg. 3. U.-St.

Trypoxylon clavatus Say: Boston Journ. I, 1837, p. 374, Nr. 2.

Trypoxylon clavatus Lec.: Say, Compl. Writ. I, 1859, p. 756, Nr. 2.

Trypoxylon clavatum Pack.: Proc. Ent. Soc. Philadelphia VI, 1867, p. 414, @.

T. clavicerum Pel. et Serv. $\uparrow, \sigma^{\nearrow}$. Reg. I, Subreg. 1 u. 2. Europa.

Trypoxylon clavicerum Pel. et Serv. : Enc. Méth. X, 1811, p. 750, Nr. 1, 오, $\sigma^{\nearrow}$.

T. collinum Smith. $q$, $\sigma^{\top}$. Reg. IV, Subreg. 3. Florida.

Trypoxylon collinum Smith: Catal. Hym. Brit. Mus. IV, 1856, p. 381, Nr. 21, ㅇ.

Trypoxylon collinum Pack.: Proc. Ent. Soc. Philadelphia VI, 1867, p. $415, \sigma^{\top}$.

T. coloratum Smith. б'. Reg. III, Subreg. 4. Borneo, Sarawak.

Trypoxylon coloratum Smith: Journ. of Proc. Linn. Soc. Zool. II, 1857, p. 106, ठ'.

T. coloratum Taschenb. + , $\sigma^{T}$. Reg. V, Subreg. 1. Mendoza $=$ mutatum $\mathrm{m}$.

Trypoxylon coloratum Taschenb.: Zeitschr. f. d. ges. Naturwissensch. XLV, 1875, p. 376, Nr. 9, 우, ơ.

T. columbianum Sauss. ‥ Reg. V, Subreg. 2. Columbia, Caraccas.

Trypoxylon columbianum Sauss.: Reise d. „Novara“, Zool. II, 1867, p. 80, Nr. 9, Taf. IV, Fig. 46, ㅇ.

T. elegantulum Smith. + . Reg. VI, Subreg. 1. Makassar.

Trypoxylon elegantulum Smith: Journ. of Proc. Linn. Soc. Zool. V, 1860, p. 84, Nr. 2, ․

T. elongratum Smith. $\sigma^{\top}$. Reg. II, Subreg. 2. Sierra Leone.

Trypoxylon elongatum Smith: Catal. Hym. Brit. Mus. IV, 1856, p. 378, Nr. 7. 
T. errans Sauss. ๆ. Reg. II, Subreg. 4. Mauritius, Brasilia.

Trypoxylon errans Sauss. : Reise d. „Novara“, Zool.II, 1867, p. 84, Nr. 18, ㅇ. .

T. excavatum Smith. + , $\sigma^{\top}$. Reg. V, Subreg. 4. Jamaica, St. Thomas, Cuba.

Trypoxylon excavatum Smith: Catal. Hym. Brit. Mus. IV, 1856, p. 380 , Nr. 17, ㅇ, $0^{7}$.

Trypoxylon excavatum Sauss.: Reise d. „Novara“, Zool. II, 1867, p. 79, Nr. 8, Taf. IV, Fig. 49.

Trypoxylon excavatum Pack.: Proc. Ent. Soc. Philadelphia VI, 1867, p. 414, 우, $\sigma^{\top}$.

T. eximium Smith. + . Reg. VI, Subreg. 1. Aru, Key.

Trypoxylon eximium Smith: Journ. of Proc. Linn. Soc. Zool. III, 1859, p. 161, ㅇ.

T. fabricator Smith.

Trypoxylon fabricator Smith: Ann. et Mag. of N.-H. (4) XII, 1873, p.101, ㅇ, o’'

T. ferox Smith. Q. Reg. VI, Subreg. 1. Makassar, Celebes.

Trypoxylon ferox Smith: Journ. of Proc. Linn. Soc. Zool. V, 1860, p. 84, Nr. 3, ㅇ․

T. figulus Linn. ㅇ. $\sigma^{\top}$. Reg. I, Subreg. 1 u. 2. Europa.

Sphex figulus Linn.: Syst. Nat. Ed. $10^{0}$, I, 2, 1758, p. 570, Nr. 9.

Sphex figulus Linn.: Faun. Suec. Ed. $2^{0}$, 1761, p. 411, Nr. 1650.

T. frigidum Smith. $q, \sigma^{\top}$. Reg. IV, Subreg. 4. Hudsons-Bay.

Trypoxylon frigidum Smith: Catal. Hym. Brit. Mus. IV, 1856, p. 381, Nr. 22, ㅇ.

Trypoxylon frigidum Pack.: Proc. Ent. Soc. Philadelphia VI, 1867, p. 415, 오, $\sigma^{\top}$.

T. frontale Smith. ․ Reg. II, Subreg. 1. Africa.

Trypoxylon frontale Smith: Catal. Hym. Brit. Mus. IV, 1856, p. 378, Nr. 8, 오.

T. fugax Fabr. Reg. V, Subreg. 2. Brasilia.

Trypoxylon fugax Fabr.: Syst. Piez. 1804, p. 182, Nr. 4.

Trypoxylon fugax Dahlb.: Hym. Eur. I, 1845, p. 281 u. 509, Nr. 5.

Trypoxylon fugax Taschenb.: Zeitschr. f. d. ges. Naturwissensch. XLV, 1875 , p. $374, \mathrm{Nr}, 7$.

T. fuscipenne Fabr. Reg. V, Subreg. 2. Brasilia.

Trypoxylon fuscipenne Fabr.: Syst. Piez. 1804, p. 181, Nr. 3.

Trypoxylon fuscipenne Taschenb.: Zeitschr. f. d. ges. Naturwissensch. XLV, 1875 , p. 372 , Nr. 3.

T. gracile Taschenb. ․ Reg. V, Subreg. 2. Venezuela.

Trypoxylon gracile Taschenb.: Zeitschr. f. d. ges. Naturwissensch. XLV, 1875 , p. $377, \mathrm{Nr} .12$, ㅇ.

T. gracilescens Smith. ㅇ. Reg. VI, Subreg. 1. Makassar, Celebes.

Trypoxylon gracilescens Smith: Journ. of Proc. Linn. Soc. Zool. V, 1860, p. 85 , Nr. 4 , ㅇ. 
T. gracillimum Smith. $\sigma^{\nearrow}$. Reg. VI, Subreg. 1. Mysol.

Trypoxylon gracillimum Smith: Journ. of Proc. Linn. Soc. Zool. VII, 1863, p. 35 , Nr. $2, \sigma^{\top}$.

T. javanum Taschenb. $\sigma^{\top}$. Reg. III, Subreg. 4. Java.

Trypoxylon javanum Taschenb.: Zeitschr. f. d. ges. Naturwissensch. XLV, 1875 , p. 378 , Nr. 13 , o'.

T. intrudens Smith. ㅇ. Reg. III, Subreg. 1. Mainpuri, Ind. Nid. Prov.

Trypoxylon intrudens Smith: Trans. Zool. Soc. Lond. VII, 1872, p. 188, Nr. 1, ․ .

T. lactitarse Sauss. $\sigma^{\top}$. Reg. V, Subreg. 3. Mexico.

Trypoxylon lactitarse Sauss.: Reise d. „Novara“, Zool. II, 1867, p. 81, Nr. $13, \sigma^{\top}$.

T. laevifrons Smith. Q. Reg. V, Subreg. 2. Brasilia, Ega.

Trypoxylon laevifrons Smith. : Ann. et Mag. of N.-A. (4) XII, 1873, p. 101, ㅇ․

T. luteitarse Sauss. ‥ Reg. V, Subreg. 3. Mexico.

Trypoxylon luteitarse Sauss.: Reise d. "Novara“, Zool. II, 1867, p. 82, Nr. 14, Taf. IV, Fig. 47, ㅇ․

T. mexicanum Sauss. $\$$, $\sigma^{\nearrow}$. Reg. V, Subreg. 3. Mexico.

Trypoxylon mexicanum Sauss.: Reise d. „Novara“, Zool. II, 1867, p. 78,

Nr. 4, Taf. IV, Fig. 45, 오.

T. neglectum Kohl. $\sigma^{\top}$. Reg. V, Subreg. 3. Carolina mer.

Trypoxylon neglectum Kohl: Verhandl. d. k. k. zool.-bot. Gesellsch. Wien, XXXIII, 1883 , p. 340 , Nr. 1, Taf. XVIII, Fig. 3, б.

T. nitidum Smith. Q. Reg. V, Subreg. 2. Brasilia.

Trypoxylon nitidum Smith: Catal. Hym. Brit. Mus. IV, 1856, p. 379, Nr. 15,

T. niveitarse Sauss. $\sigma^{\top}$. Reg. V, Subreg. 2. Brasilia.

Trypoxylon niveitarse Sauss.: Reise d. „Novara“, Zool. II, 1867, p. 81, Nr. 12, $\sigma^{\top}$.

T. obsonator Smith. Reg. I, Subreg. 4. Japan, Hiogo.

Trypoxylon obsonator Smith: Trans. Ent. Soc. Lond. 1873, p. 194.

T. ornatum Smith. $q$. Reg. V, Subreg. 2. Brasilia.

Trypoxylon ornatum Smith: Catal. Hym. Brit. Mus. IV, 1856, p. 380, Nr. 16, Q.

T. palliditarse Sauss. + , $\sigma^{\nearrow}$. Reg. V, Subreg. 1 et 2 . Brasilia, Argentina.

Trypoxylon palliditarse Sauss.: Reise d. „Novara“, Zool. II, 1867, p. 77,

Nr. 2, 우, o’.

Trypoxylon rostratum Taschenb.: Zeitschr. f. d. ges. Naturwissensch. XLV, 1875 , p. 371, Nr. 2.

T. pennsylvanicum Sauss. ㅇ. Reg. IV, Subreg. 3. Pennsylvania.

Trypoxylon pennsylvanicum Sauss.: Reise d. "Novara“, Zool. II, 1867,

p. $82, \mathrm{Nr} .15$, ㅇ. 
T. petiolatum Smith. ․․ Reg. III, Subreg. 4. Borneo, Sarawak.

Trypoxylon petiolatum Smith: Journ. of Proc. Linn. Soc. Zool. II, 1857, p. 105 , 오.

T. pileatum Smith. + . Reg. III, Subreg. 1. Madras.

Trypoxylon pileatum Smith: Catal. Hym. Brit. Mus. IV, 1856, p. 377, Nr. 5, ㅇ. .

T. placidum Smith. ㅇ. Reg. VI, Subreg. 1. Mysol.

Trypoxylon placidum Smith: Journ. of Proc. Linn. Soc. Zool. VII, 1863, p. 35 , Nr. 1, 오.

T. politum Say. Reg. IV, Subreg. 3. New Jersey, Pennsylvania, Illinois.

Trypoxylon politus Say: Boston Journ. I, 1837, p. 373, Nr. 4.

Trypoxylon politus (Lec.): Say, Compl. Writ. II, 1859, p. 756, Nr. 1.

Trypoxylon politum Pack.: Proc. Ent. Soc. Philadelphia VI, 1867, p. 413.

T. providum Smith. Q. Reg. VI, Subreg. I. Batchian.

Trypoxylon providum Smith: Journ. of Proc. Linn. Soc. Zool. V, 1860, p. $125, \mathrm{Nr} .1$, 오

T. punctulatum Taschenb. Q. Reg. V, Subreg. 2. Brasilia.

Trypoxylon punctulatum Taschenb.: Zeitschr. f. d. ges. Naturwissensch. XLV, 1875, p. 372, Nr. 4, ?.

T. rejector Smith. O. Reg. III, Subreg. 1. Mainpari, N.-W. Prov.

Trypoxylon rejector Smith: Trans. Zool. Soc. Lond. VII, 1872, p. 189, Nr. 2, Taf. XXI, Fig. 4, ․

T. Rogenhoferi Kohl. $q$, $\sigma^{\top}$. Reg. V, Subreg. 2. Ypanema, St. Paulo.

Trypoxylon Rogenhoferi Kohl: Verhandl. d. k. k. zool.-bot. Gesellsch. Wien XXXIII, 1883, p. 342, Nr. 2, Taf. XVIII, Fig. 4.

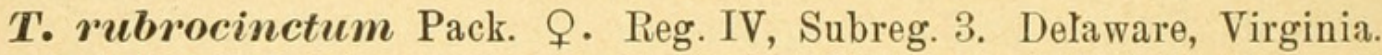

Trypoxylon rubrocinctum Pack.: Proc. Ent. Soc. Philadelphia VI, 1867, p. 416 , ㅇ.

T. rufimanum Spin. Reg. V, Subreg. 2. Parà.

Trypoxylon rufimanum Spin.: Mem. Accad. sc. Torino (2) XIII, 1853, p. 59 , Nr. 42 .

T. rufosignatum Taschenb. $\sigma^{\top}$. Reg. V, Subreg. 2. Brasilia.

Trypoxylon rufosignatum Taschenb.: Zeitschr. f. d. ges. Naturwissensch. XLV, 1875, p. 374, Nr. 8, б’.

T. rugifrons Smith . Reg. V, Subreg. 2. Brasilia.

Trypoxylon rugifrons Smith: Ann. et Mag. of N.-A. (4) XII, 1873, p. 100, 오.

T. scutatum Chevr. ㅇ, ð’. Reg. I, Subreg. 2. Eur. mer. Reg. II, Subreg. I. Abyssinia.

Trypoxylon scutatus Chevr.: Mittheil. schweiz. ent. Gesellsch. II, 6, 1867, p. 231, ․․

Trypoxylon scutigerum Taschenb.: Zeitschr. f. d. ges. Naturwissensch. LV, 1881, p. 780 , Nr. 14 , б 
T. scutiferum Taschenb. + . Reg. V, Subreg. 2. Brasilia.

Trypoxylon scutiferum Taschenb. : Zeitschr. f. d. ges. Naturwissensch. XLV, 1875 , p. 379 , Nr. 16 , Q.

T. subimpressum Smith. $\sigma^{\top}$. Reg. V, Subreg. 4. St. Domingo.

Trypoxylon subimpressum Smith: Catal. Hym. Brit. Mus. IV, 1856, p. 380, Nr. 18, $\sigma^{\top}$.

T. succinctum Cress. $\$$. Reg. V, Subreg. 4. Cuba.

Trypoxylon succinctum Cress.: Proc. Ent. Soc. Philadelphia IV,1865, p.149, ․ .

T. superbum Smith. $q$. Reg. V, Subreg. 2. Brasilia, Ega.

Trypoxylon superbum Smith: Ann. et Mag of N.-H. (4) XII, 1873, p. 100, ㅇ.

T. texense Sauss. ․ Reg. IV, Subreg. 3. Texas.

Trypoxylon texense Sauss.: Reise d. „Novara“, Zool. II, 1867, p. 77, Nr. 3, ㅇ.

T. toltecum Sauss. ㅇ. Reg. V, Subreg. 3. Mexico, Orizaba.

Trypoxylon toltecum Sauss.: Reise d. „Novara“, Zool. II, 1867, p. 83, Nr. 17, Q.

T. tridentatum Pack. . . Reg. IV, Subreg. 3. New-York, New-Jersey.

Trypoxylon tridentatum Pack.: Proc. Ent. Soc. Philadelphia VI, 1867, p. 417, .

T. vaguim Smith. ‥ Reg. V, Subreg. 2. Brasilia, St. Paulo.

Trypoxylon vagum Smith: Ann. et Mag. of N.-H. (4) XII, 1873, p. 99. Q.

T. xantianum Sauss. Q, o'. Reg. IV, Subreg. 2. California, St. Lucae.

Trypoxylon Xantianum Sauss.: Reise d. "Novara“, Zool. II, 1867, p. 78,

Nr. 5, १, ठ․

Gen. Solierella Spin. (Taf. VIII, Fig. 6).

(Solier, nom. propr.)

Solierella Spin., Hist. fis. Chile, Gay, Zool, t. VI, tab. II, fig. $5 \alpha, 5 b, 5 c \ldots \ldots . . . . .1851$ Solierella Smith, Cat. Hym. Ins. Brit. Mus., p. IV, p. 312, pl. VIII, fig. 2 . . . . . . . . 1856 Niteliopsis Sidn. Sm. Saunders, Trans. Ent. Soc. Lond., p. III, p. 410 . . . . . . . 1873

Statur klein, gedrungen. Kopf ein wenig breiter als das Bruststück. Oberkiefer mit einem Ausschnitte in der Mitte ihres Unterrandes, am Ende zugespitzt. Kopfschild kurz; Fühler kräftig, knapp am oberen Kopfschildrande eingefügt, von einander fast ebensoweit als von den Augen abstehend. Geisselglieder gedrungen, länglich, und mit Ausnahme des ersten kleineren in der Länge nur wenig verschieden. Endglied bei den $q$ stumpf kegelförmig, bei den $\sigma^{\nearrow}$ zugespitzt. Augen nur sehr mässig convergent, Scheitel daher von ziemlicher Breite; der Unterrand der Augen erreicht die $\mathrm{Oberkieferbasis.} \mathrm{Nebenaugen} \mathrm{regelmässig} \mathrm{rund;} \mathrm{sie} \mathrm{bilden} \mathrm{in} \mathrm{ihrer} \mathrm{Stellung}$ ein gleichseitiges oder gleichschenkeliges Dreieck. Die beiden hinteren liegen nur wenig vor der Linie, welche man sich an den Hinterrand der Netzaugen und über den Scheitel gelegt denkt.

Hinterwulst des Pronotum mit dem Dorsulum nahezu in gleichem Niveau. Die Schulterbeulen reichen nicht bis zu den Flügelschuppen hin. Dorsulum von 
beträchtlicher Länge. Bei Sol. miscophoides Spin. ${ }^{1}$ ) (Hist. Chile, Gay, t. VI, p. 352, Taf. II, Fig. 5, 1851) erscheint das Mittelsegment hinten in schräger Richtung abgeschnitten und eine Kante trennt seine abstürzende Fläche von den Seiten; auf dem Horizontaltheile wird durch zwei nach hinten convergente Runzelleisten ein grosses, trapezförmiges Feld abgegrenzt, welches in der Mitte von einer Längslinie durchzogen und an den Seiten von einem weissen Filze - ähnlich wie bei Dinetus - eingerahmt wird. Die erwähnten Runzelleistchen greifen auch auf die abstürzende Fläche über und vereinigen sich nicht weit oberhalb der Stelle, wo das zweite Segment an das Mittelsegment geheftet erscheint.

Die Radialzelle is t a bgestutzt, lanzettlich, ihre Anhangszelle deutlich, ohne besonders gross zu sein. Cubitalzellen kommen drei vor; die erste davon ist viel grösser als die beiden folgenden zusammengenommen, die zweite dreieckig, gestielt, und nimmt die erste Discoidalquerader vor ihrer Mitte, nicht weit hinter ihrem Anfange, die zweite hinter ihrer Mitte auf; die dritte Cubitalzelle ist ein wenig schräg gestellt. Das Frenum der Hinterflügel beginnt am Ursprunge der Radialader und besteht aus einer einzigen Häkchengruppe. Bei Sol. miscophoides zeigen sich zehn Häkchen. Die Cubitalader der Hinterflügel entspringt in erheblichem Abstande hinter dem Abschlusse der mittleren Schulterzelle, näher dem Spitzenrande des F́lügels.

Beine wie bei Pison, Nitela und Sylaon sehr schwach bewehrt. Schienen an der Aussenseite mit Spuren von Dörnchen. Mittelschienen einspornig. Vordertarsen ohne Wimpernkamm. Klauen und Klauenballen mässig entwickelt. Hinterleib kräftig, der zweite Dorsalring an seiner Basis flach eingedrückt, mit einer vertieften Längslinie in der Mitte, an den Seiten nicht gekantet. Endsegment (q) kegelförmig wie bei Pison, ohne Pygidialfeld, nicht gegen die Bauchseite hin eingezogen wie bei Sylaon.

Diese erst in zwei Arten bekannt gewordene Gattung unterscheidet sich von der ihr nächst verwandten Gattung Sylaon Picc. besonders durch die Ausrandung an der unteren Kante der Oberkiefer und den Verlauf der Discoidalqueradern im Vorderflügel.

S. Sidn. Smith Saunders beschreibt eine Gattung Niteliopsis (Trans. Ent. Soc. Lond., p. III, p. 410, 1873), welche ich nicht aus eigener Anschanung kenne; aus der guten Beschreibung und aus den Vergleichen, welche Saunders

1) Ich kenne Solierella miscophoides Spin. - ein Stück $(Q)$ befindet sich in den Sammlungen des k. k. zoologisehen Hof-Cabinetes in Wien - und finde, dass wohl die Abbildung der Spinola'schen Arbeit, nicht aber auch die Beschreibung allenthalben genau darauf stimmt. Während nämlich die Figur des Flügelgeäders in Uebereinstimmung mit der lateinischen Gattungsdiagnose (, areolis cubitalibus tribus, prima et secunda sigillatim nervum recurrentem excipientibus $^{\text {(j) }}$ und dem von mir geprüften Stücke dentlich zeigt, dass die zweite Cubitalzelle beide Discoidalqueradern aufnimmt, heisst es im spanischen Texte: „la primera (celdilla) mayor que las dos seguientes reunidas, recibiendo la primera nerviosidad recurrente $\dot{a}$ corta distancia de su extremidad; la segundo muy chiquita, peciolada, recibiendo la segunda recurrente un poco mas alla del medio". Wahrscheinlich hat sich Spinola im Texte geirrt; doch ist wohl auch möglich, dass die erste Discoidalquerader bei Solierella in veränderlicher Weise bald in die erste und bald in die zweite C'abitalzelle mündet. 
mit den nahe verwandten Gattungen Nitela und Pison anstellt, geht aber die Synonymie von Niteliopsis mit Solierella zur Genüge hervor.

Lebensweise. Was man in dieser Hinsicht von Solierella weiss, beschränkt sich auf die spärlichen Angaben, welche Saunders (von Niteliopsis) macht. Die europäische Art ( $S$. pisonoides Saund.) lebt in dürren Brombeerzweigen. Die Puppengehäuse sind von einem blass lehmfarbigen Stoffe, länglich eiförmig, runzelig und ziemlich gebrechlich. Im Monat Juli bricht das vollkommene Insect hervor. Eine kleine, $4 \mathrm{~mm}$. lange Goldwespe (Homalus nanus Saund., Trans. Ent. Soc. Lond., p. III, 1873, p. 411) ist als Parasit von dieser Art zu verzeichnen.

Geographische Verbreitung. S. miscophoides bewohnt die neotropische Region (Chili), S. pisonoides die jonischen Inseln Corcyra und Leucadia; letztere dürfte im mediterran-paläarktischen Gebiete wohl weiter verbreitet sein.

\section{Solierella pisonoides Saund.}

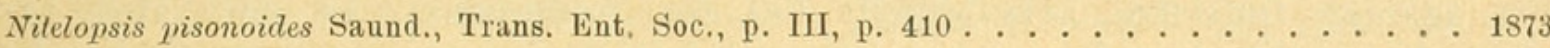

"Nigra, nitida; mandibulis apice castaneis; clypeo in utroque sexu pilis albidis sericeis circumcincto; prothoracis linea interrupta alba; scutelli lineola vel punctis duobus albidis; calcaribus tarsisque pallidis, his apice nigrescentibus. Femina. Long. corp. 5-6 mm. Expans. alarum 8-10 mm.

Mas, similis at minor, antennis apice acutis, 13-articulatis. Long. corp. $4-5 \mathrm{~mm}$.

Habitat in Insulis Jonicis (Corcyra et Leucadia) rubis exsiccatis. Imagines mense Julio maturatae."

Gen. Sylaon Piccioli (Taf. VIII, Fig. 5; Taf. IX, Fig. 8).

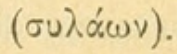

Silaon Piccioli, Bull. soc. ent. ital. ann. I, p. 283, tab. I, fig. 2 . . . . . . . . . 1869 Silaon Costa, Ann. Mus. Zool. Univ. Napoli (Ann. VI), p. 82 . . . . . . . . . . 1871 Ammosphecidium Kohl, Verhandl. d. k. k. zool.-bot. Gesellsch. Wien, 1877, p. 701 . . . . 1878

Statur klein. Der Kopf übertrifft das Bruststück an Breite.

Aussenrand der Oberkiefer ohne Ausschnitt. Kopfschild kurz, in der Mitte erhaben und mit einer Längskante versehen, beim $\varnothing^{\lambda}$ zugleich mit der angrenzenden Partie der Stirne silberfilzig behaart. Augen oval, an ihrer Innenseite nicht ausgerandet, von einander weit abstehend, gegen den Scheitel nicht convergent, ihr Unterrand an die Oberkieferbasis stossend. Stirne und Scheitel ohne wulstige Auftreibungen. Nebenaugen deutlich und rund, in ein fast gleichseitiges Dreieck gestellt. Fühler fadenförmig, kräftig und kurz, knapp am Kopfschilde eingefügt; ihre Glieder sind in der Länge wenig verschieden; das erste und zweite Glied ist ein wenig kürzer als die folgenden, das Endglied beim $\sigma^{\nearrow}$ scharf zugespitzt und kürzer als das vorletzte Glied, beim $\subseteq$ länger und normal konisch und stumpfspitzig. Pronotumwulst quer, mit dem Dorsulum fast in gleichem Niveau. Die Schulterbeulen reichen nicht zur Flügelbasis zurück. 
Schildchen auffallend gross, halb so lang als das Dorsulum, rechteckig und von geringer Convexität. Hinterschildchen schmal, linear. Mittelsegment an seinen Hinterecken abgerundet, hinten steil abfallend. Auf seiner Horizontalfläche, welche merklich kürzer als das Dorsulum ist, erscheint durch zwei Runzeln ein grosses, halbellipsenförmiges Feld abgegrenzt. welches mit seinem Ende auf die abfallende Hinterfläche übergreift. Die Flügel sind verhältnissmässig gross. Die Radialzelle der Vorderflügel ist gross, breit lanzettlich, am Ende abgestutzt und hat eine Anhangszelle. Cubitalzellen sind drei entwickelt; die erste ist viel grösser als die beiden folgenden zusammengenommen, die zweite deutlich gestielt, ein wenig kleiner als die dritte, die dritte schief gestellt und an der Radialader schmäler als an der Cubitalader. Die erste Discoidalquerader mündet in die erste Cubitalzelle, ein wenig vor deren Ende, die zweite Discoidalquerader jenseits der Mitte der zweiten Cubitalzelle. Die Basalader vereinigt sich mit der Schulterquerader oder trifft ausnahmsweise in höchst unbedeutender Entfernung vom Abschlusse der inneren mittleren Schulterzelle auf die Medialader. In den Hinterflügeln fällt der Ursprung der Cubitalader nicht mit dem Abschlusse der mittleren Schulterzelle zusammen, sondern liegt ein wenig vor dem Ende der über die Schulterzelle hinausreichenden Verlängerung der Medialader. Bei der einen bekannten Art zähle ich sieben Frenalhäkchen. Beine schlank, aber nicht in dem nämlichen Grade wie bei Nitela, ihre Bewehrung unbedeutend. Mittelschienen einspornig, ausserdem Mittel- und Hinterschienen mit einigen wenigen, wegen ihrer Kleinheit nur schwer (L. b) bemerkbaren Dörnchen besetzt. Hinterschienen etwas länger als Vorder- und Mittelschienen. Metatarsus der Vorderbeine fast ein wenig länger als die drei folgenden Glieder zusammengenommen, ohne Wimpernkamm. Metatarsus der Mittelbeine an Länge den drei folgenden Gliedern zusammengenommen gleich, und Metatarsus der Hinterbeine kürzer als die drei folgenden Glieder. Klauenballen kräftig entwickelt, Klauen spitzig und ungezähnt. Hinterleib sehr fein und dicht punktirt (L. $b$ ), matt glänzend. Der zweite Hinterleibsring oben an der Basis ähnlich wie bei Nitela, Prosopigastra, Tachyrhostus etc. mit einem ausgedehnten Längseindrucke behaftet. Das Aftersegment hat kein Pygidialfeld, ist kegelförmig, beim q grösser und spitzer als beim $\sigma^{\nearrow}$ und, indem es nicht nur herabhängt, sondern sogar ein wenig gegen die Bauchseite hereingezogen ist, erscheint die Hinterleibsspitze gekrümmt.

Geographische Verbreitung. Von Sylaon ist eine einzige Art bekannt; diese bewohnt die mediterran-paläarktische Region.

\section{Sylaon compeditus Piccioli.}

Silaon compeditus Piccioli, Descr. d'un nuov. gen. d'Imen. fam. Sféc., p. 283, Taf. I, Fig. 1, 2, 91869 Silaon compeditus Costa, Ann. Mus. Zool. Univ. Napoli (Ann. VI), p. $82 \ldots \ldots$. . . . . 1871 Ammosphecidium Helleri Kohl, Hymenopt. Beitr. (Verhandl. d. k. k. zool.-bot. Gesellsch. Wien, 1877), p. 701, б, ?. 
Long. 3-4.5 mm. Niger; prothorax, postscutellum, tibiae et nonnunquam tarsi albide picta. Alarum squamulae bruneae. Calcaria pallide flava. Alae hyalinae in limbo apicali paulum infumatae; stigma et venae luteo-fusca. Frons punctato-rugosa, genae subaciculato-rugosae (L. b). Metathorax in dorsulo confertim (L. $b$, sub L. a vix visib.) in pleuris fortius punctatus. Segmenti mediani area dorsalis subreticulate rugosa, rugis longitudinalibus praevalentibus; area decliva, postica irregulariter transversim rugosa (L. a); latera segm. mediani longitudinaliter rugoso-striatae. Abdomen subnitidum punctulatum.

o. Long. 3-4 mm. Clypei margo apicalis in medio dentis instar productus. Segmentum anale mutice conicum, non recurvum.

․ Long. 35-4.5 mm. Clypei margo muticus. Segmentum anale acute conicum, recurvum.

Italia, Tirol. merid., Gallia merid.

Schwarz. Taster schmutziggrau bis dunkelbraun. Oberkiefer schwarz, vor der Spitze lehmgelb oder pechroth. Tarsen schwarzbraun, mitunter der Metatarsus und die zwei folgenden Glieder der Mittel- und Hinterbeine weisslich. A uf dem Bruststückesowohl wie an den Beinen treten Zeichnungen in Form von Fleckchen und Linien a uf, welche sich verschieden combiniren: 1. $\sigma^{\lambda}$, weisslich sind zwei punktartige Fleckchen oder eine Linie auf dem Hinterschildchen, sowie Makeln hinten, hart an der Basis der Hinterschienen; 2. $\sigma^{\top}$, stimmt mit der Comb. 1 überein; indessen zeigen auch die Mittelschienen an ihrer Basis hinten einen kleinen, weissen Fleck; 3. $\sigma^{\nearrow}$, zur Zeichnung der Comb. 1 treten zwei weisse Seitenfleckchen auf dem Hinterwulste des Pronotum; 4. $\sigma^{\nearrow}$, Comb. 3, in der Zeichnung der Beine jedoch wie $2 ; 5 . \sigma^{\nearrow}, \rho$, ausser den Zeichnungen von 4 sind auch die Schulterbeulen weiss (diese Zeichnungscombination scheint die häufigste zu sein).

Der Kopfschild ist kurz, seine Mittelpartie erhaben, von einer Längskante durchzogen, welche hinauf bis zum Fühlergrunde, herab bis zum äussersten Rande zieht. Dieser ist beim $\sigma^{x}$ in eine sehr scharfe, leicht ersichtliche (L. $a$ ) und als Fortsetzung der Kante erscheinende Spitze vorgezogen, während er beim $Q$ bogenförmig verläuft. Stirne mässig gewölbt, körnig gerunzelt. Die Nebenaugen, welche ein gleichschenkeliges Dreieck bilden und sehr wenig vor der an den Hinterrändern der Facettenaugen gezogen gedachten Querlinie stehen, sind vom Hinterhauptsrande etwas mehr entfernt, als ihre doppelte Entfernung von dem benachbarten Facettenauge beträgt. Backen fein und unregelmässig nadelrissig gerunzelt. Die Fühler sind verhältnissmässig dick, die Schäfte kurz. Die weissbereiften Geisseln verdicken sich bis zu den vorletzten Gliedern ein wenig und sind porös rauh. Das erste Geisselglied ist kugelig und ebenso wie das zweite um etwas kürzer als die folgenden; das Endglied beim $\subseteq$ stumpf kegelförmig und länger als das vorletzte, beim $\sigma^{\top}$ sehr entschieden und scharf zugespitzt und kürzer als das vorletzte Glied. Stirne, Kopfschild und spärlich auch die Wangen beim $\sigma^{\top}$ sind mit einem silberweissen, aber nicht dichten Haarfilze bedeckt. 
Das Mesonotum erscheint dicht, unter der Lupe $a$ wenig merklich, unter der Lupe $b$ deutlich punktirt. An seiner Basis sieht man zwei Linien, deren Länge nicht viel mehr als ein Drittheil der Länge des Dorsulums beträgt; durch sie wird die Stelle angedeutet, an die sich der grosse Längsmuskel des Thorax ansetzt. Metathoraxseiten dicht punktirt, ihre Punktirung gröber als die des Notum. Schildchen gross und wie das Notum punktirt. Mittelsegment kürzer als der Metathorax, hinten steil, aber nicht senkrecht abstürzend. Das grosse, durch Runzeln abgegrenzte halbelliptische Feld seiner Horizontalfläche wird von einigen unregelmässig angeordneten, manchmal divergirenden Längsrunzeln durchzogen; im schwächeren Grade der Entwicklung zeigen sich auch Querrunzelchen. Seiten des Mittelsegmentes der Länge nach runzelstreifig. Abstürzende Fläche unregelmässig querrunzelig, in der Mitte mit einer flachen Grube. Die übrigen Hinterleibsringe sind sehr fein punktirt (L. $b$ ), die hinteren feiner als die vorderen.

Die Bruststückseiten, die Sternen, sowie die Dorsalringe des Hinterleibes werden von einem durch sehr kurze weisse Härchen gebildeten Filze mehr weniger reich bedeckt.

Geographische Verbreitung. Im wärmeren Alpengebiete Süd-Tirols, so bei Gries (7-8), bei Klobenstein (1200 Meter s. m. ${ }^{18} / 7$ ) und Kollern (1250 Meter s. m. ${ }^{6} / 8$ ), Ungarn (Sajo), Toscana (Piccioli), Umgebung von Neapel (Emery), in Frankreich bei Toulouse (durch Rudow zur Einsicht mitgetheilt).

Gen. Nitela Latr. (Taf. VIII, Fig. 7, 8).

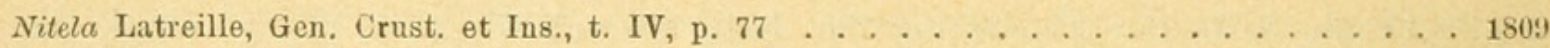

Nitela Olivier, Encycl. méth. Hist. nat. Ins., t. VIII, p. 205 . . . . . . . . . . . . 1811

Nitela Blanchard, Hist. nat. Ins., t. III, p. 360 . . . . . . . . . . . . . . . . 1840

Nitela Dahlb., Disp. méth., p. I, p. 6, 29. Gen. . . . . . . . . . . . . . . . . 1812

Nitela Dhlb., Hym. Eur., t. I, Tab. exam. syn. spec. Crabr., p. 511, 64. Gen., et Tab. exam.

syn. gen. Crabr., 64. Gen. . . . . . . . . . . . . . . . . 1845

Nitela Pel., Hist. nat. Ins. Hym., t. III, p. 209, 12. Gen. . . . . . . . . . . . . . 1845

Nitela Schenck, Grabwesp. Nassau's (Jahrb. d. Ver. f. Naturk. Herz. Nassau), p. 18 und 108,

IV. Gen. (Taf. I, Fig. 6) . . . . . . . . . . . . . . . . 1857

Nitela Taschenb., Schlüssel z. Bestimm. (Zeitschr. f. d. ges. Naturwissensch. X), p. 100, 27. Gen. 1857

Nitela Taschenb., Hym. Deutschl., p. 155 und 183, 5. Gen. . . . . . . . . . . . 1866

Nitela Thoms., Opusc. entom, Fasc. II, p. 231 . . . . . . . . . . . . . . . . 1870

Nitela Costa, Ann. Mus. zool. Univ. Napoli (Ann. VI), p. 48 . . . . . . . . . . . 1871

Nitela Sidn. Sm. Saunders, Trans. Ent. Soc. Lond, p. III, p. 412 . . . . . . . . . . . . 1873

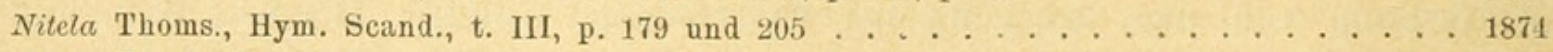

Nitela Taschenb., Nyss. u. Crabr. Mus. Univ. Halle (Zeitschr. f. d. ges. Naturwissensch.,

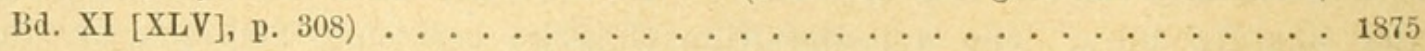

Körper klein und schwarz. Kopf quer, von ähnlicher Bildung wie bei Solierella Spin. und Sylaon Pice. Oberkiefer ohne Ausrandung an ihrem Unterrande, am Endezweis pitzig, innere Spitze kürzer; Innenrand ungezähnt. Augen gegen den Scheitel ein wenig convergent; ihr unterer Rand erreicht nicht vollkommen die Oberkieferbasis. Nebenaugen normal, rund, gewölbt, fast in einem gleichseitigen Dreiecke. Fühler in beträchtlichem 
Abstande von einander, dem Kopfschilde eingefügt, fadenförmig; in teressant ist die bei Grabwespen ungewohnte Länge des ersten Geisselgliedes, welches den folgenden Gliedernan Längenichtnachsteht.

Ober jeder Fühlerinsertion dehnt sich eine flache, dem Bewegungsbedürfnisse des Fühlerschaftes entsprechende Vertiefung aus. Kopfschild in der Mitte erhaben, der ganzen Länge nach mit einer Kante versehen, nach den Seiten dachförmig abfallend. Diese Kante setzt sich auch über den unteren Stirntheil fort und trennt die Fühlergruben.

Der Hinterwulst des Pronotums steht nur wenig unter dem Niveau des Dorsulums, ist oben durch eine lineare Quervertiefung in zwei Leisten geschieden, von denen sich die vordere winkelig nach hinten erweitert und daselbst die Querrinne unterbricht. Die Epimeren des Mittelbrustsegmentes erscheinen durch eine senkrechte Kerblinie von den ihnen eingelagerten Episternen und durch eine horizontale von dem Sternum getrennt.

Radialzelle der Vorderflügel gestreckt, mit einer kleinen Anhangszelle. Flügelmal klein. Cubitalzelle ist nur eine entwickelt, ungefähr von der Grösse der Radialzelle, von rhomboidischer Gestalt; sie wird von der ersten Cubitalquerader geschlossen und nimmt die erste Discoidalquerader an ihrer hinteren Aussenecke auf. Discoidalzelle ist eine einzige vorhanden; sie ist rhombisch. Die Basalader trifft weit hinter dem Abschlusse der inneren mittleren Schulterzelle auf die Medialader; das Venenrohr der Vena postica (V. submed.) ist an seiner Endhälfte, welche die äussere mittlere Schulterzellevon unten begrenzt, in starker Resorption begriffen, in Folge dessen stark verblasst und durch dieconcave Submediallinie noch vor Abschluss der äusseren mittleren Schulterzelle zugleich mit dem unteren Theile der zweiten Schulterquerader vernichtet, so dass die untere Aussenecke der äusseren mittleren Schulterzelle an derjenigen Stelle in einer weiten Lücke geöffnet erscheint, wo die concave Submediallinie austritt. An den Hinterflügeln ist das Geäder in Folge einer Resorption, die in der Richtung vom Saume gegen die Basis durch die Abschnürung der Venenrohre erfolgt sein muss, erloschen, so dass man ausser der Rand- und Unterrandader und den ebenfalls in Auflösung begrif- fenen basalen Rest der Vena postica kein Geäder mehr wahinimmt. Geblieben sind nur noch die Convexlinien, auf welchen die Venenrohre gelegen.

Beine schlank, fast ganz unbewehrt; Tarsen dünn; Mittelschienen mit einem einzigen Sporne. Mittelsegment so lang als das Dorsulum; seine hintere steil abstürzende Fläche von der Rückenfläche und den Seiten durch scharfe Kanten abgetrennt. Zweiter Hinterleibsring oben mit einem starken Längseindrucke; Aftersegment konisch zugespitzt, Dorsaltheil oben ein wenig abgeplattet, o hne Pygi dialfeld; Ventralplatte (q) seitlich zusammengedrückt, kielförmig. Bei den $\sigma^{\nearrow}$ ist das Aftersegment stumpf und viel kürzer.

Ueber die Lebensweise von Nitela ist man verhältnissmässig gut unterrichtet, was bei der Kleinheit und relativen Seltenheit der Thiere nicht zu 
erwarten war; Schen $\mathrm{ck}^{1}$ ) vermuthet eine parasitische Lebensweise, da er diese Wespchen von Mai bis in den Herbst an alten, von Insecten durchlöcherten Pfosten, Baumstämmen, Zäunen und Gartenthüren in Gesellschaft anderer kleiner Grabwespen und Bienen (Passaloecus, Stigmus, Trypoxylon, Crabro, Prosopis etc.) getroffen und durch Bohrlöcher aus- und einschlüpfen gesehen hat, ohne dass es ihm gelungen ist, auch nur einmal ein mit Larvenfutter beladenes Exemplar zu beobachten.

Nach dem, was aus folgenden Beobachtungen von Giraud hervorgeht, bewahrheitet sich die Vermuthung Schenck's nicht. Giraud sah in der Nähe von Wien Nitela in grosser Anzahl an einem alten, zum Theile verdorrten Baume (Acer campestre). Die Nestlöcher waren bis zur Höhe von mindestens sechs Meter längs des Stammes und der Hauptäste vertheilt. Sehr selten soll sich Nitela in Brombeersträuchern einnisten. Im Marke eines sehr dünnen Brombeerzweiges (aus Fontainebleau) fand Giraud einen ganz engen und regelmässigen Gang mit vier durch verschimmelte Häufchen von Nahrungsresten und Excrementen abgesonderten Zellen, und in einer dieser Wiegen einen sehr kleinen Cocon, von dem er folgende Beschreibung liefert: ${ }^{2}$ ) „Die Puppe ist $5 \mathrm{~mm}$. lang, fast walzenförmig, an ihren beiden Enden, welche frei sind und mit den als Scheidewand dienenden Stoffen nicht zusammenhängen, abgerundet und ein wenig verjüngt, blassroth, lichter als das Mark, ganz undurchsichtig und ohne Glanz, aus einem dichten Gewebe, ohne sichtbares seidiges Gefäde und so morsch, dass sie beim geringsten Drucke zerbricht. In der fünften Zelle lag ein anderer rother, pergamentartiger, ein wenig glänzender und wenig durchscheinender Cocon von der nämlichen Länge; er enthielt eine Chrysis cyanea als Schmarotzerin. Es ist mir noch nicht gelungen, mit Sicherheit die Insectengattung $\mathrm{zu}$ bestimmen, welche zur Versorgung des Nestes gedient hat, aber die Restchen von Beinen und Fühlern in den Zwischenräumen und in einer noch garz mit allerdings vom Schimmel unkenntlich gemachten Vorrathe gefüllten Zelle lassen mich annehmen, dass es die Larven einer Homoptere waren. Das Auskriechen erfolgte am 21. und 23. Juni (Paris)."

Auch Edw. Sm. Saunders beobachtete Puppengehäuse von Nitela und schreibt darüber: ${ }^{3}$ ) „Sie waren glänzend, von dunkel fleischrother Farbe, gegen das Afterende hin dunkler, locker in getrennten Schlupfwinkeln des Markes und, so viel ich bemerkt habe, nicht in regelmässigen Reihen angebracht."

Von der Gattung Nitela citirte man bisher eine einzige Art, N. Spinolae Latr. Diese halte ich für eine Mischspecies, da ich unter meinem Materiale, das fast ausschliesslich in Mittel-Europa gesammelt wurde, zwei Arten finde; diese können wegen ihrer Aehnlichkeit leicht zusammengeworfen werden, und ich zweifle nicht daran, dass so mancher Autor bei der Beschreibung oder der Bestimmung von $N$. Spinolae Latr. beide Arten oder vielleicht gar nur die

1) Zusātze und Berichtig. zu den Nassau'schen Grabwespen (Jahrb. d. Ver. f. Naturk. Herz, Nassau, XVI. Heft, p. 142, 1864).

${ }^{2}$ ) Ins. qui hab. les tig. sèch. de la Ronce (Ann. Soc. Ent. Franc., IV. sèr., t. VI, 1866).

s) ${ }_{n}$ On the hab. and econ. of cert. Hym. Ins." etc. (Trans, Ent. Soc. Lond, P. III, 1873). 
verkannte Art, von der ich jüngst in den Verhandlungen der k. k. zool.-bot. Gesellschaft in Wien, 1883, p. 15 („Neue Hymenopteren des k. k. zoologischen Hof-Cabinetes in Wien") eine Beschreibung geliefert habe, vor sich gehabt hat. Welche von beiden Arten die $N$. Spinolae Latreille's ist, kann dessen Angaben nicht entnommen werden; auch die meisten übrigen Beschreibungen von $N$. Spinolae sind zu ungenau, als dass man nachweisen könnte, welche von beiden Arten in den einzelnen Fällen gemeint ist; deswegen habe ich für die häufigere Art, deren Stirne und Mesonotum zart punktirt ist und auf welche wenigstens die Dahlbom'sche (Hym. eur. I, p. 297) und Thoms on'sche (Opusc. ent. p. 239, 1871, Hym. Scand. III, p. 205) Beschreibung unzweifelhaft stimmt, den Namen "Spinolae" beibehalten, ohne dass ich jedoch die Sonderung der bekannt gewordenen Fundortsnotizen, wie es wünschenswerth gewesen wäre, habe vornehmen können; für die abgetrennte Art habe ich den Namen fallax gewählt.

Besieht man den Vorderflügel von Nitela genau, so wird man bemerken, dass sich die untere concave Cubitallinie und die obere concave Discoidallinie in einem etwas hinter der einzigen Cubitalquervene liegenden Punkte (,krit. Punkt" Adolph.) bis zur Vereinigung einander genähert haben; ausserdem sieht man schwache Spuren einer untergegangenen zweiten Discoidalquervene und eine nur mehr durch eine „convexe Linie“ angedeutete Cubitalquerader als Rest eines ehemaligen reicheren Venennetzes. Diese erloschene Cubitalquerader mündet vorne ungefähr in der Mitte des längeren Radialaderschenkels und hinten ziemlich weit saumwärts von dem kritischen Punkte entfernt. Ich halte diese Cubitalquerader für die primäre dritte Cubitalquerader, da sie viel zu weit vom kritischen Punkte entfernt auf die Cubitalader trifft, denn nach Erfahrung liegt dieser bei Aculeatengattungen mit drei Cubitalquervenen in der Nähe der zweiten Cubitalquervene. Es ist nun die Frage, was aus der primären zweiten Cubitalquervene geworden ist. Da man davon keine Spur wahrnehmen kann und die erste Discoidalquerader vor der ersten recenten Cubitalquervene mündet, so glaube ich annehmen zu sollen, dass diese recente Cubitalquerader durch Verschmelzen aus der primären ersten und zweiten Cubitalquerader in analoger Weise wie bei der nahe verwandten Untergattung von Pison entstanden ist, welche Smith als eigenes Genus "Parapison" hingestellt hat. Diese Anschauung gewinnt an Wahrscheinlichkeit, wenn man berücksichtigt, dass auch bei Sylaon und Solierella, welche Nitela in allen anderen Dingen, wie in der Kopfbildung, der Beschaffenheit der Beine und des Endsegmentes und wohl auch in der Lebensweise ausserordentlich nahe stehen, die Vereinigung der ersten und zweiten Cubitalquerader schon weit fortgeschritten ist, weshalb die zweite Cubitalzelle deutlich gestielt erscheint. Nach Art der Einmündung der zweiten Discoidalquerader steht Nitela der Gattung Sylaon am nächsten und bildet mit dieser und Solierella einen Complex aufs engste verwandter Gattungen.

Resumirt man die Phasen, in welchen sich der Nitela-Flügel bei seiner Umwandlung aus dem früheren Zustande bis zu dem heutigen befand, so ergibt sich: Ursprünglich hatte er drei Cubitalzellen, die mittlere davon war gestielt; nach und nach wurde er zweizellig, indem die zweite Cubitalzelle in Folge der 
Verlängerung des Zellstieles (durch Verschmelzen der ersten und zweiten Cubitalquervene) verschwand. Die obere concave Discoidallinie und die untere concave Cubitallinie näherten sich mehr und mehr und schnitten die Cubitalader an; von dieser Stelle aus erfolgte nun die Auflösung eines Theiles der Cubitalader, der zweiten (respective dritten) Cubitalquerader, der Discoidalquerader u. s. w. bis zum jetzigen Zustande des Flügels.

\section{Nitela Spinolae Dhlb.}

? Nitela Spinolae Latr., Gen. Crust. et Ins., t, IV, p. 77 . . . . . . . . . . . . . . . . 1809

? Nitela Spinolae Olivier, Encycl. méth. Hist. nat. Ins., t. VIII, p. 205 . . . . . . . . 1811

? Nitela Spinolae Blanchard, Hist. nat. Ins., t. Ill, p. 360 . . . . . . . . . . . . . 1840

! Nitela Spinolae Dhlb., Hym. Eur., t. I, p. 297, Nr. 180, đ', \& . . . . . . 1845

? Nitela Spinolae Lep., Hist. nat. ins. Hym., t. III, p. 210, Q Atl., pl. XXVII, fig. 1 . . . . 1845

? Nitela Spinolae Schenck, Nass. Grabwesp. (Jahrb. d. Ver. f. Naturk. Herz. Nassau, 12. Heft),

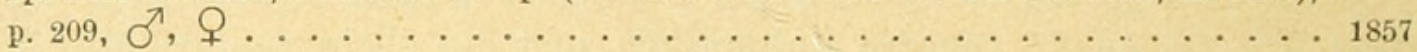

? Nitela Spinolae Taschenb., Schlüss. z. Best. etc. (Zeitschr. f. d ges. Naturw. X), p. 100 . 1857

? Nitela Spinolae Taschenb., Hym. Deutschl., p. 183, ठ, $\ \ldots . . . . . . . . .1866$

Nitela Spinolae Thomson, Opusc. entom., Fsc. II, p. 239, Nr. 1 . . . . . 1870

? Nitela Spinolae Costa, Ann. Mus, zool. Univ. Napeli (Ann, VI), p. 49, Nr. 1 . . . . . 1871

Nitela Spinolae Thomson, Hym. Scand., t. III, p. 205, Nr. $1, \sigma^{\top}$,,$\ldots . . . .1874$

Long. 4-6 mm. б, ․ Subaeneo-nigra aut nigra; tibiarum calcaria pallide testacea; alae cinerascenti-hyalinae, venae nigro-fuscae. Frons et mesonotum subtilissime rugulosa et dense punctulata (L. b); genae aciculato-striolatae. Oculi in vertice plus quam longitudine flagelli articuli secundi et tertii, sed minus quam long. primi, secundi et tertii inter se distant. Mesopleurae paullum sculpturatae, fere politae. Area dorsalis segmenti mediani reticulate rugosa aut longitudinaliter striato-rugosa; latera longitudinaliter rugis subregularibus striata; truncatura transverse rugosa (L. a). Abdominis segmenta sequentia nitida.

\section{Europa.}

Schwarz, mit geringem Erzschimmer. Schienensporne blass lehmgelb. Flügel graulich wasserhell, Geäder schwarzbraun. Kopf von der Breite des Bruststückes. Mittlere Kopfschildpartie am Vorderrande quer abgestutzt, mit scharfen Seitenecken. Die geringste Entferuung der Augen auf dem Scheitel beträgt ein wenig mehr als die Länge des zweiten und dritten Geisselgliedes zusammengenommen, aber weniger als die der drei ersten Geisselglieder. Die hinteren Nebenaugen nähern sich stark den Facettenaugen, so dass die Entfernung von diesen etwa den Durchmesser eines Nebenauges ausmacht. Wangen fein nadelrissig. Stirne etwas gewölbt, ausserordentlich fein, nur unter der Lupe $b$ noch sichtbar gerunzelt und dicht punktirt; ihre Mitte wird von einer Linie durchzogen, welche in den meisten Fällen weniger in das Auge fällt als bei der folgenden Art. Mesonotum in ähnlicher Weise wie die Stirne punktirt; Pleuren glänzend, fast poliert, nur mit geringen Spuren von Pünktchen und feinen Runzelchen (L b). Mittelsegment an den Seiten bald mehr bald weniger regelmässig und etwas spärlich längs- 
runzelig gestreift, auf der abstürzenden Fläche unregelmässig querrunzelig, auf seiner Horizontalfläche deutlich und unter der Lupe a leicht sichtbar netzartig gerunzelt, manchmal längsrunzelig gestreift, mit unbedeutenden Querrunzelchen zwischen den Längsstreifen. Die übrigen Hinterleibsringe sind glänzend, mit ungemein feinen Pünktchen, denen Härchen entwachsen, sehr dünn besetzt (L. $b$ ).

Geographische Verbreitung. Nach Dahlbom in Gothland (1/8). In der Schweiz sammelte sie Frey-Gessner bei Genthod am Genfersee, MeyerD ür um Burgdorf und Tournier um Peney $(5 / 10)$. In den Tiroler Alpen fing ich sie bei Landeck $\left({ }^{25} / 7\right)$ und auf dem Mittelgebirge von Bozen bei Kollern (7, 8, 1250 Meter s. m.). Wien (Gira ud). Während diese Fundorte für N. Spinolae Kohl als sicher gelten, findet man in den verschiedenen Arbeiten Fundortsaufzeichnungen, von denen sich nicht mit Gewissheit angeben lässt, für welche von beiden Arten, für Spinolae oder fallax, sie zu gebrauchen sind; die Mehrzahl davon bat wahrscheinlich doch für erstere Art zu gelten.

Scandinavien: Höberg (Westro-Gothia, Gyllenhal), Arås Wermlandiae (Zetterstedt), Wadstenalöt in Ostro-Gothia (18/7); Deutschland: Herrstein ( $\sigma^{\top}$,, , Tischbein), Umgebung von Berlin (Ruthe, Stein), Münden ( $\sigma^{\top}$, Wissmann), Weilburg und Wiesbaden (Schenck), Halle $(17 / 6-25 / 7$, Taschenberg), Bamberg (Funk); Frankreich: Paris bei St. Germain, Fontaineblau; Italien: Genua (Spinola).

\section{Nitela fallax Kohl.}

Nitela fallax Kobl, Neue Hymenopt. d. k. k, zool. Hof-Cab. Wien (Verhandl, d. k, k, zool.-bot. Gesellsch., Bd. XXXIII, p. 331), ठౌ, ?

Long. 4-6 mm. o', ‥ Subaeneo-nigra aut nigra; tibiarum calcaria pallide lutea; alae cinerascenti-hyalinae, venae nigro-fuscae. Facies evidenter subreticulato-rugosa (L. b), non punctulata; tempora ("genae") aciculatostriolatae. Oculi in vertice quam longitudine flagelli articuli secundi et tertii plus sed quam long. primi, secundi et tertii inter se minus distant. Dorsulum evidenter transverse striato-rugosum (L. a); scutellum longitudinaliter et subtiliter rugosum (L. b). Pleurae mesothoracis paulum sculpturatae, fere politae. Area dorsalis segmenti mediani reticulato-rugosa; latera segm. med. rugis subregularibus longitudinaliter striata; truncatura transverse rugosa (L. a). $A b$ dominis segmenta nitida.

\section{In alpibus tirolensibus. Vindobona (Mus. zool. Vindobon.).}

N. fallax unterscheidet sich in beiden Geschlechtern von $N$. Spinolae Latr. in hervorragender Weise durch die Sculptur. Die Stirne ist nicht punktirt, sondern deutlich netzrunzelig; noch auffallender und schon unter der Lupe a leicht wahrnehmbar sind die Runzelstreifen, welche quer über das Dorsulum streichen; dieses ist bei $N$. Spinolae ebenfalls punktirt. Schildchen mit feinen (L. b) Längsrunzelchen. Runzeln auf dem Horizontaltheile des Mittelsegmentes netzartig, zerknittert und gröber als in den meisten Fällen bei N. Spinolae. 
N. fallax erkenne ich in sechs männlichen und drei weiblichen Stücken. Trotzdem ich noch nicht im Stande war, auch andere unterscheidende Merkmale aufzufinden, halte ich diese Art für eine gute, da die Sculptur bei den Nitela nächst verwandten Gattungen grosse Beständigkeit zeigt und sämmtliche neun Stücke vollkommen miteinander übereinstimmen.

Ich entdeckte sie in Tirol bei Gummer im Eggenthale (2. September), 1200 Meter s. m., und bei Klobenstein auf dem Ritten, 1200 Meter s. m. Ein von Giraud bei Wien erbeutetes Stück befindet sich in den Sammlungen des k. k. Hof-Naturaliencabinetes in Wien. Auch die eine und die andere Fundortsangabe von $N$. Spinolae in den Werken der Autoren dürfte $N$. fallax für sich beanspruchen können.

Gen. Miscophus Jur. (Taf. VIII).

Miscophus Jurine, Nouv. méth. class. Hym., p. 205 . . . 1807 Miscophus Latr., Gen. Crust. Ins., t. IV, p. 72, Nr. CDXCIII . . . . . . . . . . . . . . . 1809

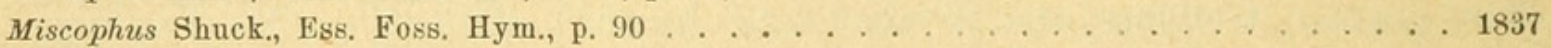

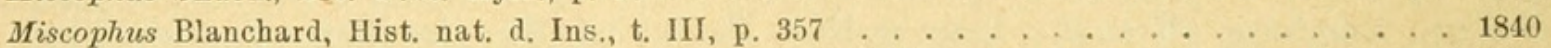
Miscophus Herr. Schäff., Nomencl, entom., p. 54, Taf. V, Fig. 31 . . . . . . . . . . . . . 1840 Miscophus Westwood, Intr. mod, classif. Ins., vol. II, Syn. Gen. Brit. Ins., p. 81 . . . . . 1840 Miscophus Dhlb., Disp. meth., p. I, 5. Fam, Pemphr,, p. 4, 19. Gen. . . . . . . . . . . . 1842 Miscophus Dhlb., Hym. Eur., t. I, Tab, exam. syn. spec. Larr., 50, Gen. . . . . . . . . . 1845 Miscophus Lep., Hist. nat. ins. Hym., t. III, p. 237, 3. Gen. . . . . . . . . . . . . . . 1845 Miscophus Schenck, Beschr. d. in Nassau aufgef, Grabwesp. (Jahrb. d. Ver. f. Naturk. Herz.

Nassau, 12. Heft, p. 22 and 195, 3. Gen. . . . . . . . . . . . . . 1857 Miscophus Taschenb., Schlüss. z, Bestimm. (Zeitschr. f. d. ges. Naturw. X), 23. Gen., p. 96 . 1857 Miscophus Smith, Cat. Brit. foss. Hym., p. 90, 2. Gen. . . . . . . . . . . . . . 1858 Miscophus Taschenb., Hym. Deutschl,, IX. Eam. Sphec. p. 156 und 202, 30. Gen. . . . . . 1866 Miscophus Costa, Ann. Mus. zool. Univ. Napoli (Ann. IV), p. 81 et 94 . . . . . . . 1867 Miscophus Thoms., Opusc. entom., Fsc. II, Ofv. Sver. Rofst., p. 242 . . . . . . . . 1870 Miscophus Thoms., Hym. Scand, t. III, p. 216 et 220 . . . . . . . . . . . . . . . . 1874 Miscophus Radoszk, Fedtsch. Reise nach Turkest., p. 22 (in russischer Sprache) . . . . . . 1877 Miscophus Edw. Saund., Syn. Brit. Het. Foss. Hym. (Trans, Ent. Soc. Lond., p. IV), p. 249 et 250, pl. V1I, Fig. 20 .

Hieher gehören Arten von 3-10 mm. Länge, schwarzer oder schwarzer und rother Färbung. Oberkiefer mit einem Ausschnitte nicht weit von der Mitte ihrer unteren Aussenkante, unbezahntem Innenrande und einfacher Endspitze. Kopfschild und Gesicht bei den $\subsetneq$ schwach, bei den $\sigma^{\nearrow}$ dichter weissfilzig. Fühler fadenförmig, hart an der Basis des Kopfschildes in ziemlichem Abstande von einander eingefügt, im männlichen Geschlechte kürzer und kräftiger. A ugen im Leben oft grün, gegen den Scheitel nur in geringem Masse oder gar nicht convergent. Die Stirne ist wulstfrei, in der Regel ziemlich flach. Die Nebenaugen sind alle drei gleichmässig rund gestaltet, regelmässig, sitzen vor der Linie, die man sich am Hinterrande der Netzaugen und quer über den Scheitel gezogen denkt, und bilden in ihrer Stellung zu einander bald ein gleichseitiges, bald 
ein gleichschenkeliges Dreieck. Der Pronotumwulst ist gut entwickelt und liegt gar nicht oder nur ganz wenig unter der Fläche des Dorsulums. Die Vorderflügel besitzen zwei Cubitalzellen, die zweite ist dreieckig und gestielt; die erste Discoidalquerader mündet an der ersten Cubitalzelle, nahe am Verlaufe der ersten Cubitalquerader, diezweite an der zweiten nahe am Verlaufe der dritten Cubitalquerader. Das Randmal ist klein, die Radialzelle ist lanzettlich zugespitzt, an Grösse bei den verschiedenen Arten verschieden, oft nicht grösser als die kleine zweite Cubitalzelle. Die Radialader der Hinterflügel, daher auch die Spitze der vorderen Schulterzelle, ist kurz; die Cubitalader entspringt weit hinter dem Abschlusse der inneren mittleren Schulterzelle, näher der Flügelspitze. Die Bewehrung der Beine ist sehr wechselnd, bei gewissen Arten (M. ctenopus Kohl) deutlich und lang, besonders der aus kräftigen, langen Wimpern gebildete Vordertarsenkamm, bei anderen aber kurz und unansehnlich. Die Mittelhüften stehen einander ein wenig näher als bei Tachysphex. Mittelschienen einspornig. Klauenballen mittelgross. Mittelsegment nicht in Felder abgetheilt, von verschiedener Länge, manchmal länger als breit. Aftersegment bei den $q$ spitz-, bei den $\sigma^{\lambda}$ abgestutzt kegelförmig; bei beiden Geschlechtern vermisst man das Pygidialfeld.

Die $\sigma^{\nearrow}$ unterscheiden sich von den 9 ausser den gewöhnlichen Geschlechtsunterschieden durch die dickeren Fühler, den schwächeren und kürzeren Tarsenkamm, wenn man überhaupt noch von einem solchen sprechen will, und das stumpfe Endsegment.

Die Artunterschiede liegen in der Clypeusform, in der Beschaffenheit der Fühler, der Stellung der Nebenaugen, in der Sculptur des Gesichtes und Mesothorax, in der Dicke der Wangen und der Erhebung der Stirne, in der Bedornung der Beine, der Grösse der Radialzelle, der Flügeltrübung, in der Länge und der Sculptur des Mittelsegmentes und erst in letzter Linie in den Färbungsverhältnissen.

Ueber die Lebensweise kann bei dieser scharf begrenzten und im Systeme ziemlich isolirt stehenden Gattung nur das Wenige bemerkt werden, was von dem Miscophus bicolor bekannt geworden ist; dieser nistet im Sande und trägt Spinnen ein; hierin dürften wohl auch die anderen Arten übereinstimmen.

Geographische Verbreitung. Von den 11 bekannt gewordenen Arten stammt eine einzige aus dem neotropischen Amerika, während die übrigen 10 Bewohner der I. und II. Subregion des paläarktischen Gebietes und für dieses eigenthümlich sind.

\section{Bestimmungstabelle der paläarktischen Miscophus-Arten.}

1 Flächenraum der zweiten gestielten Cubitalzalle etwa so gross wie der der Radialzelle. [Vorderes Nebenauge von den hinteren weiter als diese von einander entfernt. Flügel fast wasserhell mit breit und dunkel 
getrübtem Spitzenrande. Mittelsegment verhältnissmässig lang, oben lederartig, matt. Wimpernkamm der Vorderbeine lang. Schwarz. Länge $6-7 \cdot 5 \mathrm{~mm}$.]

M. gallicus Kohl

- Flächenraum der zweiten gestielten Cubitalzelle kleiner als der der Radialzelle

2 Kopf und Bruststück stark bronzeglänzend, stellenweise poliert. Stirne mit einer tiefen Mittellinie, gewölbter als bei einer anderen Art. [Vorderes Nebenauge von den hinteren nahezu ebenso weit als diese von einander entfernt. Mittelsegment lang. Flügel glashell auch an ihrem Rande. Wimpernkamm der Vorderbeine lang. Hinterleib und Beine mehr weniger gelblichroth, stellenweise schwärzlich, stark befilzt. Länge $61 / 2-7.5 \mathrm{~mm}$.] .

M. pretiosus Kohl $\left(6^{1}\right)$

- Kopf und Bruststück dunkel mit geringem Erzschimmer oder heller erzfarben, in diesem Falle aber nirgends polirt . . . . . . . . . .

3 Vordertarsenkamm sehr lang und kräftig. Wangen schmächtig; Stirne fast flach. Vorderes Nebenauge von den hinteren viel weiter als diese unter sich entfernt. Mittelsegment gestreckt, seine Hinterecken scharf. Die übrigen Hinterleibssegmente und die Beine ganz oder wenigstens grösstentheils roth. [Länge $8-9 \mathrm{~mm}$.] .

M. czenopus Kohl $\left(5^{2}\right)$

- Vordertarsenkamm kurz und schwach; Wangen ziemlich kräftig; Stirne von mässiger Wölbung. Vorderes Nebenauge von den hinteren weniger weit als diese unter sich entfernt. Beine schwarz. Hinterleib schwarz oder schwarz und roth

4 Punktirung der Stirne und des Scheitels gedrängt, fast lederartig (L. $b$ ). Mittelbrustseiten deutlich dicht punktirt (L. $b$ ) .

- Punktirung der Stirne und des Scheitels zwar dicht, aber nicht gedrängt und nicht lederartig (L. b). Mittelbrustseiten nur undeutlich und sehr schwach sculpturirt, fast glatt, daher stark glänzend. [Dorsalfläche des Mittelsegmentes von schrägen Längsrunzeln durchzogen. Hinterleib schwarz oder roth und schwarz. Länge $4-6 \mathrm{~mm}$.] M. concolor Dhlb.

5 Hinterleib roth und schwarz. Punktirung des Dorsulums, Schildchens und Hinterschildchens gedrängt (L. $b$ ). [Dorsalfläche des Mittelsegmentes fast netzartig, wie zerknittert, unregelmässig gerunzelt, oder nur an ihrem vorderen Dritttheile, seltener der ganzen Länge nach mit nach hinten stark divergirenden Längsrunzeln versehen. Länge $5-9 \mathrm{~mm}$.]

M. bicolor Jui. (1)

- Hinterleib ganz schwarz. Punktirung des Dorsulums, Schildchens und Hinterschildchens zwar dicht, jedoch nicht gedrängt (L. b). [Dorsalfläche des Mittelsegmentes von schrägen Längsrunzeln besetzt. Länge $5-6 \mathrm{~mm}$.]

M. niger Dhlb. (2)

1) $M$. pretiosus kommt wohl auch in Stücken mit vorwiegend schwarzem Hinterleib vor.

$\left.{ }^{2}\right)$ Bei der Veränderlichkeit des Flügelgeäders ist es möglich, dass es Stücke von $M$. ctenopus gibt, bei denen die Radialzelle wie im Flügel von $M$. gallious die Grösse der zweiten Cubitalzelle nicht oder nur unbedeutend übertrifft. 


$$
\text { б. }
$$

1 Flächenraum der Radialzelle so gross wie der der gestielten Cubitalzelle. [Hinterbruststück lang, oben lederartig, feinkörnig und matt (L. b). Flügel fast wasserhell mit stark und breit getrübtem Spitzenrande. Bedornung der Beine deutlich. Vorderes Nebenauge von den hinteren weniger weit als diese von einander entfernt. Schwarz. Länge $6-6.5 \mathrm{~mm}$.]

M. gallicus Kohl (4)

- Flächenraum der Radialzelle grösser als jener der gestielten Cubitalzelle

2 Die hinteren Nebenaugen stehen einander näher als eines derselben dem vorderen. Mittelsegment hinten mit starken Seitenecken. [Kopf und Thorax lederartig gerunzelt. Flügel hell, am Spitzenrande breit und stark getrübt. Bedornung deutlich. Mittelsegment so lang als am Grunde breit. Beine und die Hinterleibsringe, das Mittelsegment ausgenommen, lichtroth. Länge $6-7 \mathrm{~mm}$.] . . . M. ctenopus Kohl (5)

- Die hinteren Nebenaugen stehen in den Ecken eines gleichseitigen Dreieckes oder so, dass die hinteren von einander weiter abstehen als eines derselben vom vorderen. Mittelsegment hinten ohne scharfe Seitenecken

3 Kopfschild fast ganz flach. Kopf und Thorax lederartig gekörnelt. Mittelsegment so lang als am Grunde breit, lederartig, körnig gerunzelt. [Flügel wasserhell mit schwach getrübtem Rande. Bedornung der Beine sehr deutlich. Hinterleib und Beine röthlich pechfarben mit angedunkelten Stellen. Länge $5.5 \mathrm{~mm}$.] . . . . . . . . . M. italicus Costa ?1)

- Kopfschild in der Mitte deutlich gewölbt. Kopf und Thorax punktirt. Mittelsegment kürzer als am Grunde breit, mit Längsrunzelstreifen versehen oder netzrunzelig. [Bedornung der Beine wenig merklich.] .

4 Punktirung der Stirne und des Scheitels gedrängt (L. b), Aussehen dieser Theile daher fast lederartig, Mittelbrustseiten dicht punktirt.

- Punktirung der Stirne und des Scheitels zwar dicht, aber nicht gedrängt, Aussehen dieser Theile nicht lederartig. Mittelbrustseiten nur undeutlich und schwach sculpturirt, fast glatt und von ziemlichem Glanze. [Dorsalfläche des Mittelsegmentes von schrägen Längsrunzeln durchzogen. Hinterleib meist roth und schwarz. Länge 4-6 mm.] M. concolor Dhlb.

5 Hinterleib roth und schwarz. Punktirung des Dorsulums, Schildchens und Hinterschildchens gedrängt (L. b.). Dorsalfläche des Mittelsegmentes fast netzartig zerknittert, gerunzelt, seltener mit schrägen Längsrunzeln versehen. [Länge $4.5-6.5 \mathrm{~mm}$.] . . . . . . . M. bicolor Jur. Hinterleib ganz schwarz. Punktirung des Dorsulums, Schildchens und Hinterschildchens zwar dicht, jedoch nicht gedrängt (L. b). Dorsalfläche des Mittelsegmentes von schrägen, oftmals undeutlichen Längsrunzelstreifchen durchzogen. [Länge $4-5 \mathrm{~mm}$.] . . . . M. niger Dhlb.

1) Es schien mir unstatthaft, auf ein einziges Stück eines männlichen Miscophus (aus Syracus), welcher wahrscheinlich der mangelhaft beschriebene $M$. italicus Costa ist, eine neue Art zu gründen. 


\title{
1. Miscophus bicolor Dhlb.
}

\begin{abstract}
Miscophus bicolor Jur., Nouv. méth. Hym., pl, Xl, 25. Gen., § . . . . . . . . . . . 1807
Larra dubia Panz., Faun. Ins. Germ., 16. Heft, 14. Bl., † . . . . . . . . . . . . 1808

Miscophus bicolor Latr., Gen. Crust. et Ins., t. IV, p. 72, ૧ . . . . . . . . . . . . 1809

Miscophus bicolor Guér., Dict. Class. Hist. Nat. X, p. 632

Miscophus bicolor Shuck., Ess. Brit. Foss., p. 92, Nr. 1 . . . . . . . . . . . . . . . 1837

Miscophus bicolor Blanch., Hist. nat. Ins., t. III, p. $357 \ldots \ldots . . . . . . . . . . .1840$

Miscophus bicolor Smith, Zoologist II, p. 697, ठ, † . . . . . . . . . . . . 1840

Miscophus bicolor Dhlb., Hym. Eur., t. I, p. 235, Nr. 135 et 466, Nr. 1, \ . . . 1845

Miscophus bicolor Lep., Hist. nat. ins. Hym., t. III, p. 237, Nr. 1, pl. XXVII, Fig. 6, ð’, 1945

Miscophus bicolor Stephens, Ill. Brit. Ent. Mand., vol. VII, p. 12, pl. XLII, fig. 3, Q . . . 1846

Miscoplius bicolor Schenck, Grabwesp. Nassau (Jahrb. d. Ver. f. Naturk. Herz. Nassau, 12. Heft,
\end{abstract}

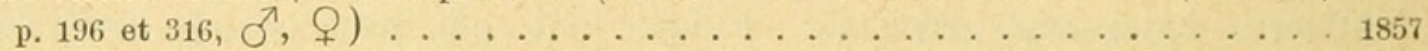

Miscophus bicolor Taschenb., Schlüss. z. Bestimm. (Zeitschr. f. d. ges. Naturw. X), p. 97 . . 1857

Miscophus bicolor Giraud, Verhandl. d. k. k. zool.-bot. Gesellsch. Wien, p. 446, O’, † . . . 1858

Miscophus bicolor Smith, Cat. brit. foss. Hym., p. 91, Nr.1, §’, ૧, pl. 1II, fig. 4 (Q). . . 1858

Miscophus bicolor Taschenb., Hym. Deutschl., IX. Fam., p. 202, Nr. 1, $\subsetneq$. . . . . . 1866

Miscophus bicolor Costa, Ann. Mus. zool. Univ. Napoli (Ann. IV), p. 94, Ø’- - Var. $a=q$ ? var. $c \quad 1867$ Miscophus bicolor Edw. Saund., Syn. Brit. Het. Foss. Hym. (Trans. Ent. Soc. Lond., p. IV),

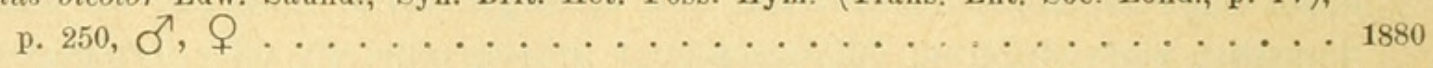

Long. $45-8 \mathrm{~mm}$. $\sigma^{\top}$, $q$. Niger, abdomen in parte anteriore rufum. Caput et thorax subaenea; alae subhyalinae, in apice obscuriores. Frons subplana microscopice rugulosa, confertim punctulata (L. $a, b)$, subopaca. Dorsulum et scutellum confertim punctata (L. a), mesopleurae densissime punctata, rugulis paucis punctaturae intermixtis. Area radialis quam areola cubitalis secunda petiolata multo major. Tibiae parce spinulosae. Pecten tarsale fere deest. Area dorsalis segmenti mediani reticulate rugosa, rugae longitudinales nonnunquam paulum praevalent; segmenti mediani pleurae longitrorsum striaterugosae. Cetera abdominis segmenta subtilissime punctulata (L. b).

万. Long. 4.5-6.5 mm. Clypei medius margo parvus, mutice subtriangularis. Abdominis segmentum secundum et tertium rufa.

ㅇ. Long. 5-8 mm. Clypei medius margo subarcuate truncatus. Abdominis segmentum secundum, tertium et quartum rufa.

Variat $q$ abdominis segmento quarto ut in $\sigma^{\top}$ nigro.

Schwarz, mit leichtem Erzschimmer. Beim $\sigma^{\nearrow}$ ist das zweite und dritte, beim $q$ das zweite, dritte und vierte Hinterleibssegment braunroth. Die Flügel sind schmutzig wasserhell, am Spitzenrande fast bis zur zweiten Cubital- und zweiten Discoidalzelle zurück bräunlich getrübt.

Die Mittelpartie des Kopfschildes erscheint leicht angeschwollen, hat einen schmalen, jedoch nicht undeutlichen Rand, welcher beim $Q$ in einem Bogen von ziemlicher Ausdehnung verläuft, beim $\sigma^{\gamma}$ dagegen nur klein ist und stumpfdreieckig vortritt. Das zweite Fühlergeisselglied übertrifft beim 오 das erste um das Doppelte an Länge. Die Nebenaugen bilden in ihrer Stellung zu einander eingleichschenkeliges Dreieck, welches bei oberflächlicher Anschauung auch für ein gleichseitiges gehalten werden könnte; die beiden hinteren sind von einander 
weniger weit entfernt als eines der hinteren vom vorderen. Die Stirne ist mikroskopisch feingerunzelt und gedrängt punktirt, ziemlich matt; diese Punktirung kann unter der Lupe $a$ eben noch wahrgenommen werden. Aehnlich, nur etwas gröber, ist die Punktirung des Dorsulums und des Schildchens, besonders aber die der Mesopleuren. Stellenweise kann man an den Mesopleuren kleine, kurze Runzelstreifchen wahrnehmen (L. $b$ ). Die Radialzelle der Vorderflügel übertrifft die zweite Cubitalzelle erheblich an Grösse. Die Zahl der Frenalhäckchen finde ich schwankend, kleinere Stücke zeigen nur neun, zehn und eilf, grössere auch zwölf und dreizehn. Die Bewehrung der Beine ist schwach, die Schienendörnchen sind ganz unansehnlich, auch die Bedornung der Vordertarsen ist derart, dass man kaum von einem Tarsenkamm reden kann.

Die Rückenfläche des Mittelsegmentes ist netzartig, oft wie zerknittert gerunzelt; manchmal herrschen unregelmässige Längsrunzeln vor. Die Seiten sind längsrunzelig gestreift. Die Länge des Mittelsegmentes ist bei $M$. bicolor und bei den folgenden Arten sichtlich geringer als dessen Breite an der Basis.

Der zweite Hinterleibsring hat oben an der Basis einen linienartigen Längseindruck, der nicht bei allen Individuen die nämliche Länge zeigt. Unter der Lupe $b$ erscheinen die Hinterleibsringe vom zweiten (incl.) an fein punktirt; diese Pünktchen sind blos die Ursprungsstellen ganz kurzer, niedergedrückter, höchst unscheinbarer Härchen.

Lebensweise. M. bicolor zeigt sich auf Sandhügeln und baut im Sande. Verwandte Bedürfnisse führen ihn dort mit Tachysphex-Arten zusammen; besonders leicht ist er beim Fang mit kleineren Stïcken ( $\sigma^{\nearrow}$ ) von T. pectinipes zu verwechseln. Auch an unübertünchten Mauern huscht das Wespchen herum und sucht in deren Löchern Spinnen, womit es die Brut versorgt. Nach Giraud („Note sur un Hymenoptère nouveau du genre Ampul. etc., Verhandl. d. k. k. zool.-bot. Gesellsch. in Wien, 1858, p. 446) trägt $M$. bicolor die Spinnen Asagena serratipes Schr., Theridium signatum Walken. und Phalangium phaleratum Panz. ein. Diese Angaben dürften richtig sein, wenigstens wurden mir mehrere von dieser Wespe abgejagte Spinnen von fachmännischer Seite als Asagena serratipes bestimmt.

Geographische Verbreitung. In der I. und II. Subregion der paläarktischen Region verbreitet. England selten: Chobdam, Weybridge, Coombe Wood, Sandhurst (Shuck., Smith, Saunders). In Skandinavien scheint $M$. bicolor zu fehlen. Deutschland: Glogau in Schlesien (Zeller), Rixdorf bei Berlin $\left({ }^{20} / 7\right.$, Dhlb.), Umgebung von Berlin (Ruthe und Stein), Halle (27/6-20/9, Taschenberg), Kelsterbach bei Frankfurt a/M., Hedemünde (Wissmann), Bamberg. (Funk). Oesterreich: Wien (Giraud), Mödling (Scheffer). Tirol: Mühlau (6/10), Zirl $(7 / 6)$, Mutters $(9 / 6)$, Letz bei Zams im Ober-Innthale $(18 / 7)$; Weissenstein bei Windisch-Matrei ( $(4 / 8)$, Untertilliach bei 1300 Meter s. m. (18/8), Gries bei Bozen auf Evonymus japonicus $(10 / 7)$, Riva $(6 / 7)$, Mezzolago im Val di Ledro $(4 / 7)$, Z. B. Ges. B. XXXIY. Abh. 
Klobenstein bei 1200 Meter (8). Schweiz: Bois des frères, Sierre $\left({ }^{26} / 7\right.$, FreyGessner), Nyon (Chevrier), Peney (1/7, $28 / 7$, Tournier), Burgdorf (MeyerDür), Zürich (Dietr. Samml.). Belgien: bei Brüssel selten (Wesmaël). Frankreich: Paris (Lep.). Italien: in Toscana ziemlich häufig (Piccioli), Susa (Giraud).

\section{Miscophus niger Dhlb.}

Larra spuria Dhlb., Exerc. Hym. ad ill. faun. Suec., p. 56, Nr. 7 . . . . . . . . . . 1833 Miscophus niger Dhlb., Hym. Eur., t. I, p. 236, Nr. 136, $\sigma^{\top}, q$, et p. 466, Nr. 2, $\sigma^{\top}, Q^{1845}$ Miscophus spurius Dhlb., Hym. Enr., t. I, p. 237, Nr. 138, 万’, Q. Tab. exam. syn.

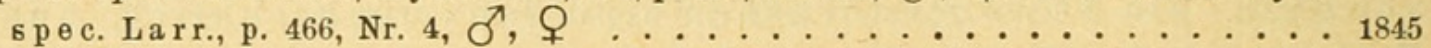
Miscophus niger Schenck, Beschr. d. in Nassauaufgef. Grabwesp. (Jahrb.

d. Ver. f. Naturk. Herz. Nassau, 12. Heft, p. 196, Nr.1) . . . . . . 1857 Miscophus spurius Schenck, Beschr. d. in Nassau aufgef. Grabwesp. (Jahrb. d. Ver. f. Naturk.

Herz. Nassau, 12. Heft, p. 196, Nr. 2) . . . . . . . . . . . . 1857 Miscophus niger Taschenb., Schlüss. z. Bestimm. (Zeitschr. f. d. ges. Naturw. X), p. 97 . 1857 Miscophus spurius Taschenb., Schlūss. z. Bestimm. (Zøitschr. f. d. ges. Naturw. X), p. 97 . 1857 Miscophus niger Taschenb., Hym. Deutschl., IX. Fam. Sphec., p. 202 und 203, Nr. 4 . . . 1866 Miscophus spurius Taschenb., Hym. Deutschl., IX. Fam. Sphec., F. 202 und 203, Nr. 2 . . 1866 Miscophus niger Thoms., 0pusc. Entom., Fsc. II, p. 242, Nr. 1, §’, Ұ . . . 1870 Miscophus niger Thoms., Hym. Scand., t. III, p. 222, Nr. 2, ठ', Q . . . . . . 1874 Miscophus niger Radoszk., Fedtsch. Reise in Turkest., p. 23, Nr. 1, ठ . . . . . . . . . 1877

Long. 4-6 mm. Niger; caput et thorax subaenea. Alae subhyalinae, in margine apicali obscuriores. Frons microscopice rugulosa et confertim punctulata (L. b), subopaca. Dorsulum et scutellum dense - minime vero confertim punctata (L. b); mesopleurae dense punctatae, punctaturae rugulis intermixtis. Area radialis alarum anteriorum quam areola cubitalis secunda petiolata major. Pecten tarsale pedum anteriorum fere deest. Area dorsalis segmenti mediani rugis longitudinalibus, irregularibus, paulum obliquis strigosa; segmenti mediani pleurae longitrorsum striate rugosae.

ऽ. Long. 4-5 mm. Clypei margo medius parvus, mutice subtriangularis.

ㅇ. Long. 4.5-6 mm. Clypei margo medius subarcuate truncatus.

Miscophus niger ist eine kleine, schwarze Art, pechroth sind nur zum Theile die Oberkiefer und die Spitze des Fühlerschaftes. Von M. bicolor ist er ausser durch die geringere Grösse durch die etwas seichtere Punktirung des Schildchens (L. b), die der Länge nach zum Theile schräg nach aussen verlaufenden Runzelstreifen der horizontalen Mittelsegmentfläche und durch die ganz schwarze Hinterleibsfärbung verschieden.

Die abstürzende Mittelsegmentfläche ist wie bei $M$. bicolor mit queren Runzelstreifen besetzt und wird durch eine Längsrinne, die Fortsetzung einer geraden Runzel, welche die Horizontalfläche halbirt, getheilt. Dasselbe gilt wohl auch von $M$. bicolor.

Leichter als mit $M$. bicolor ist $M$. niger wegen seiner Kleinheit mit M. concolor Dhlb. zu verwechseln. $M$. concolor ist viel glätter, glänzender; die Sculptur auf der Stirne istnicht wiebeinigergedrängt, 
auch die des Dorsulums viel dünner. Besonders glänzend erscheinen bei concolor die Mesopleuren. In der Sculptur des Mittelsegmentes steht niger dieser näher als bicolor.

In der Lebensweise gleicht $M$. niger der vorigen Art. Ich fing ihn immer an Sandplätzen, in der Nähe von Mauern, wo er sich an windfreien heissen Sommertagen emsig herumtummelt. Zuerst tritt er im Mai, am häufigsten im Juni und Juli auf; einzelne Weibchen kann man noch Ende September und Anfangs October beobachten.

Geographische Verbreitung. Diese Art ist aus Central-Europa bekannt und geht bis zum Polarkreise. In der Mediterranregion wurde sie ausser im südlichen Tirol meines Wissens noch nicht beobachtet. In Folge ihrer geringen Grösse und ihrer ausserordentlichen Flüchtigkeit ist sie nur schwer bemerkbar und wird nicht sehr oft gesammelt. Daher glaube ich auch, dass sie im Mittelmeergebiet da und dort noch wird gefangen werden.

Von England kennt man $M$. niger nicht. Scandinavien: Ostro-Gothia in Wadstena Löt, Medbamraäng (Zetterst.), Bahusia bei Uddevalla (Gyllenhal, Marklin); Skanien nicht weit von Lund, $\sigma^{\lambda}$, $\subsetneq$ (Dahlbom), beim Dorfe Glösbo in Gestricia ( ${ }^{25} / 8$, Dahlbom), in Sandgräben bei Stendjörke, Gothland ( $\sigma^{\top}$, $q$, 30/7, D a hlbom), Finland, bei Uleåberg ( $65^{0}$ n. Br., Nylander). Deutschland: Hedemünde ( $q$, Wissmann), Wellingholthausen $\left(14 / 8\right.$, Sickmann $\left.{ }^{1}\right)$, Jungfernheide und Rixdorf bei Berlin $\left({ }^{17} / 7,20 / 7, \mathrm{Dahlbom}\right)$, Umgebung von Berlin (nach Ruthe und Stein häufig), Halle ( $7 / 5-30 / 9$, T aschenb.). Oesterreich: Türkenschanze bei Wien (Rogenhofer), in Tirol bei Zams $(25 / 7)$, bei Bozen $(3 / 6-19 / 9)$, Klobenstein (1200 Meter, 8). Schweiz: St. Moriz im Oberengadin (Morawitz), Bois des frères $(16 / 10$, 우).

\section{Miscophus concolor Dhlb.}

Miscophus concolor Dhlb., Hym. Eur., t. I, p. 236, Nr. 137, б', T, et Larr., p. 466,

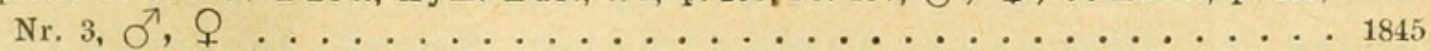
Miscophus concolor Schenck, Beschr. d. in Nassau aufgef. Grabwesp. (Jahrb. d. Ver. f. Naturk.

Herz. Nassau, 12. Heft, p. 196, Nr. 2, et p. 316, $\left.\delta^{\top}\right) . \ldots . . . . . .1857$ Miscophus concolor Taschenb., Schlüss, z. Bestimm. (Zeitschr. f. d. ges. Naturw. X), p. 97 . 1857 Miscophus concolor Taschenb., Hym. Deutschl., IX. Fam., p. 203, Nr. 3 . . . . . . 1866 Miscophus concolor Costa, Ann. Mus. zool. Napoli (Aun. IV), p. 95 . . . . . . . 1867 Miscophus concolor Thoms., 0pusc. ontom., Fsc. II, p. 243, Nr. 2, 万', … 1870 Miscophus concolor Thoms., Hym. Scand., t. III, p. 221, Nr. 1, ठ',

Long. 3-6 mm. $\sigma^{\nearrow}$, Q. Niger, caput et thorax subaenea et subglabra, pedes et antennae nonnunquam rufo-picea; mandibulae et segmentum abdominis secundum rufa, aut rufo-picea. Alae subhyalinae. Frons subconvexa, dense non tamen confertim punctulata, subnitida. Dorsulum et scutellum punctulatum (L. b). Ocelli posteriores inter se paulo plus distant, quam quorum unus ab

1) Verzeichniss der bei Wellingholthausen bisher aufgefundenen Raubwespen mit biologischen uud literarischen Notizen (V. Jahresb. d. naturwiss. Vereines zu Osnabrück), Franz Si c k ma n n, 1883. 
ocello anteriore. Mesopleurae subpolitae. Area dorsalis segmenti mediani longitrorsum striate-rugosa. Tibiae parce spinulosae; tarsi antici brevissime aculeati O. $_{\text {. }}$ Area radialis alarum anter. quam areola cubitalis secunda multo major.

万. Long. $3-5.5 \mathrm{~mm}$.

․ Long. 45-6 mm. Clypei margo medius recte truncatus.

M. concolor ist die kleinste bekannte Miscophus-Art, überhaupt eine der kleinsten Grabwespen. Schwarz. Kopf und Thorax schwach erzfarben. Oberkiefer pechroth. Fühler schwarz oder dunkel pechroth bis pechgelb. Zweiter Hinterleibsring roth. Beine schwarz oder röthlich. Am nächsten verwandt ist M. niger Dhlb.; von ihm unterscheidet er sich durch die seichtere Punktirung der Stirne, den fast gerade abgestutzten Kopfschildrand beim , welcher bei niger schwach bogenförmig verläuft, die glänzenden, fast glatten, weil nur sehr mangelhaft śculpturirten Mesopleuren und die Färbung des Hinterleibes. $M$. bicolor ist viel grösser, durchschnittlich fast doppelt so lang, seine Stirne gedrängt punktirt, daher von mattem Aussehen, auch die Punktirung des Mittelbruststückes ist viel dichter, ein Unterschied, welcher besonders an den Pleuren auffällt. In der Sculptur des Mittelsegmentes gleicht $M$. concolor dem $\boldsymbol{M}$. niger; es ist oben nicht wie bei $M$. bicolor unregelmässig gerunzelt, sondern mit Längsrunzelstreifchen besetzt, die sich zum Theile gegen die Seiten hin biegen. In der Ausdehnung der rothen Farbe auf dem Hinterleibe soll $\boldsymbol{M}$. concolor variiren.

Die Lebensweise ist von der des $M$. bicolor wohl nicht verschieden; Näheres weiss man nichts darüber.

Geographische Verbreitung. Skandinavien: Lackalänga bei Lund $(17 / 8$, 1836) Q, Glösbo in Gestrizien, ${ }^{25} / 8,1840$ (Dahlbom), Wadstena Löt, Ostro-

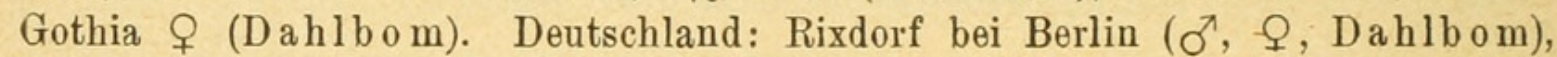
Umgebung Berlins (Ruthe und.Stein), Mombach (Schenck), Wellingholthausen ( $14 / 8$, Sickmann), Bamberg (Funk). Belgien: bei Brüssel (Wesm.). Schweiz: Peney $\left({ }^{28} / 6,1 / 7,29 / 7\right.$, Tournier). Italien: Ligurien, Umgebung von Neapel (Costa).

\section{Miscophus gallicus Kohl.}

? Miscophus ater Lep. (non v. d. Lind.!), Hist. nat. Ins. Hym., t. III, p. 238, Nr. 2, † . . 1845 Miscophus gallicus Kohl, Verhandl. d. k. k. zool.-bot. Gesellsch. Wien, XXXIII. Bd., p. 347, Nr. $1, \delta^{7}$, ? 1883

Long. 6-7.5 mm. $\sigma^{\top}$, + . Niger; mandibulae in medio et antennarum scapus antice flavescentia. Alae hyalinae, in margine apicali late infuscatae, venae nigro-fuscae. Areola cubitalis secunda magnitudine areae radiali circiter aequalis. Pedes spinulosi. Frons et thorax opaca, coriacea, subtilissime et confertim punctulata (L. b) pube cineria pruinosa. Segmentum medianum subelongatum - longitudo ejus latitudini basali aequalis - coriaceo-opacum 
et velut cetera abdominis segmenta cinereo-subpruinosum, area dorsalis linea tenui mediana divisa, truncatura rugis curvatis transversis et superne foveola instructa.

o'. Long. 6-6.5 mm. Facies subplana, quam in $q$ paullulum convexior. Ocelli posteriores ab ocello anteriore quam inter se paullo minus distant. Flagelli articulus secundus quam primus tantummodo sesqui longior.

ㅇ. Long. 6.5-7.5 mm. Facies fere plana, tantummodo paullulum convexa. Ocelli posteriores ab ocello anteriore quam inter se plus distant. Antennarum flagelli articulus secundus quam primus duplo longior. Pecten tarsale magnum.

\section{Massilia (Gallia); Peney (Helvetia).}

Schwarz. Oberkiefer in der Mitte und Fühlerschaft an seiner Vorderseite gelblich. Flügel wasserhell mit schwarzbraunem Geäder, am Spitzenrande bis nahe an die Zellen heran stark schwärzlich getrübt. Kopf und Thorax, in geringerem Masse auch der Hinterleib, wird von einem graulichen Tomente zart reifartig überzogen.

Q. Die mittlere Kopfschildpartie ist mit einem breiten Rande versehen, welcher fast gerade, nur sehr schwach bogenförmig verläuft, und wird von den Seitenlappen des Clypeus beiderseits durch einen Einschnitt getrennt. Gesicht fast flach, nicht stärker gewölbt als bei folgender Art ( $M$. ctenopus Kohl). Fühler mässig lang, ihr zweites Geisselglied kaum mehr als zweimal so lang als das erste. Die hinteren Nebenaugen sind unter einander weniger weit entfernt als vom vorderen, bilden also übereinstimmend mit $M$. ctenopus in ihrer Stellung ein spitzes, gleichschenkeliges Dreieck.

Gesicht und Bruststück matt lederartig, unter der Lupe $b$ fein und gedrängt punktirt. Die Sculptur liegt wegen der erwähnten reifartigen Befilzung bei frischen Stücken nicht offen zu Tage. Die Radialzelle der Vorderflügel ist klein, hat ungefähr die Grösse der gestielten zweiten Cubitalzelle. Die Bewehrung der Beine viel stärker als bei M. bicolor Jur., der Tarsenkamm des ersten Paares gut entwickelt, lang, wenn auch nicht so lang und seine Dornen nicht so kräftig wie bei $M$. ctenopus. Das Mittelsegment ist graulich bereift, ähnlich wie bei ctenopus gebildet und sculpturirt, lang, seine Länge kommt etwa seiner grössten Breite an der Basis gleich; hinten fällt es steil ab. Die abfallende Fläche zeigt bogenförmig gekrümmte Querrunzeln und in der Mitte der oberen Hälfte eine Grube. Die Dorsalfläche wird durch eine Mittellinie halbirt und erscheint wie die Mittelsegmentseiten unter der Lupe $a$ lederartig und matt, unter der Lupe $b$ ganz fein körnig gerunzelt. Zum Unterschiede von ctenopus mag noch erwähnt werden, dass die Kantenrunzel zwischen der Dorsalfläche und dem abstürzenden Theile keine scharfen Seitenecken bildet. Die übrigen Hinterleibsringe zeigen nichts Erwähnenswerthes.

Das $\sigma^{7}$ sieht dem $q$ sehr ähnlich, nur ist die Mittelpartie des Kopfschildes in stärkerem Masse bogenförmig, die Stirne convexer, die Fühlergeissel, 
deren zweites Glied kaum mehr als $1.5 \mathrm{mal}$ so langals das erste ist, dicker. Die hinteren Nebenaugen sind von einander gerade noch bemerkbar weiter entfernt als eines derselben vom vorderen.

Von $M$. bicolor unterscheidet sich $M$. gallicus durch die schwarze Färbung, den schlankeren Bau, den breiteren Kopfschildrand, die flachere Stirne, die Stellung der Nebenaugen $Q$, die feinere Sculptur des Kopfes und Bruststückes und die stärkere Haarbereifung dieser Theile, die viel kleinere Radialzelle, die schärfer abgesetzte Flügelrandtrübung, die stärkere und längere Bedornung der Beine, das gestrecktere, lederartige Mittelsegment und endlich die schwarze Körperfärbung. In allen diesen Punkten, mit Ausnahme des letzterwähnten, unterscheidet er sich auch von $M$. niger Dhlb. (= spurius Dhlb.).

M. ctenopus steht dem M. gallicus entschieden am nächsten, ist aber nicht leicht zu verwechseln, da er eine andere Färbung, einen viel kräftigeren und noch längeren Tarsenkamm, schärfere Hinterecken des Mittelsegmentes besitzt; das zweite Fühlergeisselglied der 우 ist bei ctenopus sichtlich länger und die Radialzelle um etwas, wenn auch nicht so viel grösser als bei bicolor und dessen nächsten Verwandten.

Geographische Verbreitung. Diese Art wurde mir von Herrn Camille Jullian aus Marseille mitgetheilt. Herr Tournier fing sie in der südwestlichen Schweiz bei Peney.

Es ist wohl möglich, dass $M$. gallicus mit $M$. ater Lep. ${ }^{1}$ ) identisch ist. Die Beschreibung Lepeletier's gibt aber über die eigentlich entscheidenden Merkmale: die Form der Stirne, die Stellung der Nebenaugen, die Grösse der Radialzelle, die Bedornung der Beine, keinen Aufschluss. Ob die Form Van der Linden's, welcher die Bezeichnung „ $\boldsymbol{M}$. ater" schuf, mit dem $\boldsymbol{M}$. ater Lepeletier's identisch ist, kann nach dem Texte nicht eruirt werden.

\section{Miscophus ctenopus n. sp.}

Miscophus ctenopus Kohl, Verh. d. k. k. zool.-bot. Gesellsch. Wien, XXXIII, p. 349, O`, Miscophus Manzonii Grib., Ann. Mus. civ. stor. nat. Genova, vol. XX, p. 386, Nr. 12, †. . 1884

Long. 6-9 mm. $\sigma^{\top}$, Q. Niger; caput, thorax et segmentum medianum subaenea, pube albida pruinosa. Calla humeralia, alarum squamulae, mandibulae, antennarum scapus et subtus pedicellum flava. Abdominis segmenta pallide rufa, nonnunquam ex parte indeterminate nigricantia; pedes rufi, femora supra nonnunquam nigra. Alae fere hyalinae, anteriores in margine apicali late infuscatae; venae luteae. Areola cubitalis secunda quam area

1) M. ater Lep., Hist. nat. Ins. Hym., t. III, p. 238, Nr. 2, Q. - „Caput nigrum, antice praesertim argenteo pubescens. Antennae nigrae. Thorax omnis niger, argenteo subpubescens. Metathorax supra subrugosus; sulco unico longitudinali dorsali impresso. Abdomen omnino nigrum. Pedes nigri, argenteo subvillosi. Alae hyalinae, apice fuscae, nervuris, puncto marginali squammaque nigris. + . Paris. -- Synonymum Lindenii cum dubio affero. Mihi enim probabile videtur a Lindenio habitum pro distincta fore nostrum Miscophum atrum, ratione habita ex metathoracis sulco dorsali unico." 
radialis minor. Pedes evidentissime spinulosae, spinulae nigrae. Frons confertim punctulata (L. b), coriacea, thorax coriaceo-rugulosa (L. b) velut frons fere opaca. Segmentum medianum elongatum, coriaceum, longitudine latitudini, basali aequalis; truncatura postica rugis transversis arcuatis instructa.

$\mathrm{o}^{7}$. Long. $6-7 \mathrm{~mm}$. Ocelli posteriores ab anteriore quam inter se plus distant. Flagelli articulus secundus quam primus sesqui longior. Frons subplana.

Q. Long. 7-9 mm. Ocelli posteriores ab ocello anteriore quam inter se evidenter plus distant. Antennae tenues; flagelli articulus secundus quam primus duplo et dimidio longior. Frons fere plana. Pecten tarsale validum et maximum.

\section{Tor; Arabia septentrionalis.}

Kopf, Thorax und Mittelsegment nicht undeutlich erzfarben. Oberkiefer, Vorderrand des Kopfschildes, Fühlerschäfte, Unterseite des ersten Geisselgliedes, Schulterbeulen und Flügelschuppen gelb. Hinterleib, das Mittelsegment ausgenommen, lichtroth, an den hinteren Segmenten stellenweise schwärzlich angelaufen. Beine ebenfalls hellroth, mit schwarzer Bedornung, die Hüften, die Oberseite der Schenkelringe und manchmal in unbestimmter Ausdehnung auch die Oberseite der Schenkel schwarz. Nach allen Anzeichen dürfte die Färbung bei dieser Art abändern, wenn sich auch annehmen lässt, dass die rothe Färbung an den Beinen und auf dem Hinterleibe vorherrschend bleibt.

․ Der Kopfschildrand ist breit, viel breiter als bei M. bicolor; die Mittelpartie des Kopfschildes hat ungefähr die nämliche Querausdehnung wie bei diesem und bildet einen flachen Bogen, welcher beiderseits durch einen Einschnitt von den Seitenlappen des Kopfschildes getrennt wird und in der Mitte nicht so weit wie bei bicolor vorspringt.

Die Fühler sind dünner als bei bicolor; das zweite Geisselglied ist etwa $2.5 \mathrm{mal}$ so lang als das erste, bei $M$. bicolor etwa zweimal. Die Stirne ist viel flacher, matt, unter der Lupe $b$ sebr fein und gedrängt punktirt. Die Nebenaugen stehen in den Ecken eines spitzen, gleichschenkeligen Dreieckes; die Entfernung der hinteren unter sich ist grösser als die eines von ihnen vom benachbarten Netzauge, aber viel geringer als die Entfernung vom vorderen Nebenauge. Die lederartige, durch eine gedrängte Punktirung hervorgerufene Sculptur des Thorax und der Stirne wird von einem kurzen, ziemlich dichten weisslichen Toment bedeckt, ohne jedoch die mattgrüne Erzfarbe des Bruststückes vollkommen zu verhüllen. Den unteren Theil des Gesichtes überdeckt eine reichere weisse Befilzung. Die lehmgelb geäderten Vorderflügel sind fast wasserhell, am Spitzenrande sehr breit, bis zu den Zellen heran stark braun getrübt. Die Radialzelle ist zwar kleiner als bei $M$. bicolor, indessen bei den vorliegenden Stücken an Fläche doch noch grösser als die gestielte zweite Cubitalzelle. Die Beine sind schlank und durch ihre lange, reiche Bedornung vor den meisten anderen Miscophus-Arten ausgezeichnet. Dex 
Wimpernkamm der Vordertarsen wird von sehr langen, kräftigen und ein wenig gebogenen Wimpern gebildet; vier sitzen auf dem Metatarsus; die erste davon ist kurz und nicht auffallend, die drei folgenden aber sind lang, besonders die beiden letzten, welchefast die Länge des Gliedes haben, dem sie an haften. Die beiden folgenden Tarsenglieder tragen je einen sehr langen, zur Kammreihe zählenden Wimperdorn. Auch die übrigen Tarsen und die Schienen weisen eine kräftige Bedornung auf, welchedurch ihr Schwarzvon derrothen Farbeder Glieder schroff absticht. Das Mittelsegment ist gestreckt, viel länger als bei $M$. bicolor, ungefähr in dem nämlichen Längenverhältnisse wie bei $\boldsymbol{M}$. gallicus; es ist etwa so lang als an seiner Basis breit; hinten fällt es sehr steil, fast senkrecht ab. Die Sculptur des Mittelsegmentes ist eine lederartige, runzelig feinkörnige (L. $b$ ); nur die abstürzende Fläche hat einige derbe, gebogene Querrunzeln; die Kante, welche beim Uebergange der Horizontalfläche zur abstürzenden Fläche gebildet wird, ist sehr scharf und bewirkt an den Seiten die Bildung einer Ecke, welche wahrgenommen wird, wenn man das Mittelsegment von der Seite besieht.

Die übrigen Hinterleibsringe tragen eine kurze Haarbefilzung, welche häufig abgerieben ist. Das $\sigma^{\top}$ gleicht dem o + ausserordentlich; es hat die nämliche Farbe und Sculptur und Form des Mittelsegmentes; es ist aber kleiner, seine Stirne etwas gewölbter, wenn schon noch ziemlich flach, seine Fühler sind kürzer und dicker; das zweite Geisselglied ist etwa doppeltso lang als das erste. Die hinteren Nebenaugen stehen vom vorderen nicht ganz so weit ab wie beim $q$, obwohl sievon ihm deutlich weiter entfernt sind als von einander. Die Bedornung der Beine ist gleichfalls stark, stärker als beim o von M. bicolor, nur fehlen die Wimperdornen auf dem Metatarsus des ersten Fusspaares.

Costa beschreibt einen Miscophus italicus ${ }^{1}$ ) aus der Umgebung von Neapel, Radoszkowsky einen $M$. sericeus $^{2}$ ) von Egypten, welche vielleicht mit $M$. ctenopus nahe verwandt sind; leider sind die Beschreibungen für eine sichere Deutung ganz unzulänglich.

1) Mr. italicus Costa (Ann. Mus. zool. Napoli [Aun. IV], p. 94, Nr. 2, 1867). „Niger, brevissime cano puberulus; abdominis segmentis primis tribus rufis, metanoto in dorso subtilissime punctulato-coriaceo, sulculo medio longitudinali, truncatura postica transverse striata; alis cinereo-hyalinis, apice late fumatis. Q. Long. corp. $6 \mathrm{~mm}$., expans al. $10 \mathrm{~mm}$. - Simile a primo aspetto al $M T$. bicolor, dal quale differisce essenzialmente pel dorso del metatorace non affato rugoso, nè reticolato; bensì finamente coriaceo, con un distinto solco longitudinale nel mezzo. Trovato nelle adjacenze di Napoli ete."

$\left.{ }^{2}\right)$ M. sericeus Radoszk. (Comptes rend. d. Hym, rec. en Egypte et Abyss. [Hor. soc. ent. ross., t. XII, p. 134, Nr. 54, 1876]). "Niger, capite thoraceque albido-tectis; antennis articulo primo, pedibus abdominisque segmentis tribus primis ferrugineis. Alis hyalinis, in medio apicis fumatis, nervis luteis. Long. $6 \mathrm{~mm}$. - La tête et le corselet couverts d'un duvet très-court, comme de la poussière, d'une couleur blanchâtre. La base des antennes et les pieds ferrugineux. Les trois premiers segments abdominaux ferrugineux, avec un duvet soyeux argenté. La moitié basale des ailes transparentes, la moitié apicale fortement enfumée; nervures ferrugineuses. Var. $\beta$. Troisième segment, hanches, cuisses et nervures des ailes noirs." 


\section{Miscophus pretiosus Kohl.}

Miscophus pretiosus Kohl, Verh. d, zool.-bot. Gesellsch. Wien, XXXIII. Bd., p. 351, Nr. 3, ㅇ 1883

Long. $7 \mathrm{~mm}$. ㅇ. . Caput, thorax et segmentum medianum aenea, nitida, pro parte polita. Mandibulae et antennarum scapi flava. Abdomen, segm. medianum exceptum, et pedes luteo-picea, ex parte nigricantia. Alae omnino hyalinae, venae pallidae. Frons convexiuscula, polita, linea frontali profunda impressa. Antennarum flagelli articulus secundus quam primus duplo et dimidio longior. Ocelli in trigonum aequilaterale dispositi, posteriores ab oculis quam inter se non plus distant. Dorsulum et mesopleurae nitida in locis detritis polita. Area radialis alarum anteriorum areolam cubitalem magnitudine superat. Pedes evidenter spinulosi; pecten tarsale pedum anteriorum magnum. Segmentum medianum subelongatum, longitudo ejus latitudini basali aequalis; area dorsalis coriaceo rugulosa (L. b), pleurae oblique rugulosae (L. b), truncatura transverse striata. Cetera abdominis segmenta tomento brevi flavo-albido obtecta. - o ignotus.

Corfu (Mus. caes. Vindob.).

Lebhaft erzfarben. Oberkiefer und Fühlerschäfte gelb, Taster und Kopfschildrand braun, Schulterbeulen braungelb. Hinterleib - das Mittelsegment abgerechnet - und Beine gelblich pechfarben; sowohl Hinterleib als die Schenkel zum Theile angedunkelt. Die Färbung der Beine und des Hinterleibes ist sicher sehr veränderlich. Bedornung schwarz. Flügel vollständig wasserhell, ohne Randtrübung, ihr Geäder blass lehmgelb. Kopfschild silberglänzend, gegen die Stirne hin gelblich behaart.

M. maritimus Smith (Cat. Brit. Foss. Hym. 1858, p. 91): ,M. niger, capite thoraceque nigro-aeneis, alis apicis fuscis. - + . $22_{2}-2^{3} /_{4}^{\prime \prime \prime}$, schwarz; Kopf und Thorax glänzend und mit schwachem Kupferschimmer, dicht und fein punktirt; Stirne mit linearem Eindrucke zwischen dem vorderen Nebenauge und der Fühlerinsertion. Thorax mit einem auf dem Mesothorax schwach bis zur Mitte des Dorsulums fortgesetzten Linieneindrucke in der Mitte des Collare. Metatliorax schwarz, mit centraler Längslinie, welche zur Grube am Rande der abstürzenden, dicht quergestreiften Fläche läuft. Basis des Metathorax mit einigen unregelmässigen, schrägen Streifen. Flügel bräunlich, glashell, mit rauchigem Apicalrande. Hinterleib glänzend, sehr fein punktirt, Hinterrand des ersten und zweiten Segmentes schwach zusammengedrückt. 万 $2-2^{1} /{ }^{\prime \prime}$, vom durch die schwächere Silberbehaarung des Gesichtes verschieden. Thorax oft mehr kupfern." (D e a l, 1856.)

$\mathrm{Zu}$ den in dieser Arbeit behandelten paläarktischen Arten ist nur noch eine einzige amerikanische Art hinzuzufügen : M. exoticus Taschenb. (Larr. u. Bemb. Mus. Halle [Zeitschr. f. d. ges. Naturw. XXXVI, p. 317, Nr. 3, 1870]). „Aeneo-niger, pro partibus argenteo-sericeus; mandibulis testaceis; alis hyalinis postice fumatis. Long. $6.5 \mathrm{~mm}$. Q. Rio de Janeiro. - Schwarz, besonders auf dem sehr fein punktirten Mittelrücken mit Erzschimmer, Gesicht, Hinterkopf, Prothorax und besonders die Seiten des übrigen Thorax, mehr oder weniger auch die Beine, mit kurzen, anliegenden Silberhaaren, aber nicht dicht bedeckt. Der Metathorax ist durchaus sehr fein quergerunzelt, auf dem Rückentheile so fein, dass man ihn auch nadelrissig nenuen könnte; durch diesen und den abschüssigen Theil geht eine tiefe Längsfurche, und zwar ohne Unterbrechung in der Grenze beider Theile. Der an der Spitze ziemlich kolbige Hinterleib ist ausserordentlich fein punktirt; die Hinterhälfte der Vorderflügel merklich getrübt. Die Kinnbacken sind in ihrer grössten Ausdehnung gelbroth."

Z. B. Ges. B. XXXIV. Abh. 
Rand der mittleren Kopfschildpartie sehr schwach gebogen, fast gerade abgestutzt, an den Seiten abgerundet; beiderseits wird die Mittelpartie des Kopfschildrandes von den Seitentheilen durch einen Einschnitt abgesondert. Die Stirnewird von einem tiefen Längseindruckedurchzogen; zu beiden Seitenvonihmerhebtsie sich in polsterartiger, polirt glänzender Wölbung. Die Nebenaugen stehen in einem fast gleichseitigen Dreiecke; die Entfernung der hinteren unter einander ist sogross als die Entfernung eines derselben vom benachbarten Netzauge und kaum grösser als die vom vorderen. Der Scheitel, vorzüglich aber der Raum zwischen den Nebenaugen, ist mit fuchsbrannem Tomente bedeckt. Die Wangen sind dicker als bei $M$. ctenopus und äusserst schwach gerunzelt, der Grund, warum sie nicht polirt aussehen.

Das Dorsulum und die Mesopleuren glänzend, sehr fein und spärlich gerunzelt, stellenweise polirt. Radialzelle grösser als die zweite Cubitalzelle. Beine deutlich bedornt, wie bei $M$. gallicus, Dornen schwarz. Tarsenkamm der Vordertarsen lang; Metatarsus mit vier Kammwimpern, davon die beiden ersten kurz; Kammwimpern des zweiten und dritten Tarsengliedessehrlang, viel länger als das Glied selbst, dem sie anhaften.

Das Mittelsegment hat das nämliche Längenverhältniss wie bei M. gallicus, ist oben sehr fein gerunzelt, lederartig, die Runzelchen der Quere nach gestellt (L. b), seine Seiten sind fein, schräg aufwärts undeutlich nadelrissig gerunzelt (L. b); die abstürzende Fläche hat grössere Querrunzeln. Die übrigen Hinterleibsringe sind mit einem weisslichgelben Haarfilze reifartig bedeckt, die Hinterränder der Ventralplatten mit einzelnen starren Börstchen besetzt.

Diese Art ist besonders durch die Stirnbildung, die Sculptur, den Erzglanz und die ganz wasserhellen Flügeln ausgezeichnet. Corfu.

\section{Verzeichniss der bisher beschriebenen Miscophus-Arten.}

M. ater Pel. ․ Reg. I, Subreg. 2. Gallia.

Miscophus ater Pel.: Hist. Nat. Ins. Hym. III, 1845, p. 238, Nr. 2, 오 (non M. ater v. d. L.!).

M. bicolor Jur. $Q$, б. Reg. I, Subreg. 1 und 2. Europa.

Miscophus bicolor Jur.: Nouv. méth. Hym. 1870, Taf. XI, Fig. 25, бో.

M. concolor Dhlb. Q, o'. Reg. I, Subreg. 1 und 2. Europa.

Larra spuria Dhlb.: Exerc. Hym. 1833, p. 56, Nr. 7.

M. ctenopus Kohl. $\sigma^{\top}$, Q. Reg. I, Subreg. 2. Tór.

Miscophus ctenopus Kohl: Verhandl. d. k. zool.-bot. Gesellsch. Wien, XXXIII, 1883 , p. 349.

M. exoticus Taschenb. ㅇ. Reg. V, Subreg. 2. Rio Janeiro.

Miscophus exoticus Taschenb.: Zeitschr. f. d. ges. Naturwissensch. XXXVI, 1870 , p. 317 (17), Nr. 3, ․ 
M. gallicus Kohl. $Q$, o $\sigma^{7}$. Reg. I, Subreg. 1 und 2. Gallia, Helvetia.

Miscophus gallicus Kohl: Verhandl d. k. k. zool.-bot. Gesellsch. Wien, XXXIII, 1883, p. 348.

M. italicus Costa. $\sigma^{7}$. Reg. I, Subreg. 2. Napoli.

Miscophus italicus Costa: Ann. Mus. Zool. Napoli IV, 1867, p. 94, Nr. 2, ठ

M. maritimus Smith. + , $\sigma^{7}$. Reg. I, Subreg. 1. Anglia.

Miscophus maritimus Smith: Catal. Brit. Foss. Hym. 1858, p. 91, ㅇ, o’

Miscophus maritimus E. Saund.: Trans. Ent. Soc. Lond., 1880, p. 251, Nr. 2.

M. niger Dhlb. Q , $\sigma^{7}$. Reg. I, Subreg. 1 und 2. Europa.

Miscophus niger Dhlb. : Hym. Eur.I, 1845, p. 236, Nr.136, p.466, Nr.2, ᄋ, o’.

M. pretiosus Kohl. Q. Reg. I, Subreg. 2. Corfu.

Miscophus pretiosus Kohl: Verhandl. d. k. k. zool.-bot. Gesellsch. Wien, XXXIII, 1883, p. 351, ․

M. sericeus Radoszk. Reg. II, Subreg. 2. Aegyptia.

Miscophus sericeus Radoszk.: Hor. Soc. Ent. Ross. XII, 1876, p. 134, Nr. 54.

Gen. Larra Fabr.

$<$ Sphex Rossi, Faun. Etrusc., t. II ...................... 1790

$<$ Larra Fabricius, Ent. Syst, t. II, p. 220................... . . 1793

Larra Latr., Préc. caract. gén. ins., p. 116, 17. Gen. . . . . . . . . . . . . . 1796

$<$ Larra Fabricius, Syst. Piez., p. 219 . . . . . . . . . . . . . . . . . . . . . 1804

$<$ Pompilus Fabr., Syst. Piez., p. 219 . . . . . . . . . . . . . . . . . . . 1804

Larra Latr., Hist. nat. gen. et part. des Crust. et Ins., t. III, p. 335 . . . . . . . 1802

$<$ Larra Latr., Hist. nat. gen. et part. des Crust. et Ins., t. XIII, p. 295, 393. Gen. . . . 1805

Larra Panzer, Krit. Revis., II. Bd., p. 127 . . . . . . . . . . . . . . . . . . 1806

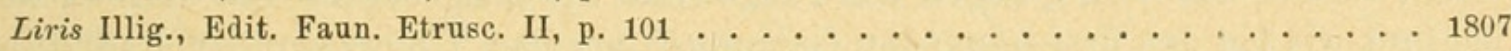

Larra Latr., Gen. Crust. Ins., t. IV, p. 70, 491. Gen. . . . . . . . . . . . . . . . . . 1808

Larra Lamark, Hist. nat. d'anim. s, vert. IV, p. 116 . . . . . . . . . . . . . . 1817

Larra Samouelle, Entom. Comp. introd. Knowl. Brit. Ins., p. 276 . . . . . . . . . . . 1819

Larra Dufour., Rech, anat. phys. s. 1. Orth. Hym. et Neur., p. II . . . . . . . . . . . 1834

Larra Shuck., Ess. indig. foss. Hym., p. 87 . . . . . . . . . . . . . . . 1837

Larra Blanchard, Hist. nat. des Ins., t. III, p. 356 . . . . . . . . . . . . . . . . 1840

Larra Herr, Schäff., Nomencl. entom., p. 54 . . . . . . . . . . . . . . . . . . . 1840

Larra Westwood, Introd. mod. Classif. Ins., vol. II, Syn. Gen. Brit. Ins., p. 81 . . . . 1840

Larra Dhlb., Disp. meth., p. I, 3. Fam. Larr., p. 3, 13. Gen. . . . . . . . . . . . . . 1842

< Larra Dhlb., Hym. Eur., t. 1, Tab. exam. syn. spec. Larr., p. 471, et Tab. exam. syn.

gen. Larr. . . . . . . . . . . . . . . . . . . . . . 1845

Tachytes Lep., Hist. nat. Ins. Hym., t. III, p. 239 . . . . . . . . . . . . . 1845

Larra Eversm., Faun. Hym. Volg. Ural, Bull. Nat. Soc. Mosc., t. IlI, p. 386 . . . . . 1849

Larra Spin., Hist. fis. y pol. Chile, Gay. Zool., t. VI, p. 322 . . . . . . . . . . . 1851

< Larrada Smith, Cat. Hym. Ins. Brit. Mus., p. 274 . . . . . . . . . . . . . . . 1856

Larra Taschenb., Schlüss. z. Bestimm. (Zeitschr. f. d. ges. Naturw. X), p. 85, 8. Gen. . 1857

Larra Schenck, Beschr. d. i. Nassau aufgef. Grabwesp., p. 198 . . . . . . . . . . . . 1857

Larra Taschenb., Hym. DeutschI., 9. Fam. Sphec., p. 158 et 199, 26. Gen. . . . . . 1866

< Larrada Saussure, Reise d. Freg. Nov., Bd. II, p. 73 . . . . . . . . . . . . . 1867

Larra Costa, Ann. Mus. zool. Univ. Napoli (Ann. IV), p. 80 et 81 . . . . . . . . 1867

$<$ Larrada Taschenb., Larr. u. Bemb. d. zool. Mus. Halle, p. 1 d. Sep. . . . . . . . . . . 1870

Larra Radoszk., Fedtsch. Reise in Turkest., p. 23 . . . . . . . . . . . . . 1877

$<$ Larra Patton,. Proc. Bost. Soc. Nat. Hist., vol. XX, p. $385 \ldots \ldots . . . . . . . . .1880$ 
Zur Gattung Larra gehören Thiere von 10-24 mm. Länge und ziemlich kräftiger Gestalt. Kopf ein wenig breiter als der Thorax; Oberkiefer mit einem Ausschnitte unweit der Mitte ihrer Unterseite; Spitze der Kiefer einfach, deren Innenrand ungezähnt. Gesichtsfilz ärmlich, nie besonders auffallend. Fühler ziemlich kräftig. Das zweite Geisselglied übertrifft die übrigen an Länge. Augen gegen den Scheitel zu convergent, ihre Convergenz aber nie sehr bedeutend; Zwischenraum zwischen den Augen auf dem Scheitel daher immer ziemlich gross. Längs der inneren Augenränder dehnen sich auf dem Gesichte leistenartige Wülste aus, die sich ungefähr in ihrer Mitte am stärksten erheben und daselbst durch einen über der Mitte der Stirne aufgetriebenen Querwulst verbunden werden. Dieser Querwulst theilt das Gesicht in zwei vertiefte Felder; in dem unteren bemerkt man flache Eindrücke, denen sich die Fühlerschäfte anschmiegen können, im oberen liegen die Nebenaugen. Das vordere Nebenauge ist normal rund, gewölbt und liegt weit vor den beiden hinteren, welche ganz flach, länglich, einander genähert und höchst undeutlich sind. Der Hinterwulst des Pronotums verläuft quer, gerade und ist nicht oder nur in sehr geringem Masse unter das Niveau des Dorsulums herabgedrückt. Die Randzelle der Vorderflügel ist breit abgestutzt und mit einer Anhangszelle ausgestattet. Cubitalzellen sind drei entwickelt; die erste ist so gross oder noch grösser als die beiden folgenden zusammengenommen, die zweite trapezisch oder, wenn die erste und zweite Cubitalquerader an der Radialader einander sehr genähert sind, subtriangulär und nimmt beide rücklaufende Nerven auf, die dritte schief gestellt, hinten ein wenig gegen den Flügelrand hin ausgezogen. Das Retinaculum beginnt wie bei den drei folgenden Gattungen vor dem Ursprunge der Radialader, näher der Flügelbasis; die Anzahl der Häkchen ist in der Regel sehr gross, bei grossen Arten reicht sie bis zu 45. In den Hinterflügeln entspringt die Cubitalader nach dem Abschlusse der Submedialzelle an der Medialader. Die Beine sind von mässiger Länge, kräftig, die Schenkel dick; die Bedornung ist kräftig. Mittelhüften weit von einander abstehend. Mittelschienen einspornig. Vorderschienen, abgesehen von dem Endsporne und einigen Enddornen, an der Aussenseite ziemlich reichlich bedornt und an der Mitte ihrer Innenseite mit einem einzelnstehenden Dorne bewehrt.

Der Wimpernkamm wird von einer bescheidenen Anzahl nicht sehr langer, aber starker Dornen gebildet. Hinterschienen ohne förmliche Längskanten, wie sie bei den beiden folgenden nächstverwandten Gattungen auftreten. Klauen und ihre Ballen von mässiger Entwicklung. Das Mittelsegment ist so lang oder länger als das Dorsulum, gestreckt, oben flach, fällt hinten sehr steil, an den Seiten, welche in der Längenrichtung parallel verlaufen, senkrecht oder nach unten sogar ein wenig sich nähernd, ab, hat daher im Allgemeinen eine parallelopipedische Gestalt. Felder sind auf dem Mediärsegmente nicht abgegrenzt. Die übrigen Hinterleibsringe sind in ihrer Gesammtlänge bei den 우 meistens länger als der Kopf, der Thorax 
und das Mittelsegment zusammengenommen, abgesehen von den schwachen und unterbrochenen Filzbinden an den Hinterrändern, glatt, wie polirt glänzend, nicht wie bei den 오 von Notogonia und Liris fein und dicht bereift oder gar feinfilzig. Bauchring des dritten Segmentes von regelmässigem Bau ohne basale Erhebung. Auf der oberen Afterklappe ist ein Pygidialfeld entwickelt; es hat beim $Q$ die Form eines Dreieckes, dessen Seiten sanft nach aussen gebogene Kanten sind, trägt keine Filzbekleidung und am Ende keine Borstenstäbchen. Beim $\sigma^{7}$ ist der Hinterleib schwach filzig bereift; das Aftersegment ist trapezisch und erscheint wie bei Tachysphex- und Tachytes-Arten am Ende ausgerandet. In Betreff der Sculptur und Punktirung mag erwähnt werden, dass sie bei Larra derber ist als bei den Arten von Notogonia und Liris.

Die Gattung Larra - Larrada Smith ${ }^{1}$ ) - wurde meistens, selbst von jüngeren Autoren, im weiteren Sinne genommen und umfasste in der Regel auch die beiden nächstfolgenden Gattungen (Notogonia, Liris). Während sie Lepeletier (Hist. nat. Ins. Hym., t. III, p. 239, 1845), wahrscheinlich durch die grosse Aehnlichkeit des Flügelgeäders verleitet, zudem noch mit der Gattung Tachytes Panz. und Tachysphex Kohl zu seiner Sammelgattung Tachytes vereinigt, hält Dahlbom (Hym. Eur., t. I, 1845) und später Patton (List of North Amer. Larr. 1880) wenigstens die Gattung Liris davon getrennt. Die durch Larra nigra v. d. L. repräsentirte Gattung trennte erst Costa im Jahre 1867 (Prosp. sist. Imen. ital.) unter der Bezeichnung Notogonia ab. Ich halte sowohl Notogonia als auch Liris und die ebenfalls verwandte und neu aufgestellte Gattung Paraliris für recht brauchbare, wenn auch der Larra und einander sehr nahe verwandte Genera, was eine Zusammenstellung der unterscheidenden Merkmale darthun dürfte.

Von Notogonia unterscheidet sich die Larra dieser Abhandlung: 1. durch die plumpere Gestalt und die dickeren Beine; 2. den kürzeren Kopfschild; 3. die an ihrer Innenkante nicht bezahnten Oberkiefer; 4. die im Allgemeinen viel geringere Augenconvergenz und die dadurch bedingte grössere Ausdehnung des

1) Die Gattung Larra wurde im Jahre 1793 (Ent. Syst., t. II, p. 220, Nr. 44) von F a b ricius errichtet. Da ein Theil Larra-Arten des Fabricius nicht gedeutet werden konnte, der übrige Theil, Larra ichneumoniformis ausgenommen, von Latreille im Jahre 1804 (Genera Crust. et Ins. IV, p. 100) als eigene Gattung (Stizus) abgetrennt wurde, so muss die Bezeichnung Larra für die durch die noch übrig gebliebene $L$. ichneumoniformis repräsentirte Gattung erhalten werden. Die Mehrzahl der Autoren sind in diesem Sinne vorgegangen, nicht so aber Klug (Symb. phys.) und Smith (Cat. Hym., p. IV, 1856, p. 274), welche von der Ansicht auszugehen scheinen, dass die Bezeichnung Larra der durch die Larra vespiformis repräsentirten Gattung gebühre, weil Fabricius mit dieser die Reihe der Larra-Arten eröffnet hatte. Dieser Umstand ist zwar nicht zu läugnen, aber es liegt in ihm nicht zugleich die Erklärung, dass durch L. vespiformis der Typus von Larra vorgezeichnet sei; dies kann auch kaum bewiesen werden, da sich Fabricius hierüber nirgends ausspricht, die Gattungsbeschreibung von Larra nicht auf Stizus allein passt und es gewiss absurd wäre, davon für eine Art eine Prioritätsberechtigung ableiten zu wollen, dass sie im Texte einige Zeilen weiter voran steht als eine andere. Zudem wäre es auch ganz gegen das übliche Vorgehen in den Fällen, wo die Sammelgattung eines älteren Forschers in mehrere Gattungen aufgelöst werden muss. 
Scheitels; 5. besonders die Form des Vorderbruststückes; 6. die kleineren Klauen und die Bedornung der Vorderschienen; 7. den verhältnissmässig längeren Hinterleib; 8. die Glätte und den Glanz des Hinterleibes beim 오 ; 9. die normale Bildung des dritten Ventralringes; 10. die Beschaffenheit des Pygidialfeldes ( $q$ ), welches unbefilzt ist und an seiner Spitze keine Borstendörnchen trägt.

Die Artunterschiede liegen hauptsächlich in dem Grade der Fühlerdicke, der Form des Pronotumwulstes, der Punktirung oder Runzelung des Mesothorax, in der Form und Sculptur des Mittelsegmentes, der Beschaffenheit der oberen Afterklappe, in dem Grade der Flügeltrübung und in der Färbung des Hinterleibes. Die Unterscheidung der Species ist wie bei Notogonia mit Schwierigkeiten verbunden.

Geographische Verbreitung. Wie viele Arten von Larra im engeren Sinne auf die einzelnen Regionen entfallen, kann so lange nicht bestimmt werden, so lange nicht die Arten der Gattung Larrada (im Sm ith'schen Sinne) gedeutet sind. Von diesen trifft es 15 Arten auf die paläarktische Region, 22 auf die äthiopische, 22 auf die orientalische, 34 auf die neotropische, 17 auf die nearktische und 25 auf die australische.

Was über die Lebensweise von Larra bekannt geworden ist, beschränkt sich auf eine kurze Notiz von Radoszkowsky und Sichel („Ess. d'une monogr. des Mutill. de l'anc. Contin." 1870 , p. 12 et p. 73) und vielleicht auch auf das, was M. Maindron über Larra modesta Smith („Notes p. serv. à l'Histoire des Hym. de l'Archip. Ind. et de la Nouv.-Guin.“, Ann. Soc. Ent. de France, 5. sér., t. IX, 1879) berichtet. "Vielleicht" sage ich deswegen, weil Larrada modesta von Smith nicht derart beschrieben worden ist, dass man entscheiden könnte, ob diese Grabwespe wirklich zur Gattung Larra dieser Abhandlung, oder zu Notogonia oder zu Liris gehört. Sollte sie auch zu einer der letzteren Gattungen gehören, so ist die Wiedergabe der Beobachtungen über ihre Lebensweise doch wohl auch hier am Platze, weil sich Notogonia und Liris in ihrem Nestbau und ihren Lebensgewohnheiten von Larra nicht wesentlich unterscheiden dürften.

Maindron berichtet p. 76: „Die Lebensweise von Larrada modesta Smith ist jener der Gattung Pelopoeus sehr ähnlich. Das Nest, welches ich in einem Hause der Stadt Ternate zwischen den Brettern einer Jalousie angebracht sah, hatte $50 \mathrm{~mm}$. Länge bei einer mittleren Breite von $20 \mathrm{~mm}$. Dieser kleine Bau war aus schwarzer Erde fein zusammengeklebt; seine Form war länglich und unregelmässig; er enthielt vier Zellen, deren Anwesenheit sich auch aussen an der vorderen Nestfläche durch ebensoviele Erhabenheiten kundgab. Diese Zellen waren sehr unregelmässig und durch sehr dicke Scheidewände von einander getrennt; ihre Innenwandungen waren geglättet und von jener Art Klebestoff ausgefüttert, mit dem die Sphegiden ihre Bauten zusammenkitten, um sie gegen Feuchtigkeit und vor Zerbröckelung zu schützen. Eine von den Zellen war an der Seite mit einer Oeffnung versehen, welche dem entwickelten Thiere als Ausgang dienen mochte. Seit einiger Zeit hatte ich eine Larrada um das Nest hin und herfliegen sehen; sie flog hinein und schnell 
wieder heraus, endlich fing ich sie. Anfangs glaubte ich, dass das Insect noch an dem Neste arbeite, wurde aber dann von dieser Annahme abgebracht, nachdem ich den Bau bei genauer Prüfung ganz vollendet und mehrere Zellen reichlich mit Spinnen versorgt fand. Es ist klar, dass dieses Insect wie viele Hymenopteren, und wie ich es bei Pelopoeus beobachtet habe, nur darauf bedacht war, die von einem Thiere derselben Art angehäuften Stoffe zu einem neven Baue zu benützen. Jede Zelle enthielt sieben bis acht kleine, gelähmte Spinnen, welche sich in durchaus wohlbehaltenem Zustande befanden und meistens ein Lebenszeichen gaben, indem sie ihre Beine schwach bewegten, wenn man sie stach. Zwei von diesen Zellen waren von Puppen besetzt, eine enthielt eine todte Larve und die andere Reste des Insectes, das vor der Reife zu Grunde gegangen war. Die Puppen sind länglich, regelmässig, unterscheiden sich nur durch ihre Körperform von jenen eines Pelopoeus, mit dem sie die Farbe und das Gewebe gemein haben. Diese Cocons sind $12 \mathrm{~mm}$. lang und 3-4 mm. breit. In einer Zelle dieses Nestes waren also die Reste des vollkommenen Insectes, das vor dem Ausschlüpfen gestorben war, und welches ich für identisch halte mit dem Imago, das ich beim Hin- und Herfliegen im Neste gefangen hatte; endlich entdeckte ich an dem Hinterleibe einer Spinne eine sehr junge, kaum $1 \mathrm{~mm}$. lange Larve, die sie eben zu verzehren anfing. Die erwachsene Larve ist $4 \mathrm{~mm}$. lang und $1 \frac{1}{2} \mathrm{~mm}$. breit, ihre Farbe blassgelb, ins Röthliche, mit feinen weissen Tupfen. Der Körper ist in dreizehn geränderte, an den Seiten ausgerandete Ringe gegliedert. Die zehn mittleren haben Stigmen. Der After ist zweilappig, der Kopf ein wenig durchscheinend, weiss, die Mundwerkzeuge dunkler, in die Länge gezogen; Kopfschild stark ausgehöhlt. Die Stelle, welche die Netzaugen einnehmen werden, ist angedeutet, und auf der Stirne sieht man zwei Nebenaugenrudimente. Der Kopfschild stellt eine halbkreisförmige Ausrandung dar, deren Krümmung nach aufwärts gerichtet ist. Die Lippe ist quer, die Oberkiefer sind bogenförmig und zweizähnig, die Unterkiefer abgerundet und unbewaffnet. Die Unterlippe ist klein und abgerundet. Die allgemeine Gestalt des Kopfes ist von der der Pelopoeus-Larve verschieden; denn bei Larrada ist er verlängert und die zusammengesetzten Augen lassen sich durch zwei Erhöhungen errathen, bei Pelopoeus hingegen ist der Kopf breiter als lang und gleichmässig abgerundet, da der Scheitel keine Erhebung zeigt. Wie alle Sphegiden-Larven ist auch diese an der Vorderseite eingekrümmt, und die Brustringe sind leicht gegen die merklich breiteren Abdominalringe gebeugt. Indessen zeigt sich keine so entschiedene Verschmälerung der Thoraxringe gegen den Kopf hin als bei den Larven von Sphex; sie ist massiger, und die Segmente sind mehr ausgerandet als bei den meisten Insecten derselben Familie. Eine amerikanische derselben Gattung hat nach Smith (Trans. ent. 1852, 2. ser., t. III) verschiedene Gewohnheiten, soll aber mit unserem Insect die Gewohnheit, äussere Nester zu bauen, theilen, was bei den Sphegiden eine seltene Thatsache ist. Dieses Hymenopteron, welches Bates in Süd-Amerika beobachtet hat, baut ein aus Pflanzenresten zusammengeklebtes Nest. Das Nest wird an ein Blatt befestigt und soll nach Angabe des Autors einem Schwammstücke gleichen." 


\section{Larra anathema Rossi.}

Sphex anathema Rossi, Faun. Etrusc., t. II, p. 65, Nr. 822, …........ 1790

Larra ichneumoniformis Fabr., Ent. Syst., t. II, p. 221, Nr. 4, o . . . . . . . . 1798

Larra ichneumoniformis Coqueb., Illustr. Icon. Ins., p. 53, tab. XII, fig. 10, \& . . . . 1801

Larra anathema Coqueb., Illustr. Icon. Ins., p. 53, tab. XII, fig. 11, o . . . . . . . 1801

Larra ichneumoniformis Panz., Faun. Ins. Germ., 76. Heft, fol. 18, †. . . . . . . . . 1801

Larra ichneumoniformis Fabr., Syst. Piez., p. 220, Nr. 4, Ø . . . . . . . . . . 1804

Pompilus teutonus Fabr., Syst. Piez., p. 194, Nr. 34, …. . . . . . . . . . 1804

Larra ichneumoniformis Latr., Hist. nat. gen. et part. des Crust. et Ins., t. XIII, p. 296 - 1805 Liris anathema Illig., Edit. Faun. Etrusc. II, p. 101, Nr. 822, ૧. . . . . . . . . 1807 Larra anathema Latr., Gen. Crust. et Ins., t. IV, p. 70 . . . . . . . . . . . . . 1809 Larra anathema Shuck., Ess. indig. foss. Hym., p. 87, Nr. 1 . . . . . . . . . 1837 Larra anathema Blanchard, Hist. nat. des Ins., t. III, p. 357 . . . . . . . . . . . . . 1840 Larra ichneumoniformis Westwood, Introd. mod. Classif. Ins, vol. II, p. 197, fig. 82, 14 . 1840

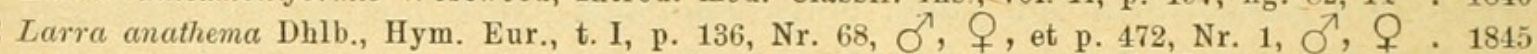
Tachytes anathema Lep., Hist. nat. Ins. Hym., t. III, p. 254, Nr. 17, §’, Larra anathema Eversm., Faun. hym. Volg. Ural (Bull. Mosc.), t. III, p. 386 . . . . . . . 1849 Larra anathema Taschenb., Schlüss. z. Bestimm. (Zeitschr. f. d. ges. Naturw. X), p. 85, $\sigma^{\top}, \bigcap^{1857}$ Larra anathema Schenck, Beschr. d. i. Nassau aufgef. Grabwesp., p. 198, ᄋ' $\sigma^{\top}$, 오 . . . . 1857 Larra anathema Taschenb., Hym. Deutschl., p. 199, o', ….......... 1866 Larra anathema Costa, Ann. Mus. zool. Univ. Napoli (Ann. IV), p. 81, 万人, $\bigcirc^{\circ} 1867$ : Tachytes grandis Chevrier. Hym. div. du Bass. du Lém. (Schweiz. enth. Mitth.), Nr. 12,

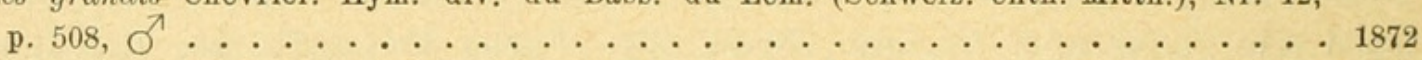
Larra anathema Radoszk, Fedtsch. Reise in Turk, p. 30, Nr. 1 . . . . . . . . . 1877

Long. 10-24 mm. $\sigma^{\top}$, ㅇ. Nigra; scapus antice, plerumque etiam tarsi obscure rufo-picea. Alarum fuscarum squamulae piceae. Segmentum secundum tertium et nonnunquam quartum rufa. Clypeus latus, antice subarcuatim, fere recte truncatus. Antennae crassiusculae. Spatium suprafrontale dense punctatum (L. a), spatium infrafrontale politum nitidissimus. Collare antice praerupte, non tamen directe ad perpendiculum abscissum. Thorax dense, in pleuris paulo sparsius punctatus. Segmentum medianum in area dorsali linea mediana instructum, dense punctulatum, puncta rugulis intermixtis; latera subnitida minus dense punctata; truncatura transverse irregulariter rugosa (L. a).

万. Long. 10-18 mm. Area pygidialis trapeziformis punctata. Abdominis segmenta non polita, pubescentia brevi pruinosa ad margines posticos cinereo-pubescentia. Oculi in vertice longitudine antennarum flagelli articuli primi, secundi et tertii inter se distant.

‥ Long. 16-24 mm. Area pygidialis triangularis convexiuscula polita nitida, punctulis quam sparsissimis punctata (L. a). Abdomen, segmentum medianum exceptum, politum nitidum ad marginem posticum segmentorum in lateribus argenteo-pubescens. Oculi in vertice longitudine antennarum flagelli articuli secundi et tertii distant.

Variat ábdomine toto nigro. Q . Long. 20-22 mm. (Var. melanaria Kohl, Raubwesp. Tirols.)

In Europae, Asiae et Africae regionibus mediterraneis.

Schwarz. Die Vorderseite des Fühlerschaftes und die Tarsenglieder sind oft dunkel pechroth. Am Hinterleibe ist in der Regel nur das zweite und dritte 
Segment selten, mehr oder weniger auch das vierte Segment roth. Uebrigens variirt diese Art mit ganz schwarzem Hinterleibe. (Var. melanaria Kohl.)

@. Der Kopfschild ist sehr breit, aber kurz, punktirt, verläuft vorne nur sehr schwach bogenförmig, so dass man ihn fast gerade abgestutzt nennen könnte; an seinem Vorderrande ist eine Randleiste abgesetzt. Der geringste Abstand der Augen am Scheitel beträgt die Länge des zweiten und dritten Geisselgliedes zusammengenommen. Die Fühler sind kräftig; ihr erstes Geisselglied kommt an Länge etwa dem letzten gleich. Der unter dem queren Stirnwulst liegende Gesichtsraum, dem sich der Fühlerschaft, dessen Länge etwa der Länge der beiden ersten Geisselglieder entspricht, anschmiegen kann, ist ausserordentlich schön polirt und glänzend. Der obere Gesichtsraum, in welchem die Nebenaugen liegen, ist deutlich punktirt (L. a), auch die Wangen sind punktirt, aber feiner. Der Hinterwulst des Pronotums fällt vorne steil, jedoch nicht wie bei L. sumatrana K., einer sehrnahe stehenden Art, senkrecht gegen den Pronotumhals ab. Die Punktirung des Dorsulums ist dicht, aber noch nicht gedrärgt zu nennen (L. $a$ ), jene der Mesopleuren um einen Grad dünner. Die Horizontalfäche des Mittelsegmentes ist dicht punktirt und zugleich auch gerunzelt; in der Mitte wird sie von einer erhabenen Linie durchzogen. Die Mittelsegmentseiten fallen senkrecht ab, glänzen stärker als irgend ein Theil des Mesothorax, und zwar deswegen, weil sie viel dünner und feiner, fast wie die Seiten des Pronotumhalses punktirt sind. Die hinten abfallende Fläche ist sehr unregelmässig gerunzelt oder ungleich steifrunzelig; die Runzeln laufen dann von aussen gegen die Mittelrinne hin, sind nicht vollkommen quergestellt, sondern beiderseits etwas schief nach oben gerichtet. Die übrigen Hinterleibsringe sind beim $q$ polirt glänzend, glatt, ohne Punktirung. Die Dorsalplatten werden hinten, seitlich, von einem weissen Filze bekleidet. Das Pygidialfeld ist ein wenig convex, dreieckig, seitlich durch Kiele abgegrenzt, an deren Innenseite ein schmales Rinnchen läuft, polirt glänzend, und zwar nicht undeutlich (L. a), aber sehr ärmlich punktirt; nicht weit von der Endspitze nimmt man eine Neigung zu einer Längsfältelung wahr. Beim $\sigma^{\top}$ ist der Hinterleib mit einer feinen Pubescenz ausgestattet, nicht polirt glänzend. Ueber die Hinterränder der Dorsalringe ziehen sich ununterbrochene graulichweisse Filzbinden. Die obere Afterklappe ist trapezförmig und punktirt. Es sei ausserdem vom o erwähnt, dass seine Fühler in der Mitte am dicksten sind, sich gegen die Spitze hin mehr als beim $ᄋ$ verjüngen, die geringste Augenentfernung am Scheitel die Länge der drei ersten Geisselglieder ausmacht und die Punktirung der Mittelsegmentseiten gröber ist.

Ueber die Lebensweise von Larra anathema habe ich nirgends etwas Näheres verzeichnet gefunden. Nach Sichel und Radoszkowsky (Monogr. d. Mutill. de l'anc. Cont., Hor. Soc. Ent. Ross. 1870, p. 12 und 73) soll bei L. anathema die Mutilla stridula Rossi (= coronata F.) schmarotzen; dieser Umstand scheint mehr dafür zu sprechen, dass $L$. anathema im Sande nistet und nicht nach Art von Pelopoeus freie Lehmnester baut.

Z. B. Ges. B. XXXIV. Abh. 
Geographische Verbreitung. Wenn der Angabe Tis chbein's (Verzeichn. d. b. Herrstein im Fürstenthume Birkenfeld aufgef. Mordwesp., Stett. Ent. Zeit., Bd. IX, 1850), dass $L$. anathema bei Herrstein, sowie der Angabe Lepeletier's, dass sie am Senegal vorkomme, kein Irrthum zu Grunde liegt, so würde sich ihr Verbreitungsgebiet, da sie ausserdem sowohl in Spanien als auch in Turkestan (Radoszkowsky, Fedtsch. Reise n. Turkest. 1877) zu finden ist, ungefähr zwischen dem 16. Grad und 54. Grad nördlicher Breite und dem 10. Grad und 90. Grad ǒstlicher Länge ausdehnen. In diesem Gebiete liegen die Fundorte: Oran (Lep.), Tanger, Barcelona, Montpellier (Sichel), Toulon, Nyon (Chevrier), Umgebung von Bozen (Gummer ${ }^{4} / 9$, Gries, St. Justina $28 / 7$, Rodlerau 12/7, Rentsch auf Foeniculum ${ }^{13} / 7$ ), Levico bei Trient ( $\mathrm{K} \circ \mathrm{hl}$ ), Rákoson, Szeged, Debreczen, Zilah (Ungarn 7, 8, Mocs.), Mehadia, Amasia (Mann). Ferner wurde sie aus Dalmatien (Frauenfeld), aus dem Gebiete der unteren Wolga (Eversmann), Toscana (Rossi), überhaupt dem ganzen continentalen Italien (Costa) und aus Sicilien und Sardinien bekannt; auf Sicilien und Sardinien soll sie nach Costa selten sein.

\section{Verzeichniss der bisher beschriebenen Larra-Arten.}

(Larra wird hier im Sinne der Larrada Smith's genommen; wo die engere Gattung ganz unzweifelhaft festgestellt werden konnte, wurde sie in Parenthese hinzugefügt.)

L. abdominalis Guer. Reg. II, Subreg. 1. Abyssinien,

Larra abdominalis Guer.: Voy. en Abyss. IV, 6. Ins., p. 358, Taf. VIII, Fig. 7.

L. acuta Patton. Reg. IV, Subreg. 3. Waterbury.

Larra acuta Patton: Proc. Boston Soc. N.-H. XX, 1880, p. 390.

L. aedilis Smith. + . Reg. VI, Subreg. 1. Celebes.

Larrada aeditis Smith: Journ. of Proc. Linn. Soc. Zool. III, 1858, p. 16, Nr. 3, ㅇ.

L. aethiops Smith (non Cress.). \&. Reg. V, Subreg. 2. St. Paulo.

Larrada aethiops Smith: Ann. et Mag. of N.-H. XII, 1873, p. 56, 오.

L. aethiops Cress. (non Smith). \&, б' Reg. IV, Subreg. 3. Colorado.

Larrada aethiops Cress.: Proc. Ent. Soc. Philadelph. IV, 1865, p. 465, ㅇ․

Larra aethiops Patt.: Bull. Un. Geol. Surv. V, 1879, p. 354, ठౌ.

L. agilis Smith. 오. Reg. II, Subreg. 1. Gambia.

Larrada agilis Smith: Catal. Hym. Brit. Mus. IV, 1856, p. 284, Nr. 34, 우.

L. Alecto Smith. ㅇ. Reg. III, Subreg. 4. Singapore.

Larrada Alecto Smith: Journ. of Proc. Linn. Soc. Zool. II, 1857, p. 103, Nr. 6, ㅇ.

L. americana Cress. (non Sauss.). $\sigma^{\top}$. Reg. IV, Subreg. 3. Texas.

Larrada americana Cress.: Trans. Amer. Ent. Soc. IV, 1872, p. 214, ठð. 
L. americana Sauss. (non Cress.). ㅇ, $\varnothing^{\nearrow}$. Reg. V, Subreg. 2. Venezuela (Caracas), Brasilia.

Larrada americana Sauss.: Reise d. „Novara“, Zool. II, 1867, p. 74, Nr. 4, ㅇ, $0^{\top}$.

L. amplipennis Smith. $\sigma^{7}$. Reg. I, Subreg. 4. Japonia.

Larrada amplipennis Smith: Trans. Ent. Soc. Lond., 1873, p. 193, o'.

L. analis Fabr. Reg. IV, Subreg. 3. Carolina, Delawara.

Larra analis Fabr.: Syst. Piez. 1804, p. 220, Nr. 8.

L. (Larra) anathema Rossi. ㅇ, ơ. Reg. I, Subreg. 2. Eur. merid., Afr. bor. Sphex anathema Rossi: Faun. Etrusc. II, 1791, p. 65, Nr. 822, ㅇ.

L. angustata Taschenb. ㅇ. Reg. V, Subreg. 2. Lagoa santa.

Larrada angustata Taschenb.: Zeitschr. f. d. ges. Naturw. XXXVI, 1876 (p. 6), Nr. 12.

L. antica Smith. $\sigma^{\nearrow}$. Reg. V, Subreg. 2. Brasilia, Amazon.

Larrada antica Smith: Catal. Hym. Brit. Mus. IV, 1856, p. 287, Nr. 45, o'.

L. appendiculata Taschenb. O. Reg. V, Subreg. 2. Congonh.

Larrada appendiculata Taschenb.: Zeitschr. f. d. ges. Naturwissensch. XXXVI, 1870 , p. 7 , Nr. 15 , 오.

L. arcuata Smith. Q. Reg. IV, Subreg. 4. Canada.

Larrada arcuata Smith: Catal. Hym. Brit. Mus. IV, 1856, p. 293, Nr. 64, ᄋ.

L. argentata Palis. Reg. IV, Subreg. 3. Unit.-Staat.

Larra argentata Palis: Ins. Afr. et Amer. 1805, p. 119, Taf. III, Fig. 9.

Lyrops argentata Say: Journ. N.-H. I, 1836, p. 370.

L. argyrea Smith. ㅇ. Reg. III, Subreg. 1. Ind. bor.

Larrada argyrea Smith: Catal. Hym. Brit. Mus. IV, 1856, p. 276, Nr. 8, ㅇ.

L. (Notogonia) argyropyga Costa. ㅇ, ơ. Reg. I, Subreg. 2. Aegyptia.

Notogonia argyropyga Costa: Atti d. Accad. fis. e mat. Napoli VII, 1875 (p. 16), 우, $0^{\top}$.

L. aterrima Smith. ?. Reg. II, Subreg. 3. Cap. (Reg. I, Subreg. 2. Tunis [Megerdah]?).

Larrada aterrima Smith: Catal. Hym. Brit. Mus. IV, 1856, p. 282, Nr. 27, ㅇ.

? Larrada aterrima Gribodo: Ann. Mus. Civ. Genova XV, p. 402, 1880, ठ․ L. (Liris) rurata Fabr. ㅇ, o’. Reg. II, Subreg. 2 und 3. Gambia, Cap. Reg. III,

Subreg. 1-4. India, Sumatra, Java, Philippinen. Reg. VI, Subreg. 1. Celebes.

Sphex aurata Fabr.: Ent. Syst. II, 1793, p. 213, Nr. 64.

Pompilus auratus Fabr.: Suppl. Ent. Syst. 1798, p. 250, Nr. 25.

Liris aurata Fabr.: Syst. Piez. 1804, p. 228, Nr. 3.

Lyrops auratus Guer.: Icon. Regn. Anim. III, 1843, p. 440 !

Liris aurata Dhlb.: Hym. Eur. I, 1845, p. 135.

Tachytes opulenta Pel.: Hist. Nat. Ins. Hym. III, 1845, p. 246, Nr. 7, ㅇ, o’' 
L. aurifrons Smith. $\sigma^{7}$. Reg. VI, Subreg. 1. Celebes.

Larrada aurifrons Smith: Journ. of Proc. Linn. Soc. Zool. III, 1858, p. $16, \mathrm{Nr} .4, \sigma^{7}$.

L. Belfragei Cress. ‥ Reg. IV, Subreg. 3. Texas.

Larrada Belfragei Cress.: Trans. Amer. Ent. Soc. IV, 1872, p. 215, \&.

L. (Liris) Braueri Kohl. ㅇ, ơ. Reg. I, Subreg. 2. Tor.

Larra (Liris) Braueri Kohl: Verhandl. d. k. k. zool.-bot. Gesellsch. Wien XXXIII, 1883, p. 256, Nr. 2, 오, o’.

L. (Liris) brunneipes Cress. Reg. IV, Subreg. 3. Colorado.

Liris brunneipes Cress.: Trans. Amer. Ent. Soc. IX, 1881, Proc. p. III.

L. campestris Smith. \&. Reg. V, Subreg. 2. Brasilia, Villa nuova.

Larrada campestris Smith: Catal. Hym. Brit. Mus. IV, 1856, p. 286, Nr. 42.

L. canescens Smith. \&. Reg. IV, Subreg. 3. Georgia.

Larrada canescens Smith: Catal. Hym. Brit. Mus. IV, 1856, p. 292, Nr. 62 , ㅇ.

L. carbonaria Smith. ㅇ. Reg. III, Subreg. 4. Singapore.

Larrada carbonaria Smith: Journ. of Proc. Linn. Soc. Zool. II, 1857, p. 102, Nr. 2, ㅇ.

L. chrysobapta Smith. \&. Reg. VI, Subreg. 1. Celebes, Tondano.

Larrada chrysobapta Smith: Journ. of Proc. Linn. Soc. Zool. VI, 1861, p. 56 , ㅇ.

L. chrysonota Smith. \&. Reg. VI, Subreg. 2. Champion Bay.

Larrada chrysonota Smith: Trans. Ent. Soc. Lond., 1869, p. 305, ㅇ.

L. (Notogonia) ciliata Smith. ․ Reg. II, Subreg. 3. Cap.

Larrada ciliata Smith: Catal. Hym. Brit. Mus. IV, 1856, p. 283, Nr. 31, ․ .

L. clypeata Smith. \&. Reg. VI, Subreg. 3. Neu-Caledonia.

Larrada clypeata Smith: Ann. et Mag. of N.-H. XII, 1873 (p. 11), 오.

L. coelesiina Smith. ㅇ. Reg. III, Subreg. 3. China, Hong-Kong.

Larrada coelestina Smith: Ann. et Mag. of N.-H. XII, 1873 (p. 11), ㅇ.

L. conspicua Smith. ㅇ. Reg. III, Subreg. 1. India.

Larrada conspicua Smith: Catal. Hym. Brit. Mus. IV, 1856, p. 276, Nr. 7, Q.

L. coronalis Smith. \&. Reg. V, Subreg. 2. Brasilia, Villa nuova, Amazon.

Larrada coronalis Smith: Catal. Hym. Brit. Mus. IV, 1856, p. 287, Nr. 43 , ㅇ.

L. Cowani Kirby. Reg. VI, Subreg. 4. Neu-Seeland.

Larrada Cowani Kirby: Trans. Ent. Soc. p. 200, 1883.

L. crassipes Smith. \&, or. Reg. VI, Subreg. 2. Austral. mer.

Larrada crassipes Smith: Ann. et Mag. of N.-H. XII, 1873 (p. 12), 오.

L. Croesus Smith. \&. Reg. II, Subreg. 1. Gambia.

Larrada Croesus Smith: Catal. Hym. Brit. Mus. IV,1856, p. 284, p. 35, ㅇ. 
L. decorata Smith. Q. Reg. V, Subreg. 2. Brasilia, Parà.

Larrada decorata Smith: Catal. Hym. Brit. Mus. IV, 1856, p. 287, Nr. 44, ㅇ.

L. (Notogonia) deplanata Kohl. ‥ Reg. III, Subreg. 2. Ceylon.

Notogonia deplanata Kohl: Verhandl. d. k. k. zool.-bot. Gesellsch. Wien, 1883 , p. 358, Nr. 2, .

L. diabolica Smith. . Reg. II, Subreg. 2 und 3. Sierra Leone, Port Natal. Larrada diabolica Smith: Ann. et Mag. N.-H. XII, 1873 (p. 11), ㅇ.

L. distincta Smith. 우 , ${ }^{7}$. Reg. IV, Subreg. 3. New-York.

Larrada distincta Smith: Catal. Hym. Brit. Mus. IV, 1856, p. 292, Nr. 60 , ㅇ.

Larra distincta Patt.: Proc. Boston Soc. N.-H. XX, 1880, p. 390, 오, $0^{7}$.

L. distinguenda Spin. $\$$, $\sigma^{7}$. Reg. V, Subreg. 2. Cayenne.

Larra distinguenda Spin.: Ann. Soc. Ent. Fr. X, 1841, p. 112, 오, $\sigma^{7}$

L. diversa Walk. O. Reg. I, Subreg. 2. Cairo.

Larrada diversa Walk.: List. of Hym. Egypt. 1871, p. 21, Nr. 105, ᄋ, ठ $\sigma^{\top}(?)$.

L. divisa Patt. . . Reg. IV. Subreg. 3. Kansas.

Larra divisa Patt.: Bull. U.-St. Geol. Surv. V, 1879, p. 368, ㅇ.

L. docilis Smith. Q. Reg. I, Subreg. 4. Japonia, Hiogo, Hakodadi.

Larrada docilis Smith: Trans. Ent. Soc. Lond. 1873, p. 192,, .

L. (Liris) ducalis Smith. Q. Reg. VI, Subreg. 1. Makassar.

Larrada ducalis Smith: Journ. of Proc. Linn. Zool. V, 1860, p. 84, ㅇ.

L. Erebus Smith. \&. Reg. I, Subreg. 4. Japonia, Hiogo.

Larrada Erebus Smith: Trans. Ent. Soc. Lond. 1873, p. 193, q.

L. exilipes Smith. $\sigma^{7}$. Reg. III, Subreg. 1. Ind. bor.

Larrada exilipes Smith: Catal. Hym. Brit. Mus. IV, 1856, p. 278, Nr. $13,0^{\top}$.

L. extensa Walk. Reg. III, Subreg. 2. Ceylon.

Larrada extensa Walk.: Ann. et Mag. of N.-H. (3) V, 1860, p. 504.

L. facilis Smith. Q. Reg. V, Subreg. 2. Ega.

Larrada facilis Smith: Ann. et Mag. of N.-H. XII, 1873, p. 56.

L. fasciata Smith. ㅇ. Reg. V, Subreg. 2. St. Paulo, Amazon.

Larrada fasciata Smith: Ann. et Mag. of N.-H. XII, 1873, p. 55.

L. (Notogonia) femorata Sauss. ९, Oð. Reg. VI, Subreg. 2. Nova Hollandia, Tasmania.

Tachytes femorata Sauss.: Mem. Soc. Phys. Genève XIV, 1, 1854, p. 20, Nr. 9, Taf. I, Fig. 6, o"!

Larrada femoralis Smith: Catal. Hym. Brit. Mus. IV, 1856, p. 285, Nr. 38, ㅇ.

Larrada femoralis Sauss.: Reise d. Novara, Zool. II, 1867, p. 74, Nr. 2, $0^{7}$, 오. 
L. ferox Smith. ‥ Reg. II, Subreg.? Africa.

Larrada ferox Smith: Ann. et Mag. of N.-H. XII, 1873 (p. 11), ․․

L. ferrugineipes Pel. $\subsetneq$. Reg. II, Subreg. 1. Senegal, Congo.

Tachytes ferrugineipes Pel.: Hist. nat. Ins. Hym. III, 1845, p, 248, Nr. 11, ㅇ.

L. festinans Smith. $Q, \sigma^{\nearrow}$. Reg. VI, Subreg. 1. Celebes.

Larrada festinans Smith: Journ. of Proc. Linn. Soc. Zool. III, 1858, p. 17, Nr. 7, ㅇ, $\sigma^{7}$.

L. fuliginosa Dhlb. @, $\sigma^{\top}$. Reg. V, Subreg. 4. Cuba.

Larra fuliginosa Dhlb.: Hym. Eur. I, 1845, p. 138 und 472, Nr. 3, 오, $\sigma^{\prime}$.

? Larrada Dahlbomi Cress. : Proc. Ent. Soc. Philadelphia IV, 1865, p. 138.

L. funerea Smith: \&. Reg. VI, Subreg. 1. Waigiou.

Larrada funerea Smith: Journ. of Proc. Linn. Soc. Zool. VII, 1863, p. 34 , ㅇ. .

L. fulvipes Smith. ‥ Reg. V, Subreg. 2 und 4. Brasilia, Jamaica, St. Domingo.

Larrada fulvipes Smith: Catal. Hym. Brit. Mus. IV, 1856, p. 288, Nr. 47 , ․

L. fulviventris Guer. Reg. V, Subreg. 4. Cuba.

Lyrops fulviventris Guer.: Iconogr. Regn. Anim. III, 1843, p. 440.

Lyrops fulviventris Sagra: Hist. Cuba VII, 1857, p. 320, Taf. XVIII, Fig. 9.

L. gastrica Taschenb. + , $ఠ$. Reg. V, Subreg. 2. Parana, Panda orient, Venezuela.

Larrada gastrica Taschenb.: Zeitschr. f. d. ges. Naturwissensch. XXXVI, 1870 (p. 5), Nr. 10, ㅇ, $\sigma^{\nearrow}$

L. glabrata Smith. + . Reg. VI, Subreg. 1. Celebes.

Larrada glabrata Smith: Catal. Hym. Brit. Mus. IV, 1856, p. 279, Nr. 14, ㅇ. .

L. (Liris) haemorrhoidalis Fabr. 오, $\sigma^{\nearrow}$. Reg. I, Subreg. 2. Aegyptia, Eur. merid. Reg. II, Subreg. 1 und 2. Sierra Leone, Gambia, Mozambique.

Pompilus haemorrhoidalis Fabr.: Syst. Piez. 1804, p. 198, Nr. 55.

L. jaculator Smith. ‥ Reg. III, Subreg. 1. Bengal. bor.

Larra jaculator Smith: Catal. Hym. Brit. Mus. IV, 1856, p. 279, Nr. 15, ㅇ․

L. (Notogonia) japonica Kohl. @. Reg. I, Subreg. 4. Japonia.

Larra (Notogonia) japonica Kohl: Verhandl. d. k. k. zool.-bot. Gesellsch. Wien, XXXIII, 1883, p. 357, ㅇ․

L. ignipennis Smith. ․ Reg. V, Subreg. 4. St. Domingo.

Larrada ignipennis Smith: Catal. Hym. Brit. Mus. IV, 1856, p. 288, Nr. 48,

Larrada ignipennis Cress. : Proc. Ent. Soc. Philadelphia IV, 1865, p. 137, ㅇ. .

L. (Notogonia) insularis Sauss. ․ Reg. III, Subreg. 3. Nicobaren.

Larrada insularis Sauss.: Reise d. „Novara“, Zool. II, 1867, p. 73, Nr. 1, ㅇ! ! 
L. irrorata Smith. + . Reg. II, Subreg. 1. Senegal.

Larrada irrorata Smith: Catal. Hym. Brit. Mus. IV, 1856, p. 284, Nr. 33, Q.

L. laboriosa Smith. \&. Reg. III, Subreg. 4. Philippinen.

Larrada laboriosa Smith: Catal. Hym. Brit. Mus. IV, 1856, p. 278, Nr. 12, ㅇ․

L. laevifrons Smith. + . Reg. IV, Subreg. 3. Florida.

Larra laevifrons Smith: Catal. Hym. Brit. Mus. IV, 1856, p. 291, Nr. 57.

L. laterisetosa Spin. Reg. V, Subreg. 2. Brasilia, Parà.

Larra laterisetosa Spin.: Mem. Accad. sc. Torino (2), XIII, 1853, p. 58, Nr. 41.

L. limpidipennis Smith. ‥ Reg. V, Subreg. 1. Parà.

Larrada limpidipennis Smith: Ann. et Mag. of N.-H. XII, 1873, p. 57.

L. Iuctuosa Smith. + . Reg. V, Subreg. 2 und 4. St. Domingo, Brasilia.

Larrada Iuctuosa Smith: Catal. Hym. Brit. Mus. IV, 1856, p. 289, Nr. 50, ㅇ.

L. (Liris?) luteipennis Cress. $\sigma^{\top}$. Reg. V, Subreg. 4. Cuba.

Liris luteipennis Cress.: Trans. Amer. Ent. Soc. II, 1869, p. 293, ठ $\sigma^{\nearrow}$

L. (Liris) magnifica Kohl. Q. Reg. VI, Subreg. 2. Nord-Australien.

Larra (Liris) magnifica Kohl: Verhandl. d. k. k. zool.-bot. Gesellsch.

Wien, XXXIII, 1883, p. 256, @.

L. mansueta Smith. \&. Reg. VI, Subreg. 1. Gilolo.

Larrada mansueta Smith: Journ. of Proc. Linn. Soc. Zool. VIII, 1864, p. 84, Nr. 2.

L. maura Fabr. ㅇ. Reg. III, Subreg. 4. Tranquebar.

Sphex maura Fabr.: Ent. Syst. II, 1793, p. 212, Nr. 55.

Pompilus maurus Fabr.: Suppl. Ent. Syst. 1798, p. 247, Nr. 11.

Liris maura Fabr.: Syst. Piez. 1804, p. 230, Nr. 10.

Larrada maura Smith: Catal. Hym. Brit. Mus. IV, 1856, p. 277, Nr. 9.

L. (Larra) melanoptera Kohl. O. . Reg. II, Subreg. 4. Mauritius.

Larra melanoptera Kohl: Verhandl. d. k. k. zool.-bot. Gesellsch. Wien, XXXIII, 1883 , p. 253, ㅇ.

L. memnonia Smith. \&. Reg. I, Subreg. 2. Aegyptia. Reg. II, Subreg. 1. Senegal. Larrada Memnonia Smith: Catal. Hym. Brit. Mus. IV, 1856, p. 281, Nr. 25, ㅇ․

L. mendax Smith. ㅇ. Reg. VI, Subreg. 1. Gilolo.

Larrada mendax Smith: Journ. of Proc. Linn. Soc. Zool. VIII, 1864, p. 84, Nr. 3 , ㅇ.

L. modesta Smith. 으, $\sigma^{\nearrow}$. Reg. VI, Subreg. 1. Aru, Salwatty.

Larrada modesta Smith: Journ. of Proc. Linn. Soc. Zool. III, 1858, p. $159,+$ ㅇ, $0^{7}$. 
L. montana Cress. Q. Reg. IV, Subreg. 3. Colorado.

Larrada montana Cress.: Proc. Ent. Soc. Philadelphia IV, 1865, p. 465, $Q$.

Larrada parvula Cress.: Ibid. p. 465, $\sigma^{\nearrow}$.

L. (Notogonia) nigra Lind. ㅇ, $\sigma^{\top}$. Reg. I, Subreg. 1 und 2. Eur., Afr. bor. Larra nigra Lind.: Nouv. Mem. Acad. Bruxelles IV, 1827, p. 23, Nr. 6, 오, $\sigma^{\top}$.

L. nigricans Smith. @. Reg. I, Subreg. 4. Nagasaki.

Larrada nigricans Smith: Trans. Ent. Soc. Lond., 1873, p. 192, ㅇ. .

L. (Notogonia) nigricans Walk. 오 $\sigma^{\nearrow}$. Reg. I, Subreg. 2. Cairo, Hor Taminal. Larra nigricans Walk.: List of Hym. Egypt. 1871, p. 21, Nr. 102, 오, $\sigma^{\top}$

L. nigripes Sauss. $q$. Reg. VI, Subreg. 2. Tasmania.

Larrada nigripes Sauss.: Reise d. „Novara“, Zool. II, 1867, p. 74, Nr. 3.

L. nigrita Pel. $Q$, o $\sigma^{\top}$. Reg. I, Subreg. 2. Oran, Madeira.

Tachytes nigrita Pel.: Hist. Nat. Ins. Hym. III, 1845, p. 240, Nr. 2, 우, б’

L. nitidiuscula Smith. ㅇ. Reg. V, Subreg. 4. Brasilia, Santarem.

Larrada nitidiuscula Smith: Catal. Hym. Brit. Mus. IV, 1856, p. 289, Nr. 51 , ㅇ.

L. nuda Taschenb. ‥ Reg. V, Subreg. 2. Venezuela.

Larrada nuda Taschenb.: Zeitschr. f. d. ges. Naturwissensch. XXXVI, 1870 (p. 5), Nr. 6, ․․

L. obliqua Smith. \&. Reg. II, Subreg. 3. Cap.

Larrada obliqua Smith: Catal. Hym. Brit. Mus. IV, 1856, p. 281, Nr. 26, 우.

L. pagana Dhlb. $\&$, ${ }^{\top}$. Reg. V, Subreg.? Ins. St. Cruz.

Tachytes pagana Dhlb.: Hym. Eur. I, 1845, p. 132, @, o’.

? Larra bicolor Fabr.: Syst. Piez.1804, p. 112, Nr. 12.

? Larra bicolor Dhlb.: Hym. Eur. I, 1845, p. 471, Patton:Proc.Boston Nr. 15.

?Larra americana Sauss.: Reise d. „Novara“, Zool.II, $\{$ Soc. N.-H.XX, 1880.
1867, p. 74 .

L. pallipes Smith. ठ․ Reg. II, Subreg.? Afrika.

Larrada pallipes Smith: Catal. Hym. Brit. Mus. IV, 1856, p. 282, Nr. 28, ठ’

L. pensylvanica Palis. Reg. VI, Subreg. 3. Florida.

Larra pensylvanica Palis: Ins. Afr. et Amer. 1805, p. 118, Taf. III, Fig. 8.

L. personata Smith. $ᄋ$, $\sigma^{\top}$. Reg. VI, Subreg. 1. Celebes.

Larrada personata Smith: Journ. of Proc. Linn. Soc. Zool. III, 1858, p. $16, \mathrm{Nr} .4$, 우 $\sigma^{7}$.

L. plebeja Taschenb. ㅇ, $\sigma$. Reg. V, Subreg. 2. Lagoa Santa.

Larrada plebeja Taschenb.: Zeitschr. f. d. ges. Naturwissensch. XXXVI, 1870 (p. 4), Nr. 5, Q, 万’.

L. polita Smith. Q. Reg. III, Subreg. 4. Borneo, Sarawak.

Larrada polita Smith: Journ. of Proc. Linn. Soc. Zool. II, 1857, p. 102, Nr. 4. 
L. polita Taschenb. Reg. V, Subreg. 2. Cogonh.

Larrada polita Taschenb.: Zeitschr. f. d. ges. Naturwissensch. XXXVI, 1870 , p. 3 , Nr. 3.

L. pruinosa Smith. ‥ Reg. V, Subreg. 2. Brasilia, Ega.

Larrada pruinosa Smith: Ann. et Mag. of N.-H. XII, 1873, p. 56.

L. (Larra) psilocera Kohl. \&. Reg. VI, Subreg. 2. Austral.

Larra psilocera Kohl: Verhandl. d. k. k. zool.-bot. Gesellsch. Wien, XXXIII, 1883 , p. 355 , ․․

L. punctata Smith. Q. Reg. II, Subreg. 3. Cap.

Larrada punctata Smith: Catal. Hym. Brit. Mus. IV, 1856, p. 282, Nr. 29, ㅇ․

L. quadrifasciata Smith. Q. Reg. V, Subreg. 2. Brasilia, Santarem.

Larra quadrifasciata Smith: Catal. Hym. Brit. Mus. IV, 1856, p. 289, Nr. 52 , ㅇ.

L. rubella Smith. Q. Reg. II, Subreg. 2. Fernando Po.

Larrada rubella Smith: Catal. Hym. Brit. Mus. IV, 1856, p. 280, Nr. 19, $q$.

I. mubricata Smith. . . Reg. V, Subreg. 2. Brasilia, Para.

Larrada rubricata Smith: Catal. Hym. Brit. Mus. IV, 1856, p. 286, Nr.41, $q$.

I. rufipes Smith. + , $\sigma$. Reg. VI, Subreg. 1. Celebes.

Larrada rufipes Smith: Journ. of Proc. Linn. Soc. Zool. III, 1858, p. 17, Nr. 6, ㅇ, $\sigma^{\nearrow}$.

L. sabulosa Smith. $\subsetneq$. Reg. VI, Subreg. 1. Ceram.

Larrada sabulosa Smith: Journ. of Proc. Linn. Soc. VII, 1863, p. 35, q.

L. semiargentea Taschenb. Q. Reg. V, Subreg. 2. Amer. merid.

Larrada semiargentea Taschenb.: Zeitschr. f. d. ges. Naturwissensch. XXXVI, 1870 (p. 3), Nr. 4, ㅇ.

L. semirufa Cress. †. Reg. IV, Subreg. 3. Colorado.

Larrada semirufa Cress.: Proc. Ent. Soc. Philadelphia IV, 1865, p. 464, ․․

Larra semirufa Pack.: 1. Rep. U.-S. Ent. Comn. 1878, p. 318, Fig. 55 u. 56.

L. sericea Smith. 오. Reg. II, Subreg. 1. Gambia.

Larrada sericea Smith: Catal. Hym. Brit. Mus. IV, 1856, p. 285, Nr. 36, . .

L. simillima Smith. . . Reg. II, Subreg.? Africa. Reg. III, Subreg. 1. Indien.

Larrada simillima Smith: Catal. Hym. Brit. Mus. IV, 1856, p. 275, Nr. 5,. .

L. solstitialis Smith. . . Reg. II, Subreg. 3. Port Natal.

Larrada solstitialis Smith: Catal. Hym. Brit. Mus. IV, 1856, p. 283, Nr. 30, . .

L. subfasciata Walk. ‥ Reg. II, Subreg. 1. Dahleck.

Larrada subfasciata Walk.: List of Hym. Egypt. 1871, p. 21, Nr. 103.

L. subpetiolata Smith. \&. Reg. V, Subreg. 2. Brasilia, Villa nova.

Larrada subpetiolata Smith: Catal. Hym. Brit. Mus. IV, 1856, p. 290, Nr. 53 , + . 
L. subtesselata Smith. ‥ Reg. III, Subreg. 1 und 4. India, Sumatra, Java. Larrada subtesselata Smith: Catal. Hym. Brit. Mus. IV, 1856, p. 277, Nr. 11, ㅇ.

L. (Larra) sumatrana Kohl. ૧. Reg. III, Subreg. 4. Sumatra.

Larra sumatrana Kohl: Verhandl. d. k. k. zool.-bot. Gesellsch. Wien, XXXIII, 1883, p. 354, ․․

L. sycorax Smith. ․ Reg. III, Subreg. 4. Borneo, Sarawak.

Larrada sycorax Smith: Journ. of Proc. Linn. Soc. Zool. II, 1857, p. 102, Nr. 3, ㅇ.

L. tarsata Smith. $q$. Reg. VI, Subreg. 1. Batchian.

Larrada tarsata Smith: Journ. of Proc. Linn. Soc. Suppl. IV, 1860, p. 124, ㅇ․

L. tenebrosa Smith. ㅇ. Reg. V, Subreg. 2. Brasilia, Ega.

Larrada tenebrosa Smith: Ann. et Mag. of N.-H. XII, 1873, p. 56, ㅇ.

L. tenuicomis Smith. \&. Reg. IV, Subreg. 2. California.

Larrada tenuicornis Smith: Catal. Hym. Brit. Mus. IV, 1856, p. 293, Nr. 63, ㅇ․

L. terminata Smith. $\sigma^{\top}$. Reg. IV, Subreg. 3. Trenton-Falls.

Larrada terminata Smith: Catal. Hym. Brit. Mus. IV, 1856, p. 291, Nr. 58.

L. texana Cress. + . Reg. IV, Subreg. 2. Texas.

Larrada texana Cress.: Trans. Amer. Ent. Soc. IV, 1872, p. 214, 우.

L. tisiphone Smith. q. Reg. III, Subreg. 4. Borneo.

Larrada Tisiphone Smith: Journ. of Proc. Linn. Soc. Zool. II, 1857, p. 103 , Nr. 5 , 우.

L. tisiphone Smith. $q$. Reg. I, Subreg. 4. Nagasaki.

Larrada Tisiphone Smith: Trans. Ent. Soc. Lond. 1873, p. 193, 오.

L. trifasciata Smith. $q$. Reg. V, Subreg. 2. St. Domingo.

Larrada trifasciata Smith: Catal. Hym. Brit. Mus. IV, 1856, p. 290, Nr. 54, ㅇ․

L. tristis Smith. Q. Reg. III, Subreg. 4. Borneo.

Larrada tristis Smith: Catal. Hym. Brit. Mus. IV, 1856, p. 277, Nr. 10, ㅇ.

L. truncata Smith. $q$. Reg. V, Subreg. 2. Brasilia.

Larrada truncata Smith: Catal. Hym. Brit. Mus. IV, 1856, p. 290, Nr. 35, ㅇ․ .

L. vestita Smith. $q$. Reg. III, Subreg. 1. India bor.

Larrada vestita Smith: Ann. et Mag. of N.-H. XII, 1873 (p. 11), ㅇ․

L. vigilans Smith. ㅇ. Reg. III, Subreg. 3. China.

Larrada vigilans Smith: Catal. Hym. Brit. Mus. IV, 1856, p. 279, Nr. 16, 우.

L. vindex Smith. Q. Reg. VI, Subreg. 1. Batchiau.

Larrada vindex Smith: Journ. of Proc. Linn. Soc. Suppl. IV, 1860, p. 123, 우.

L. vinulenta Cress. Reg. V, Subreg. 4. Cuba.

Larrada vinulenta Cress.: Proc. Ent. Soc. Philadelphia IV, 1865, p. 138.

L. Vollenhovia Rits. Reg. II, Subreg. 2. Nieder-Guinea.

Larrada Vollenhovia Rits.: Tijdschr. v. Entom. XVII, 1874, 194, Taf. XI,

Fig. 5. 


\section{Gen. Notogonia.}

$<$ Tachytes Dhlb., Hym. Eur., t. I, Tab. exam. syn. spec. Larr., p. 468, 28. Gen. . . . . 1845

$<$ Tachytes Lep., Hist. nat. Ins. Hym., t. III, p. 239 . . . . . . . . . . . . . . . 1845

$<$ Tachytes Sauss., Mél. Hym. (Mém. Soc. Phys., Fasc. I, Génève), p. 20, Gruppe III . . 1854

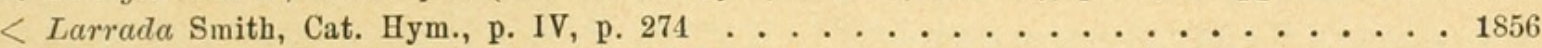

$<$ Tachytes Schenck, Jahrb. d. Ver. f. Naturk. Nassau, XII, 189 . . . . . . . . . . 1857

$<$ Tachytes Taschenberg, Schlüss. z. Bestimm. d. i. Deutschl. aufgef. Mordwesp. (Zeitschr.

f. d. ges. Naturwiss. X), p. 83 . . . . . . . . . . . . . 1857

Tachytes Taschenberg, Hym. Deutschl., 9. Fam. Sphec., p. 200 . . . . . . . 1866

$<$ Larrada Sauss., Reise d. österr. Freg. „Novara“, Bd. IJ, p. 73 . . . . . . . . . . . 1867

Notogonia Costa, Ann. Mns. zool. Univ. Napoli (Ann. IV), p. 80 et 82. . . 1867

$<$ Larrada Taschenberg, Larr. u. Bemb. d. zool. Mus. Halle (Zeitschr. f. d. ges. Naturw.,

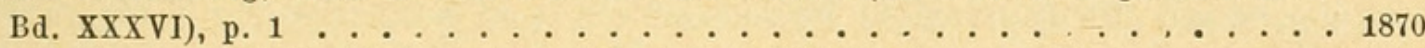

Larra Patton, List of North Amer. Larr. (Bost. Soc. Nat. Hist., vol. XX), p. 385 . . . 1880

Kopf ein wenig breiter als das Bruststück. Oberkiefer mit einem Ausschnitte in der Nähe der Mitte ihrer unteren Aussenkante und einem Zahne am Innenrande zwischen der Mitte und der Basis. Oberkieferspitze einfach. Gesichtsfilz ärmlich, nie besonders auffallend. Fühler schlanker als bei voriger Gattung, ihr zweites Geisselglied länger als die übrigen. Augen gegen den Scheitel hin convergent; Convergenz beim $\sigma^{\top}$ grösser als beim $\$$, bei den verschiedenen Arten verschieden, im Allgemeinen stärker als bei Larra. Bezüglich der leistenartigen Auftreibungen auf der Stirne und der Beschaffenheit der Nebenaugen stimmt Notogonia mit Larra und beiden folgenden Gattungen überein. Der Hinterwulst des Pronotums ist schmäler als bei Larra und zum Unterschiede davon unter das Dorsulum herabgedrückt, und zwar gegen die Seiten hin stärker als in der Mitte, so dass es fast dreieckig aussieht.

Vorderflügel wie bei Larra, mit einer breit abgestutzten und mit einer Anhangszelle ausgerüsteten Radialzelle, drei Cubitalzellen von den nämlichen Form- und Grössenverhältnissen wie bei Larra; die beiden Discoidalqueradern endigen an der zweiten Cubitalzelle, bei manchen Arten in einem Punkte an der Cubitalader. Die Beine sind verhältnissmässig länger als bei den LarraArten, daher die fast Pompilus-artige Tracht, kräftig bedornt. Mittelhüften von einander weit abstehend. Mittelschienen einspornig. Vorderschienen, abgesehen von ihren Enddornen und einem nicht weit von der Mitte ihrer Innenseite sitzenden Dorne, unbewehrt. Der Wimpernkamm der Vordertarsen (ㅇ) wird von einer nur mässigen Anzahl von Dornen gebildet, welche meistens nicht besonders lang sind und nur bei ganz wenigen Arten, z. B. Notogonia (Larrada) ciliata Smith (Cat. Hym., P. IV, p. 283, Nr. 31, 1856) eine aussergewöhnliche Mächtigkeit erreichen. Die Hinterschienen zeigen zwar nicht immer, aber doch bei den allermeisten Arten zwei scharfe Längskanten, denen Dornen aufsitzen. Die Klauen sind sehr lang, länger als bei Larra, in seltenen Fällen nicht weit von der Basis ihres Innenrandes mit einem Zahne versehen, die Ballen klein. Das Mittelsegment ist so lang oder länger als das Dorsulum, gestreckt, von parallelopipedischer Form, also wie bei Larra. 
Die übrigen Hinterleibsringe sind, vorausgesetzt, dass sie nicht unnatürlich auseinandergezogen sind, zusammengenommen etwa so lang als Kopf, Bruststück und Mittelsegment. Sie werden von einem feinen Reif oder auch einem förmlichen Filze überzogen, darum sieht der Hinterleib nie so recht polirt glänzend aus, selbst bei abgeflogenen Stücken nicht. Das dritte Ventralsegment der $Q$ hat in der Mitte, näher der Basis, eine Convexität, deren Grösse und Form bei den Arten ungemein schwankt; häufig erscheint das Segment fast zu einem Kielezusammengedrückt, welcher steil gegen den zweiten Ring abfällt. $\mathrm{Zu}$ jeder Seite der Wölbung sieht man einen mehr oder weniger ausgedehnten ovalen, flachen Eindruck von matter Farbe. Diese Eindrücke sind immer vorhanden, wenn die Convexität bedeutend ist, und gestatten den Trochanteren der Hinterbeine eine freiere Bewegung. Die $\sigma^{\nearrow}$ zeigen diese Verhältnisse der dritten Ventralplatte gar nicht oder nur sehr schwach.

Die obere Afterklappe besitzt ein Pygidialfeld; es ist beim $q$ wie bei Larra geformt und von einem mehr weniger feinen, manchmal subtil reifartigen Filz überzogen, welcher sich leicht abnützt, daher bei abgeflogenen Stücken wenig oder gar nicht mehr wahrzunehmen ist; am Ende des Pygidialfeldes sieht man einige steife Borstenstäbchen nach hinten starren. Die obere Afterklappe des $\sigma^{\top}$ ist trapezisch, oft nicht unbeträchtlich gewölbt und am Ende ausgerandet. Die Punktirung ist viel feiner als bei Larra-Arten. Notogonia wurde im Jahre 1867 durch Costa (Ann. Mus. zool. Univ. Napoli, Ann. IV) von Larra abgetrennt.

Von Larra unterscheidet sie sich 1. durch den Zahn an der Innenkante der Oberkiefer, 2. den längeren Kopfschild, 3. die grössere Annäherung der Augen am Scheitel, 4. besonders die Bildung und Stellung des Pronotums, 5. die Art der Bedornung der Vorderschienen, die längeren Klauen, meistens auch die scharfkantigen Hinterschienen, 6. die Wölbung auf dem dritten Bauchringe (Q), 7. den reifartigen Filz auf den Hinterleibsringen ( + ), 8. das fein befilzte Pygidialfeld ( $q$ ).

Von Liris, welcher Notogonia noch näher steht als Larra, unterscheidet sie sich 1. durch den Kieferausschnitt, den man bei Liris vermisst, 2. den einzähnigen Innenrand der Kiefer, 3. den Mangel einer Bedornung an der Aussenseite der Vorderschienen (Q).

Auch mit Paraliris ist nicht leicht eine Verwechslung möglich, wenn man berücksichtigt, dass Paraliris keinen Ausschnitt am Unterrande der Oberkiefer, einen unbefilzten, mit kräftigen Depressionen gekennzeichneten Hinterleib, ein nacktes Pygidialfeld, vor allem aber eine andere Mittelsegmentform besitzt.

\section{Notogonia pompiliformis Panz.}

? Larra nigra Latr., Hist. nat. gen. et part. Crust. et Ins., t. XIII . . . . . . . . . . . 1805 Larra pompiliformis Panz., Faun. Ins. Germ. Init., 106. Heft, 17. Bl., + (non 89 . Heft, 13. B1., 1805) 
Tachytes nigra v. d. Lind, Observ. ${ }^{1}$. . . . . . . . . . . . . . . . 1825 Tachytes nigra Lep., Hist. nat. Ins. Hym., t. III, p. 242, Nr. 3, ठ, 오 . . . . . . 1845 Tachytes pompiliformis Dhlb., Hym. Eur., t. I, p. 130, Nr. 66, ㅇ, et p. 469, 오 1845 Tachytes pompiliformis Schenck, Beschr. d. i. Herz. Nassan aufgef. Grabwesp. (Jahrb. d. Ver.

f. Naturk. Herz. Nassau, 12. Heft, p. 132, Nr. 1, $\delta^{\top}$, Q. . . . . . . . . . 1857 Tachytes pompiliformis Taschenb., Schlüss. z. Bestimm. d. i. Deutschl, aufgef. Mordwesp.

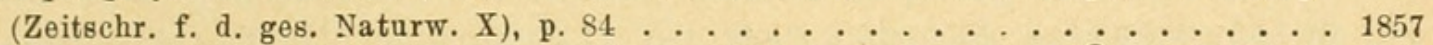
Tachytes pompiliformis Taschenb., Hym. Deutschl., 9. Fam. Spec., p. 201, ․․ . . . . 1866 Notogonia nigra Costa, Ann. Mus. zool. Univ. Napoli (Ann. IV), p. 82, ठ, ㅇ 1867

Long. 8-12 mm. $\sigma^{\top}$, + . Nigra. Alae subinfuscatae ad apicem obscuriores. Pedes nigri, tarsi apicem versus paulo rufescentes. Corpus cinereopuberulum, fasciis tribus abdominis cinereis. Dorsulum antice in medio sulco tenui et brevi, lineolis duabus internis valde approximatis formato, instructum, densissime punctulatum. Metapleurae transverse striatae aut substriatae. Segmentum medianum coriaceum, opacum; area dorsalis subreticulate rugosa; latera striata (L. a).

万. Long. 8-10 mm. Oculi in vertice quam longitudine flagelli articuli primi et secundi paululo plus inter se distant.

‥ Long. 9-12 mm. Oculi in vertice longitudine flagelli articuli secundi inter se distant. Areae pygidialis vage punctatae tomentum cinerascens saepe plus minusve detritum.

Europa mediterranea et ex parte centralis; Africa et Asia mediterranea.

Schwarz. Taster braun. Endglieder der Tarsen dunkel pechroth oder auch ganz schwarz.

Die geringste Entfernung der Augen auf dem Scheitel beträgt beim $\{$ die Länge des zweiten Fühlergeisselgliedes, während sie beim $\sigma^{\nearrow}$ ein wenig mehr als die Länge des ersten und zweiten Geisselgliedes zusammengenommen, aber weniger als die des zweiten und dritten ausmacht. Das Éndglied ist beim $ᄋ$ kaum länger als das Pedicellum. Vom vorderen Nebenauge zieht sich eine Furche nach unten, welche aber den Querwulst an der Stirne nicht vollständig überwindet. Das Dorsulum ist matt glänzend, vorne in der Mitte, also hinter der Dreiecksspitze des Pronotumwulstes zum Unterschiede von der folgenden Art nicht eingesenkt, die beiden mittleren Linien auf dem Dorsulum sind einander so nahe, dass sie eine linienartig schmale Furche bilden, während sie sich bei der folgenden Art in deutlichem Abstande von einander befinden. Die Punktirung des Dorsulums ist sehr dicht, unter der Lupe a schwer und übrigens nur dann

1) Bis jetzt wurde in Verzeichnissen die Artbezeichnung „nigra v. d. L. “ verwendet. Diese kann vor der Panzer'schen „pompiliformis“ (106. Heft, 17. Bl., 1808) keinen Vorzug geniessen, weil sie bereits von Latreille (1805 l. c.) für eine "Larra vergriffen worden ist, die aber nicht gedeutet werden kann (es ist ebenso leicht möglich, dass die Latreille'sche Larra nigra mit Tachysphex nitida Spin. als mit Not. pompiliformis dieser Arbeit identisch ist). Dass $\mathrm{P}$ a n z e r eine andere verwandte Grabwespe ebenfalls unter dem Namen „Larra pompiliformis“ (89. Heft, 13. B1., 1805) beschreibt, hat nichts zu bedeuten, denn sie gehört zu einer anderen Gattung. 
bemerkbar, wenn der feine, grauliche, schwach bräunelnde Haarfilz, der auf dem Dorsulum liegt, abgenützt ist. Da die Punktirung trotz ihrer sehr grossen Dichte noch immer nicht eine gedrängte genannt werden kann, worunter ich diejenige meine, bei welcher die Pünktchen nur mehr durch dünne Scheidewände von einander getrennt werden, und weil die Pünktchen sehr zart sind (L. b), so erscheint das Dorsulum bei abgeflogenen Stücken immerhin noch etwas glänzend. Die vereinigten Epimeren und Episternen des Metathorax sind von vorne nach hinten runzelig gestreift, unterhalb der Hinterflügel deutlicher als weiter unten.

Das Mittelsegment ist fast glanzlos. An dessen Seiten ziehen sich Runzelstreifen in schräger Richtung nach oben; diese sind zwar nicht spärlich, aber auch nicht hart an einander gedrängt, so dass zwischen je zwei noch eine dritte von derselben Dicke Platz hätte. Die Horizontalfläche ist netzrunzelig; es treten jedoch oft die Querrunzeln mehr hervor. Die hintere Fläche stürzt sehr steil ab, ist mit queren Runzelstreifen versehen und in der Mitte längsgefurcht.

Die Erhebung des dritten Bauchringes und zu dessen Seiten die abgeflachten, opaken Stellen sind bei dieser wie bei der folgenden Art gut sichtbar. Die Filzbekleidung der Pygidialfläche ist sehr häufig zum Theile wenigstens abgestossen und auf der nunmehr glänzenden Fläche sieht man einzelne Punkte (L. a).

Lebensweise. Lichtenstein berichtet in den Bull. d. Ann. Soc. Ent. de France, sér. V, t. III, 1873, XV, über „Tachytes pompiliformis Panz. = nigra Latr.": "Ich sah dieses Insect im Sande graben und darin $10-12 \mathrm{~cm}$. lange Gänge machen; am Grunde derselben legte es eine kleine runde Zelle an, in welche es vier oder mehr kleine, $1 \mathrm{~cm}$. lange Heuschrecken, die mir ChortipusLarven, wahrscheinlich von $C h$. variabilis oder $C h$. pratorum zu sein schienen, schleppte. Einer der Heuschreckenlarven war das Ei von Tachytes zwischen den beiden Vorderbeinen an der Brust angeklebt."

$\mathrm{Ob}$ nun Lichtenstein unter dieser "Tachytes pompiliformis" wirklich die hier beschriebene Art oder eine der schwarzen Tachysphex-Formen meint, dies zu entscheiden fehlen Anhaltspunkte. Doch scheint es eine der letzteren gewesen zu sein, da $N$. pompiliformis sonst Larven von Gryllus einträgt.

Geographische Verbreitung. In wärmeren Europa, Nord-Afrika und West-Asien. Wien (Hofcab. W.), Ofen (Anker, W. Hofcab.), Nagyvárad bei Pest (8, Mocs.), Mehadia (Mann, W. Hofcab.), Jekaterinoslaw (Bramson), Sarepta, Spalato (W. Hofcab.), Halle (Taschen b.), Thüringen (S chmiedekn.), Perleberg (Rudow), Peney bei Genf (Tournier), Corsica (Mann), Marseille (C. Jullian), Oran, Saintes (Lep.), Tanger, Sicilien (Costa, Frey-Gessner), Prov. Neapel (Costa), Toscana (Piccioli), Piemont (Garbiglietti), Spanien (verbreitet).

Nach Taschenberg soll Not. pompiliformis auch in Neu-Freiburg (Brasilien) vorkommen, was wohl mit Recht zu bezweifeln ist. 


\section{Notogonia nigrita Lep.}

Tachytes nigrita Lep., Hist. nat. Ins. Hym., t. III, p. 241, Nr. $2, \sigma^{\top}$, ㅇ․ . . . . . . . 1845 Tachytes nigrita Lucas, Explor. scient. Algér., t. III, p. 247, pl. XIII, fig. 10 . . . . . . 1849

Long. 10-16 mm. Nigra, alae fuliginosae, violascentes. Corpus fuliginosopruinosum, fasciis tribus cinereis paulum conspicuis abdominis. Dorsulum densissime punctulatum antice in medio paulo impressum; lineae musculares 2 internae sulci linearis instar non approximatae. Metapleurae coriaceae. Segmentum medianum coriaceo-opacum; area dorsalis in medio ruga tenuissima longitudinali divisa, striis subitilibus haud densissimis transverse striata; latera fere aciculatim oblique striolata.

$0^{7}$. Long. 11-13 mm. Oculi in vertice longitudine articuli secundi et dimidiati primi inter se distant.

․ Long. 14-16 mm. Oculi in vertice longitudine articuli secundi flagelli inter se distant. Areae pygidialis tomentum fuscum nonnunquam detritum.

Europa et Africa mediterranea.

Ist der vorigen Art ähnlich, aber grösser, mit dunkelbraunem, nicht graulichem Tomente bedeckt, was der Art bei dem Umstande, dass die grauen Filzbinden unscheinbarer sind, eine viel dunklere Tracht verleiht. Das Dorsulum ist vorne in der Mitte in ziemlicher Ausdehnung seicht sattelförmig eingedrückt; die beiden mittleren Muskellinien, durch welche aussen die Stellen angedeutet sind, wo sich innen die Längsmuskeln des Mesothorax ansetzen, liegen in deutlichem Abstande von einander.

Die Punktirung des Dorsulums erscheint um einen Grad derber als bei Not. pompiliformis, was freilich durch Beschreibung nicht recht anschaulich zu machen und nur bei sorgfältigem Vergleich unter einer Lupe (L. $b$ ) zu erkennen ist. Die Trübung der Flügel ist stark schwärzlich, fast dunkler als bei Larra anathema Rossi, viel dunkler als bei $N$. pompiliformis. Ich besitze ein Stück, angeblich aus Ungarn, welches ich hieher zählen möchte, das aber lichtere Flügel besitzt. Das Mittelsegment ist matt, viel feiner sculpturirt als bei der verglichenen N. pompiliformis; seine Seiten sind sehr fein schräg nach oben nadelrissig gestrichelt; die Horizontalfläche wird von feinen, schwach ausgesprochenen Runzelstreifen quer durchzogen und durch eine Längslinie halbirt. Die Kante, welche die Dorsalfläche mit der steil abfallenden Fläche bildet, ist durch eine kräftige Runzel gekennzeichnet; auch der Uebergang der Mittelsegmentseiten zur Dorsalfläche ist stellenweise durch einige kurze, gröbere Runzeln, welche sich plötzlich unter den feineren verlieren, ausgezeichnet. Das Ventralsegment, sowie die Augenentfernung am Scheitel sind von der nämlichen Beschaffenheit wie bei N. pompiliformis. Das Endsegment des $\sigma^{\top}$ erscheint beträchtlich stärker als bei- $N$. pompiliformis ausgeschnitten.

Geographische Verbreitung. Oran (Lep.), Constantine, Bona, Lacalle (Lucas), Alicante in Spanien, Cypern, Ungarn(?). 


\section{Notogonia japonica Kohl.}

Notogonia japonica Kohl, Verhandl. d. k. k. zool.-bot. Gesellsch. Wien, XXXIII. Bd., p. 357,

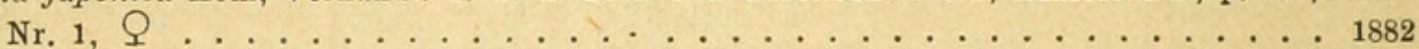

Long. 9-11 mm. ․ Nigra; tarsi apicem versus rufescentes. Alae subhyalinae. Abdominis segm. 2, 3 et 4 cinereo-marginata. Oculi in vertice longitudine flagelli articuli secundi et primi dimidiati inter se distant. Metapleurae distincta striato-rugosae. Segmentum medianum supra et in lateribus grossius reticulato-rugosum. Area pygidialis pube cinerea obtecta. Segmentum ventrale tertium gibbosum subcompressum, areis ovalibus deplanatis conspicuis.

o' ignotus.

Japan, Kioto (Roretz leg. 1875).

Durchschnittlich ein wenig kleiner als $N$. pompiliformis Panz. (= nigra v. d. L.). Die Länge des zweiten Fühlergeisselgliedes ist etwa um die Hälfte des ersten Geisselgliedes kleiner als der geringste Abstand der Augen auf dem Scheitel. Der Thorax ist dicht punktirt, die Punkte sind tiefer gestochen und ein wenig grösser als bei $N$. pompiliformis oder nigrita Lep., obschon noch immer fein und an Stellen, welche ihres ins Bräunliche gefärbten Tomentes entblösst sind, unter der Lupe a sichtbar. Die Sculptur des Mittelsegmentes ist viel gröber als bei den erwähnten Arten, nicht nur oben netzrunzelig, sondern auch an den Seiten, wo jedoch die schrägen Querrunzeln das Uebergewicht behalten.

Die Erhabenheit und die opaken ovalen Flecken des dritten Bauchringes sind deutlich. Die obere Afterklappe überzieht ein grauer Filz. ठ unbekannt.

Japan.

Gen. Liris Fabr.

Liris Fabr., Syst. Piez., p. 227, Nr. 40. . . . . . . . . . . . . . . . 1804

Liris Dhlb., Disp. meth. Spec. Scand., p. I, 3. Fam. Larr. . . . . . . . . . . . . . . . 1842

Liris Dhlb., Hym. Eur., t. I, Tab. exam. syn. spec. Larr., p. 471, 29. Gen. et Tab. . • 1845

$<$ Tachytes Lep., Hist. nat. ins. Hyn. IlI, p. 239 . . . . . . . . . . . . . . . . 1845

Liris Patton, List of North-Amer. Larr. (Bost. Soc. Nat. Hist. XX, p. 385) . . . . . . 1880

Kopf ein wenig breiter als das Bruststück. Oberkiefer ohne einen Ausschnitt in der Mitte ihrer Aussenkante; ihr Innenrand zeigt zwischen der Mitte und der Basis zwei Zähne. Die Filzbehaarung auf dem Gesichte ist reich, bedeckt zumeist dessen Sculptur, zieht sich über den Scheitel hinauf und hängt mit dem Filze der Wangen zusammen. Fühler wie bei Notogonia; auch die Convergenz der Augen ist wie bei Notogonia. Die inneren Augenränder werden wie bei beiden vorangehenden Gattungen von leistenartigen, wulstigen Auftreibungen begleitet, welche selbst wieder durch einen Querwulst verbunden sind und auf diese Weise zwei Räume begrenzen. Die hinteren Nebenaugen sind ebenfalls wie bei Larra 
und Notogonia flach, länglich, schwer wahrzunehmen und liegen weit hinter den vorderen, regelmässig runden und gewölbten Nebenaugen. D er Hinterwulst ist wie bei Notogonia und Paraliris, nämlich schmäler als bei Larra, unter das Niveau des Dorsulums herabgedrückt, und zwar gegen die Seiten hin stärker als in der Mitte, dreieckig. Die Flügel sind ganz wie bei Notogonia. Beine verhältnissmässig ein wenig länger als bei Larra-Arten, fast so lang als bei Notogonia. Mittelhüften weit von einander abstehend. Bedornung der Beine im Ganzen kräftig. Mittelschienen einspornig. Vorderschienen, abgesehen von ihren Enddornen und einem einzelnen, nicht weit von der Mitte der Innenseite sitzenden Dorne, mit einigen kurzen, aber leicht bemerkbaren Dornen bewehrt. Wimpernkamm wie bei Notogonia. Die Hinterschienen zeigen an der Hinterseite wie die meisten Notogonia-Arten zwei deutliche, scharfe Längskanten, denen Dornen entspringen, und ausserdem eine oder zwei meist minder scharfe Kanten; diese letzteren sind unbedornt, weil sie an der Seite der Schienen liegen, welche dem Hinterleibe angeschmiegt werden kann. Die Fussklauen sind wie bei Notogonia lang und gestreckt. Auch das Mittelsegment und die Ventralplatte des dritten Segmentes zeigen den nämlichen Bau wie diese Gattung; die Erhabenheit auf dem dritten Bauchringe tritt mitunter, z. B. bei Liris ducalis Smith, wo sie wie bei Nysson oder Gorytes gerade und kegelförmig ist, noch viel auffälliger hervor. Die Hinterleibsringe werden, wohl in der Regel auch das Bruststück und Mittelsegment an vielen Stellen von einem reifartigen, oft metallisch glänzenden Haarfilz oder einer gröberen, kurzen, anliegenden Behaarung überdeckt.

Das Analsegment ( $($ ) hat ein flaches, dreieckiges Pygidialfeld, das in ähnlicher Weise wie bei Tachytes-Weibchen mit kurzen Härchen besetzt ist, und am Ende die Borstenstäbchen wie Notogonia.

Den Hauptunterschied von Notogonia bildet die Beschaffenheit der Oberkiefer und die Bedornung der Vorderschienen. Mit Larra ist sie noch weniger leicht zu verwechseln wegen der Bildung des Pronotums, der Beschaffenheit der Oberkiefer und des Pygidialfeldes, der geringeren Scheitelbreite u. s. w. Von Paraliris endlich weicht sie ab durch ihre Bedornung der Vorderschienen, den Bau des Mittelsegmentes und die Beschaffenheit des Hinterleibes und dessen Pygidialfeldes.

Geographische Verbreitung. Die Artenzahl von Liris scheint nicht gross zu sein; mit Sicherheit kann ich sechs Larra-Arten hieher rechnen; davon sind zwei Bewohner des mediterran-paläarktischen und auch äthiopischen Gebietes, eine andere, Liris aurata Fabr., sogar Bewohnerin dreier Hauptregionen, der äthiopischen, orientalischen und eines Theiles der australischen Region. Ferner leben zwei Arten, wie es scheint, ausschliesslich in der australischen und eine einzige sichere Liris-Art in der nearktischen Region. 


\section{Liris haemorrhoidalis Fabr.}

Pompilus haemorrhoidalis Fabr, Syst. Piez., p. 198, Nr. $55 \ldots \ldots \ldots \ldots \ldots \ldots$. . . . 1804 Liris Savignyi Spin., Compt. rend. Hym. rec. en Egypte (Ann. Soc. Ent. France, t. VII,

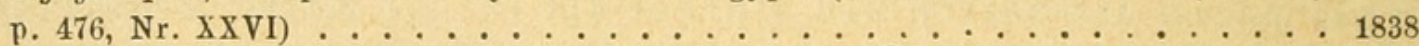
Lyrops haemorrhoidalis Guér., Icon. regn. anim., t. III, p. 439, 오 . . . . . . . . . . . 1843 Lyrops aureiventris Guér., Icon. regn. anim., t. III, p. 440, pl. LXX, Fig. 9, $\sigma^{\nearrow} \ldots \ldots \ldots 1843$ Liris orichalcea Dhlb., Hym. Eur., t. I, p. 135, $\sigma^{\top} \ldots \ldots \ldots \ldots \ldots$. . . . . . 1845

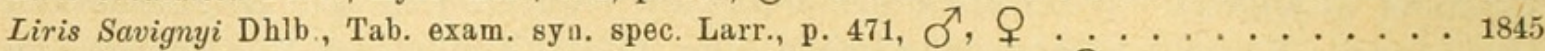
Tachytes illudens Lep., Hist. nat. ins. Hym., t. III, p. 249, Nr. 12, … . . . . . . . 1845

Long. 18-25 mm. O. Nigra; antennarum articuli basales, mandibulae ex parte, palpi, alarum squamulae, pedes - coxae, trochanteres et femorum basis plerumque nigra excepta - margines segmentorum, segmentum sextum et septimum (ㅇ) ferrugineo-rufa. Capitis, thoracis et abdominis maxima pars tomento denso, aurichalceo sericea. Alae lutescentes apicem versus ab initio areae radialis et areolae cubitalis secundae nigricantes, in margine apicali obscuriores; veneae luteae. Oculi in vertice longitudine flagelli articuli secundi et trientis primi inter se distant. Metapleurae coriaceae. Latera segmenti mediani striate rugosa (L. a); rugae ad aream dorsalem coriaceam crassescentes. Segmentum ventrale subcompresse-gibbosum utrinque aream deplanatam ovalem gerens; segm. ventr. quartum et quintum nitida, satis vage punctata; punctatura segm. ventr. sexti et septimi densior (ㅇ).

o'. Long. 15-20 mm. Mihi ignotus. Articulus secundus tarsorum posteriorum dilatatus et complanatus (s. Guér. l. c.).

Europa, Asia et Africa mediterranea (Hispania, Sicitia, Syria, Aegyptia) et Africa tropica (Tette, Guinea).

L. haemorrhoidalis ist die schönste und grösste Larride Europas. In Folge eines sehr dichten, schön messinggelb glänzenden Filzes, welcher fast den ganzen Kopf, Thorax und Hinterleib bedeckt, ist bei ihr weder die Sculptur, noch die Farbe des Integumentes überall sichtbar. Filzfrei sind fast nur die Metathoraxund Mittelsegmentseiten, sowie die Ventralringe mit Ausnahme der abgeflachten Stellen auf dem dritten Ringe. Selbstverständlich reibt sich dieser Haarfilz ab; zuerst verliert er sich an den der Abnützung mehr preisgegebenen Stellen, während er an den geschützteren, z. B. auf dem Gesichte, vorne an den Wangen, auf dem Pronotumwulst, den Seiten des Dorsulums, in den Vertiefungen um das Schildchen herum, an den Seiten der Dorsalflächen des Mittelsegmentes verbleibt. Der Körper ist der Hauptsache nach schwarz. Rostroth sind die Taster, zum grössten Theile die Oberkiefer, die vier Basalglieder der Fühler, die Flügelschuppen, die Beine - die Hüften, Schenkelringe und die Schenkelbasis sind meist schwarz - die Hinterränder der Hinterleibsringe, übrigens die beiden Endringe fast ganz. In der Ausdehnung des Roth ist diese Art wohl auch veränderlich. Die Flügel sind gelblich tingirt, am Rande in ziemlicher Breite, nämlich auch über die ganze Radial-, zweite und dritte Cubitalzelle ausgedehnt, rauchfärbig. Die rauchige T'rübung selbst ist von dem Abschlusse 
der Radialzelle und der äussersten unteren Spitze der dritten Cubitalzelle an bis zum Rande hin viel dunkler.

Die Augenentfernung auf dem Scheitel beträgt um ein Dritttheil des Pedicellum mehr als die Längedes zweiten Geisselgliedes. Dorsulum vorne in der Mitte, also oberhalb der Dreieckspitze des Pronotumwulstes eingedrückt; in der tiefsten Stelle des Eindruckes liegen einander sehr nahe gerückt, aber nicht etwa wio bei Not. pompiliformis Panz. zusammen eine lineare Furche darstellend, die beiden mittleren Linien, die Ansatzmarken der Längsmuskel. An abgeriebenen Stücken sieht man auf dem Dorsulum und dem Schildchen unter der Lupe $b$ sehr dicht und deutlich gestochene feine Punkte, welche wohl die Ursprungsstelle der Filzhärchen waren. Die Metapleuren sind lederartig; die Seiten des Mittelsegmentes sind der Quere nach, gegen die Horizontalfläche ein wenig schräg, runzelig gestreift. Die Runzelstreifen sind deutlich, nur mässig dicht angeordnet und verdicken sich in der Nähe der Seitenkanten der lederartig sculpturirten Dorsalfläche, die ungefähr so lang als breit ist; die abfallende Fläche ist sehr steil, ohne senkrecht zu sein, und wird in der Mitte von einer Furche durchschnitten. Der dritte Bauchring ist deutlich convex, vorne wie zusammengedrückt, beiderseits mit einem grossen, flachen ovalen Flecke behaftet, welcher noch von Haarfilz überzogen wird, da er der Abnützung weniger ausgesetzt ist als die convexen Partien. Auf dem fünften und sechsten Ringe sieht man sehr zerstreut sitzende Pünktchen, während die Punktirung des siebenten Ringes viel dichter ist.

Das $\sigma^{\nearrow}$ kenne ich nicht. Guérin behauptet von ihm, dass das zweite Tarsenglied der Hinterbeine in auffallender Weise verbreitert und plattgedrückt sei, was beim 우 nicht der Fall ist. Die Details über die Lebensweise sind noch nicht erforscht.

Geographische Verbreitung: L. haemorrhoidalis gehört zur mediterranpaläarktischen und äthiopischen Region. Sicilien (Mann C.), Spanien (Waltl.), Egypten (Galam), Cairo (Lep.), Tette, Senegal (Gerstäcker), Syrien.

\section{Liris Brameri Kohl.}

Liris Braueri Kohl, Verhandl. d. k. k. zool.-bot. Gesellsch. Wien, XXXIII. Bd., p. 356,

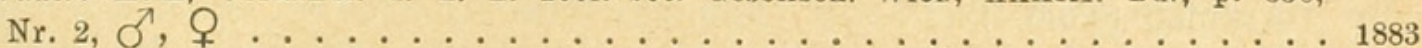

Long. 15-21 mm. б, ㅇ. Atra, pedes concolores, tarsi apicem versus rufescentes; variat pedibus piceo-rufis. Antennarum articuli basales rufi. Caput, pronotum et $\sigma^{\top}$ dorsulum ex parte tomento aureo vestita. Alae fuliginosae, in apice obscuriores, violascentes. Metapleurae coriaceae, paulum rugosae. Segmenti mediani latera striate rugosa (L. a).

$\sigma^{\top}$. Long. $15-19 \mathrm{~mm}$. Oculi in vertice longitudine flagelli articuli secundi inter se distantes. Segmentum ventrale tertium tumidum, valde convexum, quartum et quintum in medio longitudinaliter late impressa. Segmenti secundi, tertii, quarti et quinti depressio postica tomento cinereo fasciatim vestita. Segmentum anale in apice excisum. 
Q. Long. 18-21 $\mathrm{mm}$. Oculi in vertice longitudine flagelli articuli quarti inter se distant. Segmenta ventralia subnitida, quartum et quintum satis vage, sextum et septimum densius punctata. Segmenti secundi, tertii et quarti depressio postica pube cinerea vestita. Area pygidialis pube obscuro-ferruginea obtecta.

\section{Tor (Arabia).}

Steht der bekannten Liris aurata Fabr. sehr nahe, ist aber doch leicht von ihr zu trennen. Thorax und Hinterleib in Folge einer schwarzbraunen Bereifung mattschwarz. Kopf, Pronotum stellenweise, beim $\sigma^{\nearrow}$ auch das Dorsulum, aber nur schwach, mit goldgelbem Haarfilz bedeckt. Flügel rauchig schwarz, mit lebhaftem violettem Schiller. Pygidialfeld (q) mit rostbraunen Härchen bedeckt.

Depression auf dem Hinterrande des zweiten, dritten und vierten Ringes beim $q$ und auch des fünften beim $\sigma^{\pi}$ mit schwachem grauem Filze reifartig bedeckt. Fühler und Beine sichtlich dünner als bei L. aurata und haemorrhoidalis. Basalglieder der Fühler mehr oder weniger geröthet.

Die geringste Entfernung der Augen auf dem Scheitel beträgt beim $q$ entschieden weniger als die Länge des fünften, etwa nur die des vierten oder fünften, beim $\sigma^{\nearrow}$ etwa die des zweiten Fühlergeisselgliedes. Die Sculptur des Mittelbruststückes ist wegen der Haarbekleidung nicht sichtbar. Metapleuren lederartig, mit einigen schrägen Runzelstreifchen. Mittelsegment matt, oben lederartig, an den Seiten deutlich querrunzelig gestreift; Runzelstreifen am Uebergange zur Dorsalfläche kräftig. Die mässig glänzenden Bauchringe sind fein und zerstreut, an den Endringen gröber punktirt; die Pünktchen sitzen ähnlich wie bei $L$. aurata in einer mikroskopisch feinen Runzelung. Die Behaarung des oberen Afterklappenfeldes $(Q)$ ist rostbraun. Beim $\sigma^{\top}$ erscheint das Analsegment ausgeschnitten.

Der Unterschied von L. aurata liegt in der dunkleren Bereifung des Körpers, dem fastganz schwarzen, nurbeim $\sigma^{\nearrow} \mathrm{schwach}$ gelbfilzigen Mesothorax, derschwärzlichen oder höchstens dunkel pechrothen Färbung der Beine, in dem geringeren Augenabstande und den dünneren Fühlern und Beinen.

Arabien (Tor). ${ }^{1}$ )

1) Mir unbekannte, zum grösseren Theile wohl nicht zu dentende Larra-Arten (Larrada Smith) aus der paläarktischen Fauna:

\section{Larra amplipennis Smith.}

Larrada amplipennis Smith: Trans. Ent. Soc. Lond., p. 193, ð’, 1873.

" $\sigma^{7}$. Length $6^{\prime \prime}$. Black, with the two basal segments of the abdom. red. Head wider than the thorax; the face covered with silvery-white pubescence, mandibles shining and obscurely ferruginous at their tips. Thorax opaque, finely and very closely punctured; wings fuscous, the posterior pair hyaline at their base; the tegulae obscurely testaceous; the nervures dark brown; the matath. with a thin cinereous pubescence. $\Lambda$ bdomen slightly shining and thinly covered with cinereous pubescence, observable in certain lights, as are also the bright silvery fascive on the apical margins of the segments. - Hiogo (Japan)." 


\section{Gen. Paraliris Kohl. ( $\pi \alpha \rho_{\alpha} \grave{\alpha}$ - Liris.)}

Paraliris Kohl, Verhandl. d. k. k. zool.-bot. Gesellsch., p. 361 . . . . . . . . . 1883

Kopf breiter als das Bruststück. Oberkiefer ohne einen A usschnitt an der unteren Aussenkante. Gesichtsfilz ein wenig reicher als bei Larra und Notogonia. Fühler schlanker als bei Larra. Augen gegen den Scheitel hin fast noch mehr convergent als bei Notogonia und Liris. Längs der inneren Augenränder verlaufen wie bei den drei vorigen Gattungen kräftige Wülste, welche durch einen Querwulst verbunden werden; auch bezüglich der Lage und Form der Nebenaugen herrscht das nämliche Vorhältniss; das vordere ist rund

\section{Larra (Notogonia) argyropyga Costa Ach.}

Notogonia argyropyga Costa: Att. Acad. scienze fis. e mat. Napoli, VII, Mem. estratt., p. $16, \sigma, q, 1875$.

"N. nigra cinereo-pubescens, clypeo, orbitis et segmentis abdominalibus $1-4 \sigma^{\top}, 1-3$ i in margine postico valvulaque anali dorsali cano-sericeo villoso-micantibus; alis cinereo-hyalinis, apice fumatis; metanoto subtilissime coriaceo, truncatura postica transversim striata, sulcoque longitudinali notata. $\sigma^{\top}$ femoribus posticis infra basi elato angulatis, ultra angulum excavatis. Basso Egitto (Cairo)."

Larra diversa Walk.

Larrada diversa Walk.: List of Hym. Egypt., p. 21, Nr. 105, P, 1871.

„Black, with silvery cinereous tomentum. Head silvery in front and behind. Mandibl. black. Metathorax finely and transversly striated, with a slight longitudinal furrow. Petiole black, very short. Abdomen red, elongate oval, a little, longer than the thorax, with three silvery patches on each side; second segm. with a black oblique streak on each side; fourth fift and sixth segm. black. Legs red; coxae and femora black, the latter with red tips; forse tarsi with long slender black spines. Wings pellucid; veins black, testaceous at the base.

$\delta^{7}$ ? Abdomen elongate-elliptical, not black towards the tip. Femora red, black above towards the base; fore tarsi without spines. Length of the body $5-6^{\prime \prime \prime}$. Cairo."

\section{Larra docitis Smith.}

Larrada docilis Smith: Trans. Ent.-Soc. Lond., p. 192, ठ, $\subsetneq$, 1873.

"7. Length $6^{\prime \prime}$. Black, slightly shining, wings subhyaline. Head: the vertex with a single ocellus placed in a smoath depression, above which are two small tubercles; the clypeus covered with silvery pile. Thorax: the proth. and mesoth. impunctate; the metathorax abruptly truncate, and finely transversely strigose above; the tegulae rufo-piceous; the wings fulvo-hyaline; the nervures ferruginous. Abdomen: the three basal segm. have a glittering silvery pile on their apical margins, only observable in certain lights; the apical segment opaque, and ferruginous at its apex. The legs and sides of the thorax have a fine glitlering cinereous pile. $-\sigma^{\top}$. This sex only differs in having the mandibles and the scape in front pale ferruginous; the anterior tibiae and all the tarsi, rufopicous. Hiogo, Hakodadi."

\section{Larra erebus Smith.}

Larrada Erebus Smith: Trans. Ent. Soc. Lond., p. 193,, 1873.

"․․ Length $61 / 2 "$. Black, the wings subhyaline, the nervures dark fuscous. The head shining; a single ocellus situated in a deep frontal irregular depression; the scape robust and compressed; the anterior margin of the clypeus broadly angular; the mandibles dark ferruginous and fringed with ferruginous hairs; the cheeks with a thin cinereous pubescence. Thorax: opaque, and closely and finely punctured; the metath. abruptly truncate and finely rugubose; transversely so above; the legs with a fine cinereous pile; the apical joint of the tarsi testaceous; the claws pale. Abdomen shining and impunctate. Hiogo." 
und gewölbt, die beiden hinteren sind einander genähert, flach und länglich, undeutlich und stehen vom vorderen sehr weit ab.

Hinterwulst des Pronotums ist wie bei Notogonia und Liris unter das Dorsulum herabgedrü ckt, dreieckig, unterscheidet sich hierin somit von Larra. Beine lang, wie bei Notogonia, ihre Schienen nicht kantig, Mittelhüften von einander weit abstehend. Mittelschienen einspornig. Die Dornen an den Beinen sind nicht zahlreich, aber lang, dünn und sehr spitz. Die Vorderschienen tragen nur Enddornen; bei der einzigen Art, auf welche diese Gattung gegründet wird, fehlt selbst der Dorn an der Mitte der Innenseite, ob immer, müsste erst die Erfahrung lehren. Klauen lang, Flügelzellbildung wie bei den drei vorhergehenden Gattungen. Das Mittelsegment gestreckt, länger als das Dorsulum, flachgedrückt; seine Rückenfläche bildet mit den Seitenflächen und der abfallenden Hinterfläche keine Kanten, geht vielmehrinentschiedener Rundung in sie über.

\section{Larra memnonia Smith.}

Larrada Memnonia Smith: Cat. Hym. Brit. Mus. IV, p. 281, Nr. 25, Q, 1856.

"Q. Length $7^{\prime \prime \prime}$. Black: the face covered with silvery pubescence, the mandibles obscurely rufo-piceous; the apical joints of the palpi pale testaceous. The thorax covered with a fine silvery pile, as well as the legs; the tarsi and apex of the tibiae ferruginous; the wings fulvo-hyaline, the nervures and tegulae behind rufo-testaceons; the scutellum smooth and shinning; the metathorax finely transversely striated, and having a central abbreviated carina not extending to the verge of the truncation, the striae coarser at the sides, the truncation also coarsely striated. The apical margins of the segments of the abdomen with fasciae of changeable silvery pile. Egypt; Senegal."

\section{Larra nigricans Smith (non Walk.!).}

Larrada nigricans Smith: Trans. Ent. Soc. Lond., p. 192, 1873.

"․ . Length $31 / 4 "$. Black, wings subhyaline, the nervures black. Head finely shagreened, the face with silvery pubescence; the mandibles ferruginous towards, their apex, with the tips black. Thorax shagreened, with the metath. rugulose; the legs with fine cinereous pile, which is very bright, and dense on the pesterion tibiae within; it is also very bright on the tarsi. Abdom. smooth and shining; with silvery fasciae on the posterior margins of the segments, observable only in certain lights. The $\sigma^{\nearrow}$ does not differ in any material respect from the $q$. Nagasaki.

Larra (Notogonia) nigricans Walk. (non Smith!)

Larrada nigricans Walk.: List of Hym. Egypte, p. 21, Nr. 102, ð’,, 1871.

„Black, dull, with cinereous tomentum. Head a little broader than the thorax, silvery in front and behind. Petiole very short. Abdomen elliptical in the male elongate-oval in the female. Length of the body $4-6^{\prime \prime \prime}$. This species is a little smaller and has paler wings than $L$. nigrita, which it much resembles. Cairo, Hor Taminab. ${ }^{4}$

Larra tisiphone Smith.

Larrada tisiphone Smith: Trans. Ent. Soc. Lond., p. 192, †, 1873.

"O. Length 6 .". Black, the wings flavohyaline; the nervures testaceous as well as the posterior margin of the tegulae. Head opaque, with a fine silvery pubescence on the face; the cheeks have also a silvery pubescence. The thorax opaque, with the mesothorax only slightly shinning and impunctate, depressed anteriorly and with two impressed lines entending to the disk; the metath. transversely striated above; the sides of the truncation also striated in the same manner; the legs shining, and with a changeable silvery pile; the posterior tibiae with some bright fulvous pubescent pile at their apex within. Abdom. smooth and shining, with changeable silvery fasciae on the apical margins of the segments, only observable in certain lights; the apical segm. opaque, except at its basal margin. Nagasaki." 
Hin terleib (zweiter bis siebenter Ring) so lang als Kopf, Thorax und Mittelsegment zusammengenommen, wohl mit längeren abstehenden Haaren ausgestattet, aber nichtbefilzt, daherglänzend, und seine sehr dünne, aber etwas derbe Punktirung recht augenfällig (L. a). Der dritte Bauchring ist leicht gewölbt, jedoch ohne förmliche Erhebung, beiderseits mit glatten, glänzenden Stellen ausgestattet, auf welchen die Trochanteren der Hinterbeine hin- und herspielen dürften. Pygidialfeld geformt wie bei den beiden vorhergehenden Gattungen, aber ohne stiftenartige Borsten am Ende und wie bei Larra unbefilzt.

Paraliris unterscheidet sich von Larra: 1. durch den Mangel des Oberkieferausschnittes, 2. die grössere Convergenz der Augen, 3. die Form des Pronotumwulstes, 4. die Bedornung der Vorderschienen, 5. die Form des Mittelsegmentes, 6. die Depressionen an den Endrändern der Hinterleibsringe.

Von Notogonia weicht Paraliris ab: 1. durch den Mangel des Oberkieferausschnittes, 2. durch die Form des Mittelsegmentes, 3. durch die unbereiften, nackten Hinterleibsringe, speciell das nackte Pygidialfeld, welches auch der Borstenstiftchen am Ende ganz und gar ermangelt, 4. die kräftigen Depressionen der Hinterleibssegmente.

Am nächsten steht offenbar Liris dieser Gattung, da sie einander in der Beschaffenheit der Oberkiefer gleichen, sonst fast in den nämlichen Punkten wie Notogonia und Paraliris von einander abweichen. In der Bedornung der Vorderbeine scheint mir Paraliris der Gattung Notogonia näher zu kommen.

Bekannt ist nur eine einzige Art:

P. Kriechbaumeri Kohl. $q$. Reg. II, Subreg. 3. Cap.

Paraliris Kriechbaumeri Kohl: Verhandl. d. k. k. zool.-bot. Gesellsch. Wien, p. 362, $\Omega, 1883$. (Type im k. zoologischen Museum in München.)

\section{Gen. Larraxena Smith.}

Larraxena Smith, Descr. of new spec. of Exot. Hym. in the Brit. Mus. (Mag. of Natur. Hist., vol. VII, ser. II, p. 30) . . . . . . . . . . . . . . . . . 1851

„Kopf ein wenig breiter als das Bruststück, vorne niedergedrückt; das vordere Nebenauge liegt in einer Stirnvertiefung, die beiden hinteren sind undeutlich; die Netzaugen nähern sich sichtlich auf dem Scheitel. Fühler fadenförmig, das Basalglied sehr stark verdickt, an der Basis des queren Kopfschildes eingefügt. Oberkiefer bogenförmig. Thorax länglich, Mittelsegment („metathorax") verlängert, hinten abgestutzt. Die Vorderflügel mit einer appendiculirten Anhangszelle und drei Cubitalzellen; die zweite Cubitalzelle ist dreieckig, gestielt und nimmt die zwei rücklaufenden Nerven auf; die erste Cubitalzelle ist so gross wie die zweite und dritte zusammen; die dritte ist schmal und schräg gestellt. Die Beine sind von mässiger Länge, die Schienen und Tarsen kräftig bedornt, die Tarsen länger als die Schienen. Der Hinterleib ist gestreckt." - Brasilien. 
Larraxena ist mir unbekannt und scheint den Gattungen Larra, Notogonia, Liris, wohl auch Tachytes, verwandt zu sein; indessen ist die Smith'sche Beschreibung viel zu ärmlich, als dass man dieser Gattung eine sichere Stelle im System anweisen könnte. Es kann auch sein, dass Smith eine Notogonia vor sich hatte, bei welcher die zweite Cubitalzelle dreieckig und schwach gestielt ist; ich kenne einige Notogonia-Arten, bei denen dies der Fall ist; dieses Verhältniss allein, welches blos in einem grösseren Grade von Annäherung zweier Cubitalqueradern beruht, würde nicht zur Aufstellung einer neuen Gattung berechtigen.

Bis jetzt ist erst eine Art bekannt geworden :

L. princeps Smith. Q. Reg. V, Subreg. 2. Brasilien.

Larraxena princeps Smith: Mag. Nat. Hist. V. VII, Ser. II, p. 30, 1851.

\section{Gen. Darala C. Ritsema. $\left.{ }^{1}\right)$}

Darala C. Ritsema, Not. fr. the Leyden Museum, vol. VI, p. 81 . . . . . . . . . . 1884

Ritsema veröffentlichte die Beschreibung dieses Genus zu einer Zeit, als diese Abhandlung im Manuscripte bereits fertig vorlag; es war mir daher nur mehr möglich, eine deutsche Uebersetzung des Originaltextes anzuschliessen; die Gattung ist mir unbekannt:

„Kopf quer, viel breiter als der Thorax, hinten am Scheitel ausgerandet, hinter den Augen erweitert; Gesicht deutlich vortretend, mit verschiedenen Eindrücken versehen, die Ecken unter den Augen winkelig ausgezogen; Augen stark convergent (Gesichtsform unten viel breiter als oben), gross, bis hart an die Oberkiefer reichend, Innenrand gerade; ein einziges Nebenauge deutlich ausgeprägt; Fühler fadenförmig, knapp ober der Kopfschildbasis eingefügt, der Schaft ein wenig verdickt und an den zwei Enddritttheilen ein wenig verbreitert und zusammengedrückt, ein bischen länger als das erste und zweite Geisselglied zusammengenommen; das dritte und vierte Geisselglied an der äussersten Basis deutlich eingekerbt, das fünfte ebenso, aber in sehr schwachem Grade; vom zweiten bis zum zehnten nimmt die Länge der Glieder gleichmässig ab, das eilfte oder End-Segment ist so lang als die beiden vorhergehenden Glieder zusammengenommen. Oberkiefer gebogen, sehr schlank und langgestreckt (ihre Spitze erstreckt sich beinahe bis zur Mitte der Augen [unteren Augenrandes? Kohl]), aussen nicht ausgeschnitten, aber innen ungefähr am zweiten Dritttheile ihrer Länge mit einem Zahne versehen. Prothorax schmäler als der Mesothorax, in einem tieferen Niveau und schief gegen eine Querrinne abstürzend, der Hinterrand fast winkelig nach hinten geneigt; Mesothorax sehr gewölbt; Metathorax etwas verlängert, vorne so breit als lang, gegen die abstürzende Fläche abschüssig; das Metanotum ist seitlich von einer scharfen Runzel ein-

1) Die Bezeichnung Darala ist bereits im Jahre 1859 von Walker für eine BombycidenGattung vergeben worden (Walker, Journ. of Linn. Soc. 187, 1859). 
gefasst, welche in einen kurzen Zahn endigt. Mittelschienen mit einem einzigen Endsporne. Vorderflügel mit einer Radialzelle, welche abgestutzt und mit einer Anhangszelle versehen ist, und mit drei Submarginalzellen, deren erste ein wenig länger ist als die beiden folgenden zusammengenommen. die zweite, welche beide rücklaufende Venen vor der Mitte ihrer Basis aufnimmt, verengt sich gegen die Radialzelle hin; die dritte ist halbmondförmig, Hinterleib kurz, breitoval, sehr gewölbt, besonders an der Basis, beträchtlich schmäler als der Thorax, gestielt, der Stiel aber sehr kurz.

Diese Gattung stimmt in mancher Hinsicht mit Larrada überein, ist aber doch verschieden durch den Mangel des Ausschnittes an der Aussenseite der Oberkiefer, durch die Form des Metathorax und die des Hinterleibes etc."

D. Schlegelii C. Rits. ठ․ Reg. III, Subreg. 3. Sumatra.

Darala Schlegelii C. Rits.: Not. fr. the Leyden Mus., vol. VI, p. 82, 1884, $\sigma^{\star}$.

\section{Gen. Piagetia Ritsema.}

(Piaget, nom. propr.)

Piagetia Ritsema, Entomologist's Monthly Magazine, vol. IX, p. 121-123 . . . . . . 1872 Piagetia Ritsema, Tijdschr. v. Entom. Ned. ent. Ver., vel. XVII, 2. deel, p. 195 . . . . 1874

Kopf ähnlich gebildet wie bei Tachysphex, welcher dieser Gattung nahe steht, etwas breiter als das Bruststück. Oberkiefer mit einem breiten Ausschnitte vor der Mitte des Aussenrandes. Augen gross, oval, gegen den Scheitel zu mässig convergent. Vorderes Nebenauge normal rund, gewölbt. Hintere Nebenaugen länglich, verflacht, daher undeutlich und wie bei Tachysphex, Tachytes etc. an Wülsten liegend. Fühler fadenförmig, beim $\sigma^{\top}$ zwölf-, beim $Q$ dreizehngliedrig. Pronotum tief unter das Niveau des Dorsulums herabgedrückt, vorne halsartig verengt. Das Mittelsegment ist etwas kürzer als das Mesonotum, verschmälert sich nach hinten und stürzt sehr steil ab; seine Hinterecken sind abgerundet. Die Radialzelle ist breit, breit abgestutzt, die Anhangszelledaher ebenfalls breit, scheint aber zu fehlen, wenn die Fortsetzung der Radialader über die Radialquerader hinaus schwachspurig oder manchmal fast gar nicht mehr bemerkbar ist. Von den drei Cubitalzellen ist die erste so lang und so gross als die beiden übrigen, die mittlere, welche die beiden Discoidalqueradern aufnimmt, trapezisch, die dritte schräg gestellt, jedoch nicht zungenförmig ausgezogen. Discoidalzellen sind zwei vorhanden. Die Hinterflügel, deren vordere Schulterzelle sich nicht so sehr gegen den Spitzenrand ausstreckt wie bei Larra, Notogonia, Tachysphex u. s. w., haben ein verhältnissmässig kurzes Frenum. Bei der einzigen mir bekannten Art besteht dieses aus zehn Häkchen.

Schienen und Tarsen bewehrt. Wimpernkamm der Vordertarsen vorhanden, aber schwach und kurzwimperig. Mittelschienen mit einem einzigen Sporne bewehrt. Hinterleib in Folge der stielartigen Verschmälerung des zweiten Hinterleibsringes keulenförmig, also ähnlich gestaltet wie bei Rhopalum, oder noch vielmehr wie bei Trypoxylon. Das zweite Segment übertrifft nämlich 
jeden der drei folgenden, die auch nach hinten an Dicke zunehmen, an Länge; vom fünften Segmente weg nimmt der Hinterleib in der Dicke wieder rasch ab. An der Afterklappe ist beim $\subseteq$ ein deutliches dreieckiges und fast flaches Pygidialfeld ausgebildet. Die Beschaffenheit des Analsegmentes bei den $\sigma^{\nearrow}$ kenne ich nicht aus eigener Anschauung; nach brieflicher Mittheilung des Herrn Ritsema in Leyden, dem wir die Kenntniss dieser Gattung verdanken, ist die obere Afterklappe bei $P$. Woerdeni $\sigma^{7}$ dreieckig, mit abgerundeter Spitze, bei $P$. Ritsemae $\sigma^{\nearrow}$ hinten abgestutzt und seicht ausgerandet, bei beiden Arten matt. Bei den $\sigma^{\prime \prime}$ kommt nach Ritsema an den Schenkelringen der Hinterbeine ein nach aussen gerichteter Dorn vor; ob sich dieses Merkmal als generelle Auszeichnung erweisen wird, kann erst die Folge lehren.

Geographische Verbreitung. Bis jetzt kennt man, einschliesslich der folgenden asiatischen Art, erst drei Arten, nämlich noch eine afrikanische und eine aus Java. Lebensweise unbekannt.

\section{Piagetia odontostoma Kohl.}

Piagetia odontostoma Kohl, Verhandl, d. k. k. zool.-bot. Gesellsch. Wien, p. 31,

Long. 7-9 mm. ‥ Nigra; palpi, mandibularum pars media, alarum squamulae, genua, tibiarum latera externa, calcaria et tarsi omnes pallide flava. Segmenti analis apex rufescens. Alae aeque hyalinae. Clypei margo anticus spinis quatuor acutis armatus. Oculi longitudine flagelli articuli secundi, tertii et quarti distant. Dorsulum fere politum. Facies, mesopleurae, segmentum medianum argenteo-sericea. Segmentum medianum in lateribus oblique, in dorso transverse striate-rugosum. Area pygidialis segmenti anatis nitida, punctis paucis instructa.

万' ignotus.

Tor (Mus. zool. Vienn.).

Schwarz. Taster, Flügelschuppen, Basis der Costal- und Subcostalader, Schenkel an der Kniespitze, Aussenseite der Schienen und die ganze Bedoruung lichtgelb. Oberkiefer in der Mitte und Fühlerschaft vorne an der Spitze lehmgelb.

Kopfschild kurz, aber breit, vorne abgestutzt und mit vier spitzen Zähnen bewehrt (Taf. IX, Fig. 1). Die Entfernung der Fühler an ihrer Basis ist geringer als die eines Fühlers vom benachbarten Auge und beträgt etwa die Länge des zweiten Fühlergeisselgliedes; das erste Geisselglied ist etwas kürzer als das zweite, das zweite so lang als das dritte oder die nächstfolgenden Glieder. Stirne fein und dicht, unter Lupe $a$ nicht mehr unterscheidbar punktirt, wenig glänzend, in der Mitte bis zum Fühlergrunde von einer deutlichen Mittellinie durchzogen. Die geringste Entfernung der Augen am Scheitel beträgt die Länge des zweiten, dritten und vierten Geisselgliedes zusammengenommen. Dorsulum glänzend polirt, unbedeutend punktirt, vorne mit einem feinen, greisen Filze überdeckt, welcher daselbst die Art der Sculptur nicht recht deutlich 
erkennen lässt; auch die sehr dicht punktirten, fast lederartigen Mesopleuren sind mit einer leichten weissen Pubescenz bedeckt. Das Mittelsegment ist an den Seiten schräg nach aufwärts und auf seiner Horizontalfläche der Quere nach mit Runzelstreifen besetzt, welche verhältnissmässig grob und nichts weniger als zahlreich sind (L. a). Abstürzende Fläche mit einer tiefen Grube in der Mitte und an den Seiten mit vereinzelten unregelmässigen Querrunzeln. Flügel gleichmässig wasserhell, ihr Geäder blass lehmgelb. Die Bedornung der Schienen und Tarsen der zwei hinteren Beinpaare ist ziemlich auffällig; der Wimpernkamm des ersten Vordertarsengliedes aus fünf $\mathrm{schwäch-}$ lichen, blassen Wimpern gebildet, welche vom Gliede fast dreimal an Länge übertroffen werden. Die beiden folgenden Glieder führen, soweit ich es wahrnehmen kann, je zwei Kammwimpern, die ihnen in der Länge gleichkommen. Der Metatarsus der vier Hinterbeine ist schwach gekrümmt, kurz, etwa so lang als das Klauenglied, an den Mittelbeinen ein wenig länger als der Schienensporn, an den Hinterbeinen ungefähr so lang als der längere der beiden Sporne; die übrigen Tarsenglieder sind an der Innenseite gegen das Ende hin verdickt, so dass sie, von der Seite betrachtet, gekrümmt aussehen.

Der übrige Hinterleib ist glänzend, nicht punktirt, das Pygidialfeld dreieckig, polirt, glatt und glänzend, mit einigen wenigen Pünktchen versehen, seine Spitze schwach abgestutzt.

$P$. odontostoma unterscheidet sich von P. Ritsemae Rits. durch die ganz verschiedene Kopfschildbildung (ein mittlerer Längskiel fehlt bei odontostoma vollständig und der Clypeus ist sehr flach), die Sculptur des Mittelsegmentes, die wasserhellen Flügel, die Färbung der Beine, die Form der Hinterschenkel. Diese bilden nahe an der Basis ihres Unterrandes keinen Winkel, wie ihn dievon Ritsema dem Texte beigegebene Figur $c$ zeigt. P. WoerdeniRits. $\sigma^{7}$ unterscheidet sichsowohl in denvorerwähnten Punkten, als auch noch in der Farbe des Bruststückes.

Geographische Verbreitung. P. odontostoma wurde von Frauenfeld bei Tor in Arabien gefangen. Die Typen, zwei , befinden sich jetzt in den Sammlungen des Hof-Naturaliencabinetes in Wien.

\section{Verzeichniss der bisher beschriebenen Piagetia-Arten.}

P. Ritsemae Rits. $\sigma^{7}$, ㅇ. Reg. III, Subreg. 4. Soerabaya auf Java.

P. Ritsemae Rits.: Ent. Monthl. Mag., t. IX, 1872, p. 120, Fig. $b$ et $c$, $\sigma^{\top}$, $q$.

P. odontostoma Kohl. . . Reg. I, Subreg. 2. Tor (am arab. Meer).

P. odontostoma Kohl: Verhandl. d. k. k. zool.-bot. Gesellsch. Wien, 1883, p. 31 , ㅇ.

P. Woerdeni Rits. O'. Reg. II, Subreg. 2. Congo-Gebiet.

P. Woerdeni Rits.: Ent. Monthl. Mag., t. IX, 1872, p. 121, Fig. $b$ et $c, \sigma^{7}$.

P. Woerdeni Rits. : Tijdschr. v. Eutom., D. XVII, 1874, p. 197, Taf. XI, Fig. 6. 


\section{Gen. Lyroda Say.}

Lyroda Say, Journ. Nat. Hist. Bost., vol. I, Nr. 3, p. 370 . . . . . . . . . . . . 1836 Morphota Smith, Cat. Hym. Ins. Brit. Mus., P. IV, p. 293 . . . . . . . . . . 1856 Morphota Smith, Journ. Proc. Linn. Soc., vol. III, p. 17 . . . . . . . . . . . . 1858 Lyroda Say, Compl. writ. Entom. North-Amer., vol. II, p. 755 . . . . . . . . . . 1859 Morphota Taschenberg, Zeitschr. f. d. ges. Naturw. Halle, t. XXXVI, p. 8 (d. S.) . . . 1870 Lyroda Patton, List North-Amer. Larr. (Proc. Bost. Soc. Nat. Hist., vol. XX, p. 385 et 386) . 1880

Zu dieser artenarmen Gattung gehören Grabwespen von kleiner bis mittelgrosser Statur.

Kopf breiter als der Thorax. Oberkiefer mit einem Ausschnitte, nicht weit von der Mitteihrer Aussenkante. Kopfschild und die untere Partie des Gesichtes silberfilzig behaart. Fühler fadenförmig, beim 오 zwölf-, beim $\sigma$ dreizehngliederig. Augen gross, oval, ohne Ausrandung, mit fast geradem Innenrande, gegen den Scheitel nicht namhaft convergent, Stirne und Scheitel breit, ohne Wülste oder leistenartige Auftreibungen. Nebenaugen rund und deutlich, auch die hinteren, welchemit dem vorderen etwas grösseren ein flaches Dreieck (• . ·) bilden. ${ }^{1}$ )

Vorderbrustrücken vorne in charakteristischer Weise halsartig verengt, hinten zu einem Wulste aufgeworfen, welcher in Folge von zwei flachbogigen Ausschnitten an seiner Oberseite drei nach hinten gerichtete Höcker zeigt und mit dem Dorsulum in einem Niveau liegt. Mittelsegment von der Länge des Mesonotum, hinten steil, fast senkrecht abstürzend, an seinen Hinterecken abgerundet. Flügelgeäder sehr ähnlich dem von Larra. Vorderflügel mit einer deutlich abgestutzten Radialzelle und einer Anhangszelle, ferner mit drei Cubitalzellen, von denen die zweite, trapezförmige, welche beide Discoidalqueradern aufnimmt, und die dritte schräge, an der unteren Aussenecke unbedeutend ausgezogene, zusammengenommen, an der Cubitalader nicht ganz so lang erscheinen als die erste Cubitalzelle. Die Basalader trifft mit der Schulterquerader zusammen. Schienen kantig und wie die Tarsen bedornt. Wimpernkamm am ersten Gliede des vordersten Fusspaares kurz und schwachdornig. Mittelschienen einspornig. Klauenballen zum Unterschiede von Larra und Notogonia, übereinstimmend mit Tachysphex und Tachytes, sehr gross. Hinterränder der Hinterleibsringe zum Theile mit silberglänzendem Filze belegt. An der oberen Afterklappe der $\subsetneq$ ist ein grosses, dreieckiges Pygidialfeld entwickelt, welches flach, seitlich scharf gekantet und mit kurzen Härchen besetzt ist.

Ueber die Lebensweise dieser exotischen Gattung weiss man noch nichts; der Hauptsache nach mag sie wohl mit den ihr nächst verwandten Gattungen übereinstimmen. Bekannt sind bis jetzt erst acht Arten, davon gehört eine einzige der östlichen Erdhälfte, der Australregion an, die sieben anderen zählen zum Theile zur neotropischen (vier Species), zum Theile zur nearktischen Fauna.

1) Lyroda ist der Gattung Tachytes und Tachysphex sehr nahe verwandt und davon durch die regelmässige Form der hinteren Nebenangen, sowie die fast parallel verlaufenden Innenrānder der Netzaugen verschieden. 


\section{Verzeichniss der bisher beschriebenen Lyroda-Arten.}

L. caliptera Say. Reg. IV, Subreg. 3. Indiana.

Lyroda caliptera Say: Bost. Journ. Nat. Hist., vol. I, N. 4, p.373, Nr.6, 1837.

Lyroda caliptera Say: Compl. writ. Ent. North-Amer., vol. II, p. 755, 1859.

L. concinna Smith. \&. Reg. V, Subreg. 2. Brasilia (Tapajos).

Morphota concinna Smith: Cat. Hym. Br. M., p. IV, p. 294, Nr. 2, 1856.

L. fusciata Smith. O. Reg. V, Subreg. 2. Brasilia (Santarem).

Morphota fasciata Smith: Cat. Hym. Br. M., p. IV, p. 294, Nr. 1, 1856.

L. formosa Smith. 9 . Reg. VI, Subreg. 1. Celebes.

Morphota formosa Smith: Journ. Proc. Linn., vol. III, p. 17, Nr. 1, 1858.

L. harpactoides Smith. Q. Reg. V, Subreg. 2. Brasilia.

M. harpactoides Smith: Cat. Hym. Br. M., p. IV, p. 294, Nr. 3, 1856.

L. subita Say. Reg. IV, Subreg. 3. Indiana.

Lyroda subita Say: Bost. Journ. Nat. Hist., vol. I, N. IV, p. 372, Nr. 5, 1837.

Lyroda subita Say: Compl. writ. Ent. North-Amer., vol. II, p. 755, 1859.

L. tridens Taschenb. Q. Reg. V, Subreg. 2. Lagoa Santa.

Morphota tridens Taschenb.: Zeitschr. f. d. ges. Naturw. Halle, t. XXXVI, p. $8,1870$.

L. triloba Say. Reg. V, Subreg. 3. Indiana.

Lyroda triloba Say: Bost. Journ. Nat. Hist., vol. I, N. IV, p. 372, Nr. 4, 1837.

Lyroda triloba Say: Compl. writ. Ent. North-Amer., vol. II, p. 755, 1859. 


\section{Erklärung der Abbildungen.}

\section{Tafel VIII.}

Fig. 1. Flügelgeäder von Pison.

2. Vorderflügel von Pison im Uebergange zum Subg. Parapison Smith.

"3. $\quad$ "Subg. Parapison.

》4. Flügelgeäder von Trypoxylon.

\#. \#, $\quad$ Sylaon.

\%6. $\quad$ \# Solierella.

” $7 . \quad$ \# Nitela.

„8. Kopf von Nitela.

»9. Flügelgeäder von Miscophus.

”10. Kopf von Miscophus bicolor Jur.

"11. " \# Lyroda.

,12. \# \# Notogonia.

\section{Tafel IX.}

Fig. 1. Kopf von Piagetia.

"2. " "Trypoxylon figulus $\mathrm{L}$.

"3. " " Pison nitidum Smith.

” 4. Hinterleib von Trypoxylon figulus L.

„5. Geöffnete Puppenhülle von Trypoxylon figulus in einer von Cynips Kollari verlassenen Eichengalle (Mayr).

”6. Brutgang von Trypoxylon figulus in einem Sambucus-Stengel (Mus. Caes. Rogenhofer).

7. Verlassene Puppenhülle von Trypoxylon figulus in einem Ribes-Stengel (Mayr).

» 8. Hinterleib von Sylaon.

" 9 und 10. Lehmnester von Pison erythropus Kohl (nach Horne und Smith).

, 11 und 12.

, 13,14 und 15 .

"Trypoxylon rejector $\mathrm{Sm}$. " 


\section{$2 \mathrm{BHL}$ Biodiversity Heritage Library}

Kohl, Franz Friedrich. 1884. "Die Gattungen und Arten der Larriden Autorum." Verhandlungen der Kaiserlich-Königlichen Zoologisch-Botanischen Gesellschaft in Wien 34, 171-268. https://doi.org/10.5962/bhl.part.26501.

View This Item Online: https://www.biodiversitylibrary.org/item/49913

DOI: https://doi.org/10.5962/bhl.part.26501

Permalink: https://www.biodiversitylibrary.org/partpdf/26501

\section{Holding Institution}

MBLWHOI Library

\section{Sponsored by}

MBLWHOI Library

\section{Copyright \& Reuse}

Copyright Status: Public domain. The BHL considers that this work is no longer under copyright protection.

This document was created from content at the Biodiversity Heritage Library, the world's largest open access digital library for biodiversity literature and archives. Visit BHL at https://www.biodiversitylibrary.org. 